


\title{
Space Commerce Workshop Report
}

\author{
National Institute of Standards and Technology \\ Nick Barbosa \\ Leah Kauffman \\ Michelle Stephens
}

National Telecommunications and Information Administration Rebecca Dorch

University of Colorado Boulder

Marcus Holzinger

This publication is available online at: https://doi.org/10.6028/NIST.SP.1500-14

March 2020

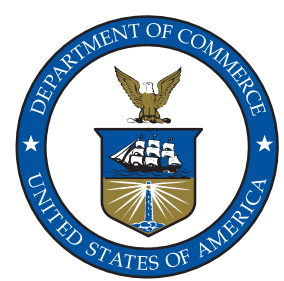

U.S. Department of Commerce Wilbur L. Ross, Jr., Secretary 
Certain commercial entities, equipment, or materials may be identified in this document in order to describe an experimental procedure or concept adequately. Such identification is not intended to imply recommendation or endorsement by the National Institute of Standards and Technology, nor is it intended to imply that the entities, materials, or equipment are necessarily the best available for the purpose.

National Institute of Standards and Technology Special Publication SP 1500-14

Natl. Inst. Stand. Technol. Spec. Publ. SP 1500-14, 95 pages (March 2020) CODEN: NSPUE2

This publication is available free of charge from: https://doi.org/10.6028/NIST.SP.1500-14 


\section{SPACE COMMERCE WORKSHOP REPORT}

\section{Preface}

The recommendations contained herein are those of the authors, derived from discussions held during the workshop, and should not be construed as official policy of the Department of Commerce (DOC) or the University of Colorado (CU). This document does not convey official policy of DOC, CU, the National Telecommunications and Information Administration, the National Oceanic and Atmospheric Administration, or the National Institute of Standards and Technology, nor does it suggest who should be responsible for taking actions identified in the recommendations.

\section{Abstract}

The Department of Commerce (DOC)Boulder Laboratories (consisting of the National Institute for Standards and Technology, the National Oceanic and Atmospheric Administration, and the National Telecommunications and Information Administration); the DOC Office of Space Commerce; and the University of Colorado Boulder held a one-day Space Commerce Workshop on September 12, 2019. Members of industry, academia, and federal government organizations were brought together to identify key technology, measurement, and modeling barriers to deploying and safely operating commercial space technology. This workshop focused on technology barriers, solutions, and standards needed to foster conditions for economic growth and technical advancement of space industry. This document describes key themes that emerged during the workshop and recommendations for overcoming the challenges of a continued increase in the number of government and commercial entities with industrially relevant objects in space.

- Data management

- Remote sensing

- Space traffic management

\section{Key Words}

- Models and algorithms - Orbital debris

- Space commerce

- Technology transfer
- Space situational awareness

- Wireless spectrum

\section{Acknowledgments}

The National Institute of Standards and Technology would like to thank the National Telecommunications and Information Administration, the National Oceanic and Atmospheric Administration, the Department of Commerce Office of Space Commerce, and the University of Colorado Boulder for their contributions to this workshop. Each of these organizations played a key role in all aspects of the workshop by contributing to the development of the format and content of the workshop; suggesting and recruiting panelist and moderators; and identifying the key themes and recommendations from the workshop that are detailed in this report. We are particularly indebted to the members of the organizing committee.

\section{Organizing Committee}

Nick Barbosa Michelle Stephens Rebecca Dorch

Marina Hague

Diane Howard

Adele Luta

Chris Muldrow

Bill Murtagh
National Institute of Standards and Technology (co-chair) National Institute of Standards and Technology (co-chair) National Telecommunications and Information Administration Office of Space Commerce Office of Space Commerce Office of Space Commerce University of Colorado Boulder National Oceanic and Atmospheric Administration 


\section{Table of Contents}

1. Executive Summary.

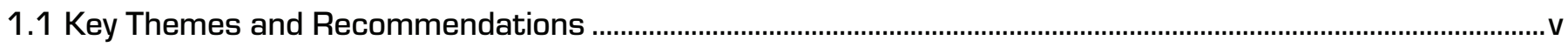

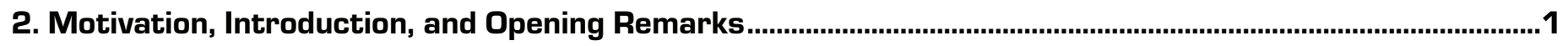

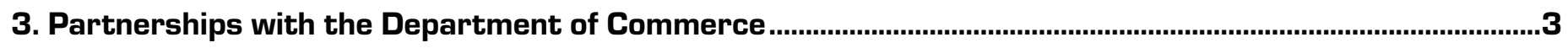

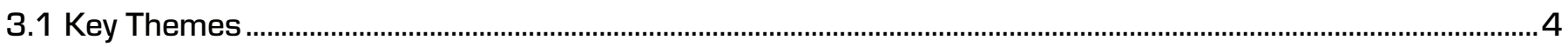

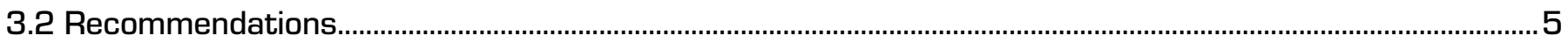

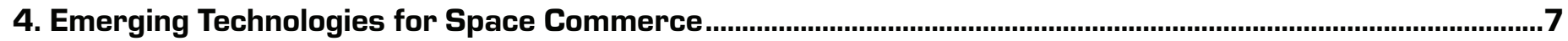

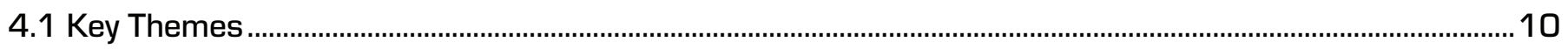

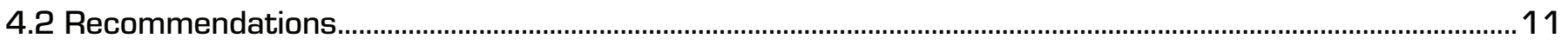

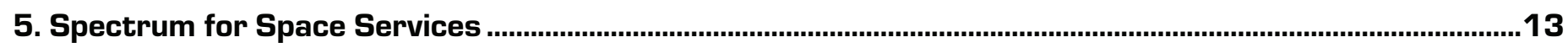

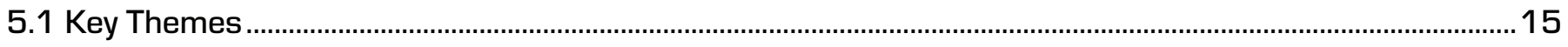

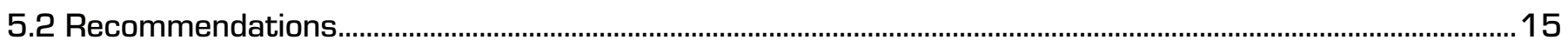

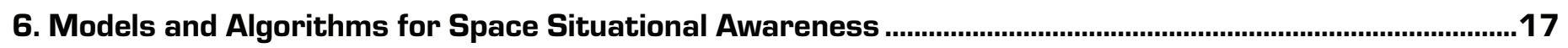

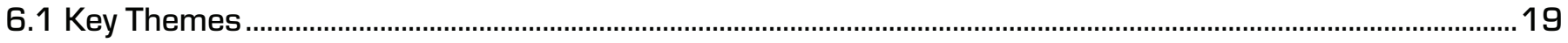

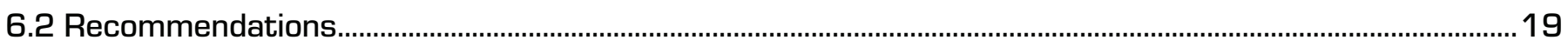

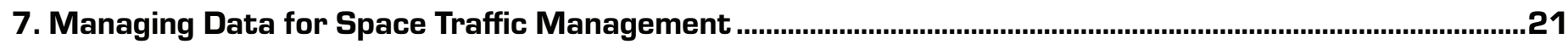

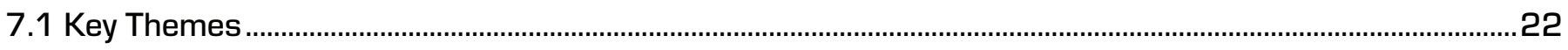

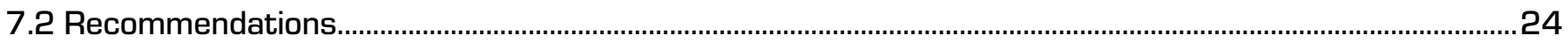

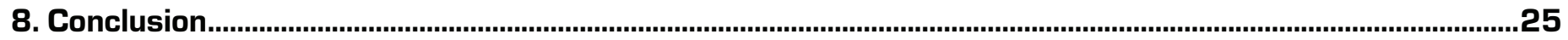

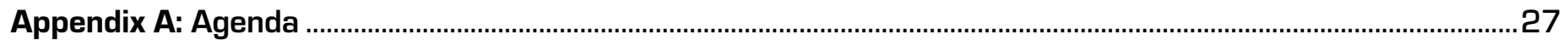

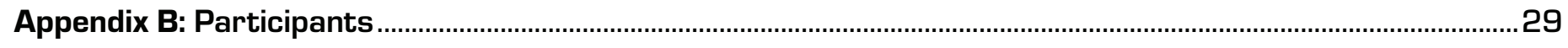

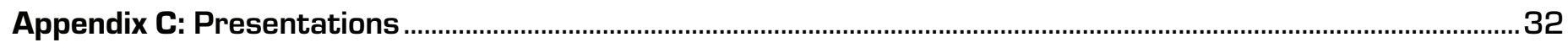

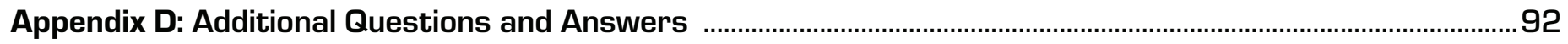

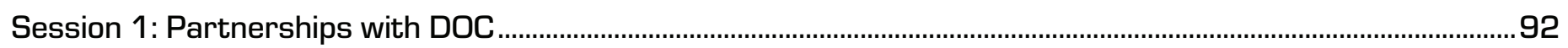

Session 2: Emerging Technologies for Space Commerce ................................................................................... 93

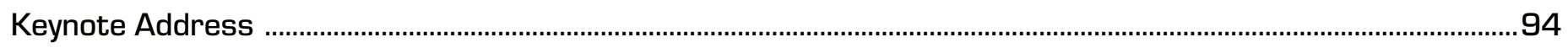

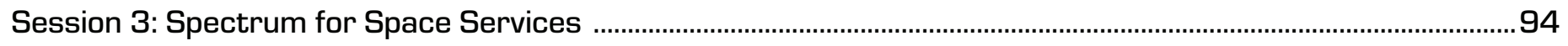

Session 4: Models and Algorithms for Space Situational Awareness ..................................................................94

Session 5: Managing Data for Space Traffic Management ....................................................................................... 95

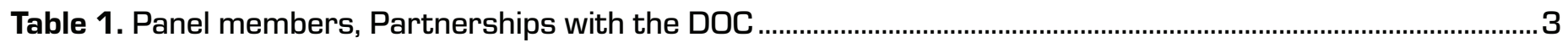

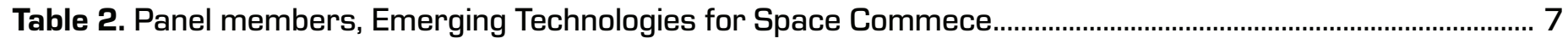

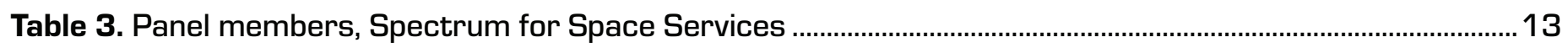

Table 4. Panel members, Models and Algorithms for Space Situational Awareness..............................................17

Table 5. Panel members, Managing Data for Space Traffic Management...............................................................21 


\section{Executive Summary}

The Department of Commerce (DOC) Boulder Laboratories (consisting of the National Institute for Standards and Technology (NIST), the National Oceanic and Atmospheric Administration (NOAA), and the National Telecommunications and Information Administration (NTIA)); the DOC Office of Space Commerce (OSC); and the University of Colorado Boulder (CU) held a one-day Space Commerce Workshop on September 12, 2019. Members of industry, academia, and federal government organizations were brought together to identify key technology, measurement, and modeling barriers to deploying and safely operating commercial space technology. Several workshops that focused on policies and partnerships in support of new space traffic management policy had already been held by the Office of Space Commerce. This workshop focused on technology barriers, solutions, and standards needed to foster conditions for economic growth and technical advancement of space industry. The workshop had 122 attendees. Approximately $40 \%$ represented local industry, $28 \%$ were from academia, $14 \%$ from the DOC, $7 \%$ were from non-profits, and the remaining were from federal and state government organizations including NASA, the State of Colorado, and Congressional representatives. A complete list of attendees can be found in Appendix $\mathrm{C}$.

\section{1 - Key Themes and Recommendations}

\section{Theme 1:}

Exponential growth of space utilization requires academia and industry to lead innovation. The government must provide careful coordination between industry, academia, and governmental organizations in areas such as standards development, technology advancement, education, and regulation; in many cases it is difficult to disentangle technical and regulatory efforts.

\section{Recommendations}

»Collaborate with academia to investigate best practices, develop novel technologies, and train professionals.

» Support emerging businesses with better coordination of and assistance for identifying existing funding opportunities, access to advice and mentoring on how to win funding, and more information on services like those provided by the Manufacturing Extension Partnership at the local, state, and federal levels.

"Assess the status of the space ecosystem supply chain and the needs of small businesses and startups to develop a supply chain roadmap to promote innovation.

"Consider universities and small businesses in any policy making, as they are on the front of the evolution of the space industry.

»Develop standards in high-priority areas of space commerce while striking the right balance between standards and open innovation. The DOC should continue to play a role in coordinating and supporting the industry-led development of standards for the space community. 


\section{Theme 2:}

Coordinated research with associated funding is needed in specific areas.

\section{Recommendations}

»Provide resources to help small businesses develop proven technologies with commercial uses into market-ready products.

» Align research funding sources with identified needs, such as:

- Space qualification of components

- New spectrum-sharing paradigms

- Optical and infrared (198 THz) spectrum options

- New spectrum analysis capabilities to source and share data

- Precise and persistent sensing using multiple sensors of different types, exhaustive associated metadata, data quality control, and verification and validation of data and algorithms to improve space situational awareness (SSA) and space traffic management (STM) models

- Additional research in astrodynamics (as applied to Earth and near-Earth orbits) to identify safe orbits that efficiently use orbit resources

- Better measurements to support orbit trajectory predictions

- Improved awareness and rigorous treatment of systemic and random uncertainty in SSA models

- Improved space weather models both to predict drag and to provide design environments for future missions

- Improved space weather data in low earth orbit (LEO) and medium earth orbit (MEO) through additional monitors and/or more open data sharing

- Quickly fusing outdated aspects of STM with modern tools

- STM data curation, independent and unbiased checks, fusing, and quality control

- Timely distribution, analysis, and ingestion of STM data from multiple sources

There are additional technical areas that were not addressed at this workshop.

\section{Theme 3:}

As space becomes more accessible, organizations need to think in broader terms about what constitutes the space industry.

\section{Recommendations}

» Develop talent of all kinds for a future space workforce that includes more than scientists and engineers. For example, service industries like food or entertainment that will support the needs of humans visiting and living in space.

»Emphasize the social impact of space to encourage students to enter the space industry.

\section{Theme 4:}

Now is the time for the community to come together to understand the essential roles of the public, private, and academic sectors as they work together. 


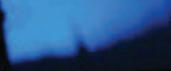

\section{DEPARTMENT OF \\ SPACE COMMERCE WORKSHOP SEPTEMBER 12, 2019} BOULDER, CO

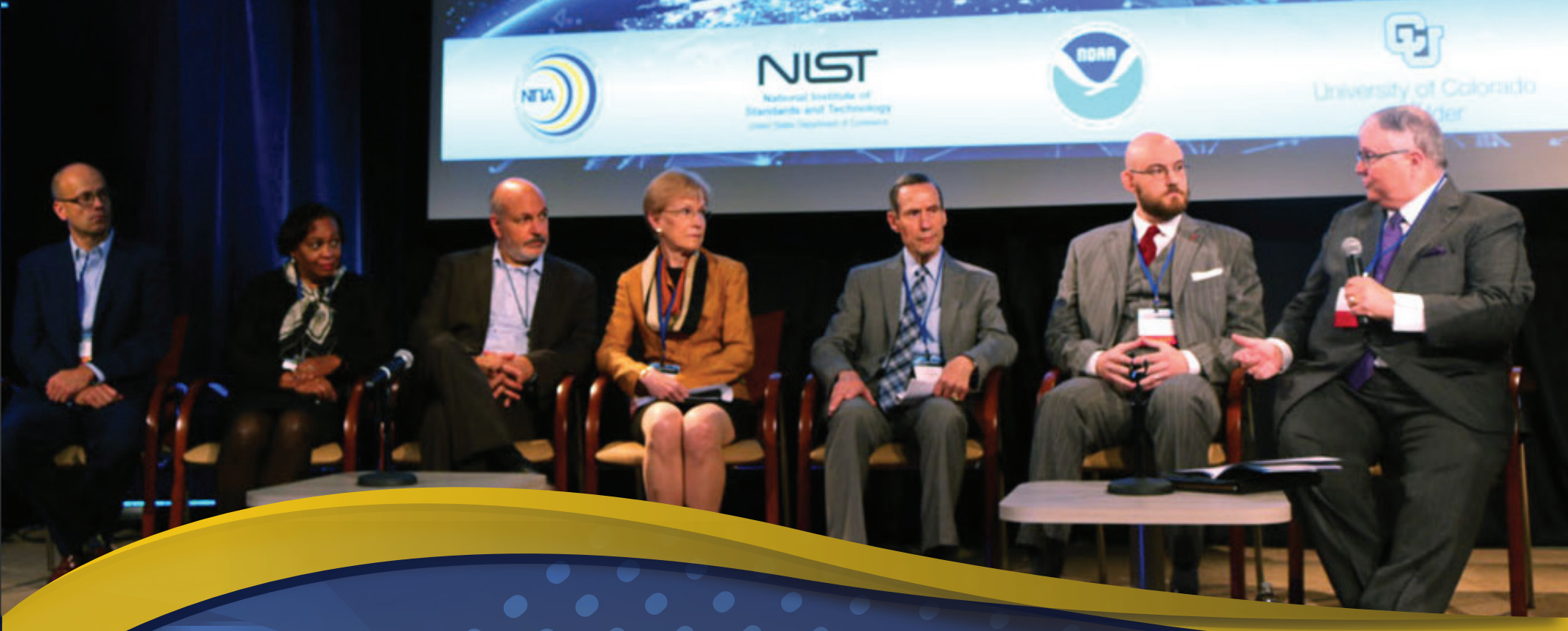

\section{Space: Open for Business}

The world's utilization of space has changed dramatically in the last two decades. Once the purview of a few large governmental space agencies and defense organizations, space now harbors active missions from countries around the world, commercial entities, nonprofit organizations, and educational institutions. The global space economy is currently estimated at $\$ 400$ billion and is expected to increase to $\$ 1-3$ trillion over the next 20 years. Space also now has value to humans beyond economic growth. Space missions create social impact in many ways: for example, by providing large-scale monitoring of severe weather events and a platform for human exploration, enhancing security assessments, and evaluating the agricultural health of a nation, to name just a few.

With this new scale of space industrialization, the world faces new challenges in managing communications spectrum, reducing and tracking orbital debris, and alerting the community to dangers posed by both space weather and orbital debris. These growing challenges in the commercial space environment must be addressed quickly to support the rapid growth of the industry. 


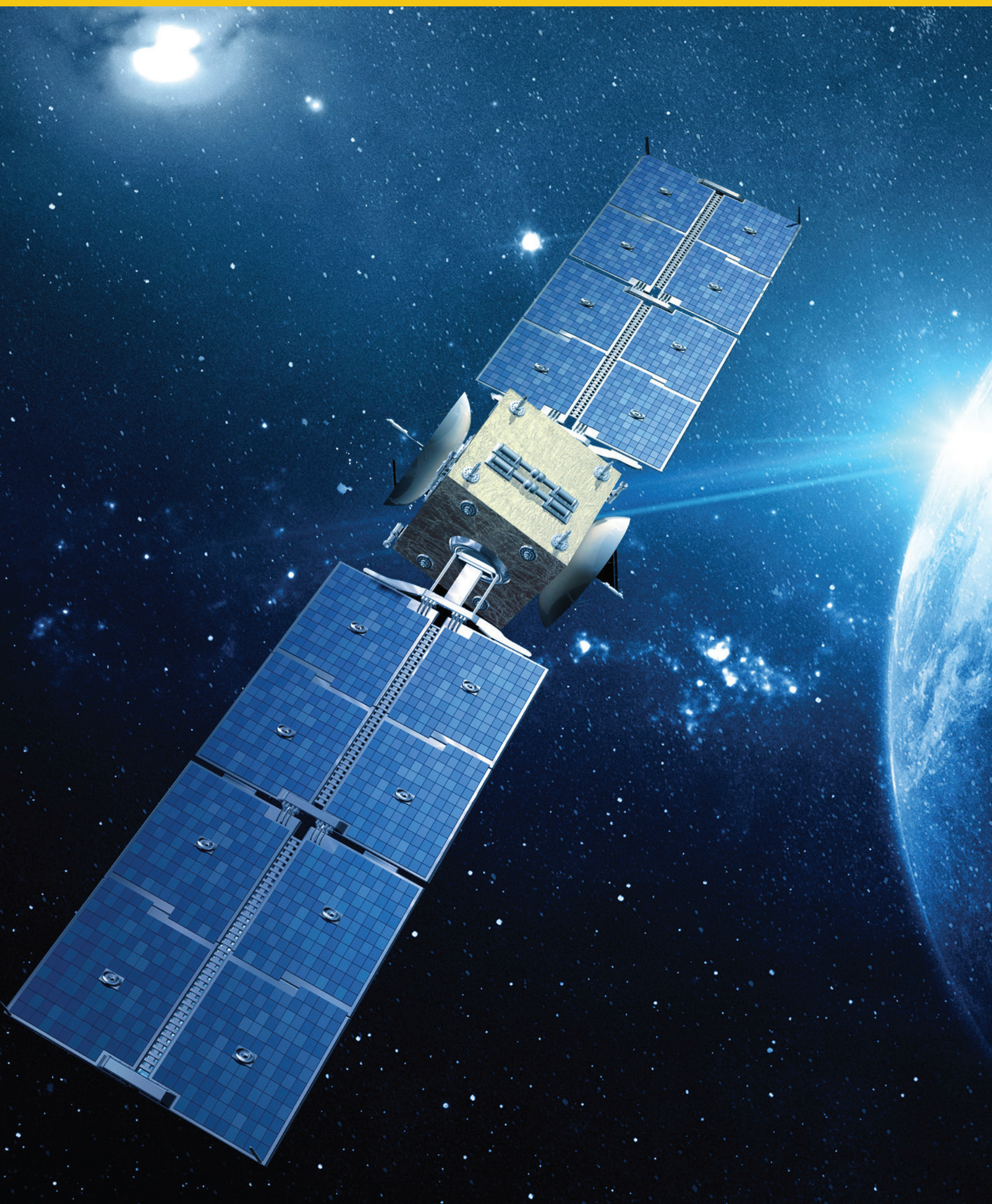




\section{Motivation, Introduction, and Opening Remarks}

Rapid developments in the space industry have fueled a $\$ 400$ billion global industry that is projected to grow to $\$ 1-3$ trillion over the next 20 years. Increased access to space means new and more challenges. Space debris and congestion problems are increasing and need to be managed carefully. New communications spectrum resources need to be made available while protecting the existing services. Space weather events affect more stakeholders and have a greater economic impact. Alerts about the dangers posed by space weather and orbital debris impact a greater number of stakeholders, leading to tighter requirements on data availability, timeliness, and accuracy. The short life cycle (around 18 months) for the missions for small satellites contribute greatly to this dramatic growth, and challenge the existing infrastructure in diverse ways, such as:

»It can take longer to get a spectrum license than the whole lifecycle of a small satellite;

» The industry lacks standards to provide guidance for how to manage the end-of-life of the small satellites without contributing to orbital debris problems.

These challenges, and others, must be addressed through innovations that change the landscape quickly. Industry and academia must lead innovation, while the DOC must find ways to leverage and coordinate activities.

The DOC Boulder Laboratories, the DOC Office of Space Commerce, and the University of Colorado Boulder held a one-day workshop to bring together members of industry, academia, and federal government organizations to identify key technology, measurement, and modeling barriers to deploying and safely operating commercial space technology. This report discusses the key themes and technical challenges for space commerce and civil space traffic management that were identified at this workshop, with the goal of informing DOC coordination of resources to apply to identified challenges. As several workshops focused on policies and partnerships in support of new space traffic management policies had already been held by the Office of Space Commerce, this workshop focused on technology barriers, solutions, and standards needed to accelerate commercial space commerce. The future of space commerce requires the best of government, industry, and academic thinking to identify key technology opportunities and challenges to deploying and safely operating space technologies. 
The workshop consisted of five panels. Each panel was led by a moderator. The panelists and moderators are listed in the tables at the beginning of each section. The panels explored the following topics:

» Partnerships with the DOC

» Emerging Technologies for Space Commerce

» Spectrum for Space Services

» Models and Algorithms for Space Situational Awareness

» Managing Data for Space Traffic Management

This report summarizes the discussion, questions, and key themes emerging from each of the five panels. The themes and recommendations that emerged during the day that are summarized here were determined by the panel moderators and workshop organizers. The workshop has provided a starting point for future discussions and actions. In the Conclusion, we suggest some possible next steps. A summary of questions and answers, where available, is included in Appendix D.

The event was opened by Dr. Walt Copan, NIST Director, and Office of Space Commerce Director Kevin O'Connell delivered the opening remarks. Dr. Copan introduced the workshop focus on technology barriers, standards, and solutions. He highlighted Colorado as a national hub for space commerce. Colorado represents the nation's second largest aerospace economy with more than 400 space companies, leading universities with nationally recognized aerospace programs, four space-related military commands plus a possible future Space Force and Space Command in Colorado, and leading federal research laboratories.

Mr. Kevin O'Connell explained the motivation for the DOC's involvement in space, and the vital role of the aerospace industry to the nation's security and future. He mentioned two key areas pertinent to the day's discussions: streamlining regulations and creating a modernized civil system for space traffic management. He stated a need to move quickly in order to prevent roadblocks on the way to a trilliondollar space economy. He touched on the importance of public-private partnerships and the role of U.S. industry in the success of this effort, as well as the need for a "whole of Commerce" approach by building relationships between the Office of Space Commerce, NIST, NOAA, and NTIA. Mr. O'Connell also pointed out that to truly grow space commerce, we need to broaden our vision of what constitutes "space commerce" beyond just technical talent to include economists, artists, teachers, and many others.

The complete text of Kevin O'Connell's opening remarks can be found at:

\section{https://www.space.commerce.gov/remarks-from-space-commerce-workshop-at-nist-boulder/}

Dr. Bobby Braun, Dean, College of Engineering and Applied Science, University of Colorado Boulder gave the keynote address. Dr. Braun described the prominent role the university plays in aerospace research, and praised the state of Colorado's depth and breadth in U.S. industry. He suggested that the "recipe for success" in space commerce has three components that must work cooperatively government, industry, and academia. He also echoed Kevin O'Connell's premise that space commerce will depend on people with skills and talents beyond just technical ability. 


\section{Partnerships with the Department of Commerce}

This panel explored the opportunities and mechanisms for public-private partnerships with the DOC that foster conditions for economic growth and technical advancement of the space industry. Panel members represented both the DOC and organizations that work with the DOC in different capacities. Panelists provided a broad overview of ways to collaborate with the DOC, including through NIST programs, cooperative institutes, standards collaboratives, and as a commercial entity performing the "heavy lifting" with the government providing "mission direction." The panelists and their affiliations are listed in Table 1.

\begin{tabular}{|c|l|}
\hline \multicolumn{2}{|c|}{ Table 1. Panel members, Partnerships with the DOC } \\
\hline $\begin{array}{c}\text { Mr. Kevin O'Connell } \\
\text { [Moderator] }\end{array}$ & Director, Office of Space Commerce \\
\hline Dr. Alexander Salter & $\begin{array}{l}\text { Assistant Professor of Economics, } \\
\text { Texas Tech University }\end{array}$ \\
\hline Ms. Mary Saunders & $\begin{array}{l}\text { Vice President, Government } \\
\text { Relations and Public Policy, } \\
\text { American National Standards Institute [ANSI] }\end{array}$ \\
\hline Dr. Conrad Lautenbacher & Chief Executive Officer, GeoOptics \\
\hline Dr. Waleed Abdalati & $\begin{array}{l}\text { Director, Cooperative Institute for Research in } \\
\text { Environmental Sciences (CIRES], } \\
\text { University of Colorado Boulder }\end{array}$ \\
\hline Ms. Carroll Thomas & $\begin{array}{l}\text { Director, Hollings Manufacturing Extension } \\
\text { Partnership, NIST }\end{array}$ \\
\hline Mr. Derek Khlopin & $\begin{array}{l}\text { Senior Advisor, National Telecommunications } \\
\text { and Information Administration, } \\
\text { U.S. Department of Commerce }\end{array}$ \\
\hline
\end{tabular}

The panel began with presentations by Dr. Alexander Salter on "The Economics of Space Debris" and Ms. Mary Saunders on "ANSI's Role in Standards Coordination to Support Emerging Technologies and National Priorities," followed by a brief introduction by each of the other panelists. Dr. Salter made a compelling case for both the economic hazards of collisions due to orbital debris and the role for public policy in addressing the hazards of orbital debris. He argued that a purely private response is probably not cost effective, in part because orbital debris is a unique economic situation. For example, orbital access is a public good, but particular orbits are pooled resources. 
Ms. Mary Saunders presented a discussion on how standards are developed in the U.S. and the role ANSI can take. The system is private-led, unlike other systems, so it is enabling for private-public partnerships. The federal government relies on private activities to develop standards. As an example of how ANSI coordinates industry-led standards development, Ms. Saunders described two standards collaboratives, one for additive manufacturing and one for unmanned aircraft systems, that created roadmaps for standards by identifying areas of high activity and priorities. Unmanned aircraft systems share some similar issues with space activities such as traffic management and object identification. Such roadmap efforts typically take 9 months.

Dr. Conrad Lautenbacher, the Chief Executive Officer of GeoOptics (recipient of the first government commercial weather satellite data purchase contract), described the value in commercial partnerships with the government as the commercial sector adds heavy lifting and efficiency, while the government provides standards.

Dr. Waleed Abdaleti, the director of the Cooperative Institute for Research in Environmental Sciences (CIRES, a partnership between the National Oceanic and Atmospheric Administration and the University of Colorado Boulder) presented joint institutes as another way to improve efficiency. In this case, the academic environment provides institutional agility while the government provides mission focus. A joint institute like CIRES also engages students and provides workforce development.

Ms. Carroll Thomas, Director of the NIST Hollings Manufacturing Extension Partnership (MEP) described the support that MEP provides in every state to small businesses. Every state needs to participate in the U.S. space economy, and manufacturing can be a catalyst in non-traditional space states. The MEP is available at no cost to support small manufacturers and can act as a link to space commerce.

Mr. Derek Khlopin, Senior Advisor at the National Telecommunications and Information Administration, U.S. Department of Commerce, described the work at NTIA as composed of three parts: policy, spectrum management, and research and technology. NTIA is responsible for advising the President on telecommunications and information policy issues and focuses research to support this mission. Areas relevant to this workshop include future spectrum requirements for space and radio frequency (RF) interference. Stakeholders are invited to speak with the NTIA.

\subsection{Key Themes}

"Small businesses and entrepreneurs seek more awareness of existing resources and programs, at both national and local levels, that support innovation.

- Better awareness of funding opportunities, access to advice and mentoring on how to win funding, as well as more information on services like those provided by MEP at the local, state, and federal levels is desired. The National Science Foundation's Innovation Corps, NASA Small Business Innovation Research, and Air Force AFWERX were mentioned by audience members as funding mechanisms.

- There are unique barriers to entry for small companies in the space arena, such as supply chain for flight-qualified parts and the global nature of the industry (for example: treaties and export laws) that need to be addressed. 
» There is a strong need for standards in many areas of space commerce. Striking the right balance between standards and open innovation will be critical.

- Successful standards development often includes several key ingredients: a demonstrated need for coordination; broad stakeholder support, not just from the federal government; clearly defined objectives; committed stakeholders; and funding.

- The question of how to encourage participation was addressed. Organizations participate in standards out of self-interest because standards move markets. Information and understanding priorities are key.

- Using best-in-class standards activities, such as the NIST cybersecurity framework, NOAA space traffic management, and NTIA RF interference (a different kind of space debris), as examples is valuable.

- The need for standards was echoed in the Data for Space Traffic Management Session in the form of better standards around who curates the data, what data should be brought in, who provides independent and unbiased checks and how, and how a confidence factor can be assigned.

» The future of space includes more than just scientists and engineers. Talent of all kinds needs to be developed for future workforce (this was echoed in Dr. Bobby Braun's keynote talk).

- Concerns were mentioned regarding generating a ready talent pool for space. Some areas are viewed as too technical by many young people in the U.S. and Europe.

- In general, it seems that many young people are more motivated by a sense of purpose and less motivated by the "gee whiz" sentiment than older generations were.

\subsection{Recommendations}

» The DOC should continue to play a role in coordinating and supporting the industry-led development of standards for the space industry. Many areas of space commerce have a strong need for standards; striking the right balance between standards and open innovation will be critical.

" Support emerging businesses with better coordination of and assistance in identifying funding opportunities, access to advice and mentoring on how to win funding, as well as more information on services like those provided by MEP at the local, state, and federal levels.

»Emphasize the social impact of space to encourage students to enter the space industry. The future of space includes more than just scientists and engineers, and talent of all kinds needs to be developed for the future workforce. 


\section{Emerging Technologies for Space Commerce}

This session explored technology needs, emerging technology solutions, mechanisms for accelerating innovation via partnerships, and seed funding. Moderator Dr. Walt Copan, Under Secretary of Commerce for Standards and Technology and NIST Director, opened the session with comments on federal technology transfer initiatives. Mr. Steven Gonzalez followed with a discussion of NASA's efforts to increase public-private partnerships and technology transfer. Introductory remarks from the remaining panelists and an open question-and-answer period followed. The session closed with a lightning round summarizing each panelist's key takeaways.

\begin{tabular}{|c|l|}
\hline \multicolumn{2}{|c|}{ Table 2. Panel members, Emerging Technologies for Space Commerce } \\
\hline $\begin{array}{c}\text { Dr. Walt Copan } \\
\text { (Moderator] }\end{array}$ & $\begin{array}{l}\text { Under Secretary of Commerce for Standards and } \\
\text { Technology and NIST Director }\end{array}$ \\
\hline Mr. Steven Gonzalez & $\begin{array}{l}\text { NASA Johnson Space Center Technology } \\
\text { Strategist }\end{array}$ \\
\hline Mr. Christopher Allison & Systems Engineer Sr., Sierra Nevada Corporation \\
\hline Mr. Michael Hurowitz & $\begin{array}{l}\text { Founder and Chief Technology Officer, } \\
\text { Orbital Micro Systems }\end{array}$ \\
\hline Mr. lan Christensen & $\begin{array}{l}\text { Director of Private Sector Programs, } \\
\text { Secure World Foundation }\end{array}$ \\
\hline Dr. Tanya Ramond & Director of Product Management, Bridgecomm \\
\hline
\end{tabular}

Dr. Copan's opening remarks noted the DOC's unique position in an era of technology convergence and its potential for impact on innovation. Dr. Copan discussed the essential nature of the university and government laboratory innovation ecosystem for driving innovation and commercial development. He followed with a description of NIST's role in supporting the U.S. early space launches through the development of the first hydrogen liquefication technologies and facilities. He also described NIST's current role in creating a common language critical to future space commerce innovation through science, measurements, and standards. Dr. Copan discussed how we need to find ways to increase the uptake of government and academic research by the private sector, and how the recent Return on Investment (ROI) initiative is designed to unleash the innovation power of America into the economy through technology 
transfer. Dr. Copan pointed to the recent ROI Green Paper issued as NIST SP 1234 that provides a synopsis on opportunities to improve the technology transfer process, and finished with a discussion of the resulting legislative package under consideration to enable increased impact from governmental science and technology.

Mr. Steven Gonzalez, NASA Johnson Space Center Technology Strategist, covered three topics in his presentation. Mr. Gonzalez opened by discussing how NASA is leveraging missions to the moon and Mars to seed and grow the commercial space market. NASA is planning to go to the moon as a step toward reaching Mars in the mid-2030s timeframe and needs to have capabilities prepositioned on the lunar surface when the first human arrives. Mr. Gonzalez described how the current lunar program is relying on public-private partnerships to offset government funding limitations, and that partnerships are also considered preferable because of the entrepreneurial opportunities that result in the sharing of ideas and technology. He discussed how partnerships come in a variety of forms, but programs like NASA's Commercial Lunar Payload Services have already generated new kinds of interactions and companies. Mr. Gonzalez then discussed how NASA is focusing on seeding new startups and companies with existing NASA technologies and incentive programs and how NASA has over 1400 technologies and over 1000 software applications that are available for licensing. He noted that approximately $20 \%$ of the technologies are currently licensed, but mostly by large companies. Mr. Gonzales described how Startup NASA was developed to provide a lower-cost licensing pathway for startups and entrepreneurs, how NASA uses the Small Business Innovation Research Program (SBIR) and the Small Business Technology Transfer program investments as seed funding to bring technology out of the NASA system, and in some cases, like the Bigelow Expandable Activity Module, how the technology eventually re-entered the NASA program. Finally, Mr. Gonzalez discussed the need to expand the scope of thinking on space commerce, suggesting that we should be thinking about how space commerce will benefit other industries.

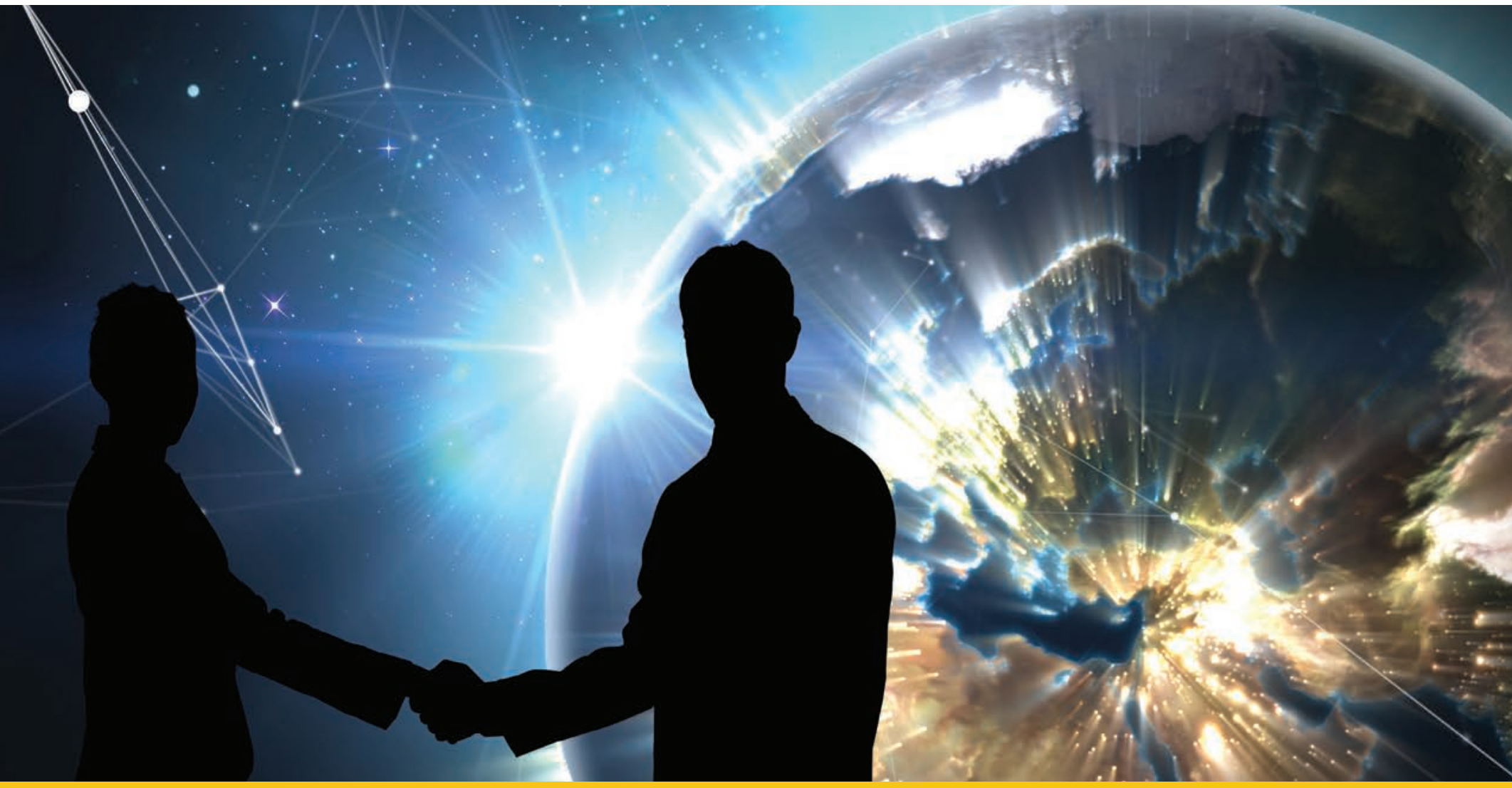


Mr. Christopher Allison, a Senior Systems Engineer with Sierra Nevada Corporation, leads their Federal Integration Team for the Dreamchaser Program, which is on contract with NASA for six International Space Station resupply flights. He is also involved in the Sierra Nevada program that develops Dreamchaser technologies for use in other applications. Sierra Nevada Corporation is an aggregator or mid-tier integrator looking for opportunities in the marketplace, relying on the commercialization of technology for revenue in addition to government funding. They are also working initiatives for non-traditional space users to address manufacturing challenges through Dreamchaser access to spaceflight.

Mr. Michael Hurowitz, the founder and chief technology officer of Orbital Micro Systems, described the company's role in developing weather remote sensing through passive microwave sensors for monitoring storm conditions and the data infrastructure to enable stakeholders to leverage the systems. Mr. Hurowitz highlighted challenges from the small business and startup perspective and identified the need for better transparency and communication among organizations working in the space industry. He noted that Orbital Micro Systems' largest competition is two federal programs that are also developing passive sensing and that better transparency and communication may have resulted in less overlap or better collaboration. Mr. Hurowitz also discussed the need for novel financing solutions for small and medium-sized manufacturing companies that don't fit the venture capital model and are too small for private equity. These companies often do not fit the traditional geo-space and satellite systems models that need hundreds of millions of dollars in debt financing and complicated insurance to guarantee viability. Mr. Hurowitz also pointed to the challenges that small businesses have in dealing with cost-intensive problems like influencing policy making and appropriations, understanding the government contracting process, and complying with international business and export control. Mr. Hurowitz praised the SBIR programs but cited that only approximately $1 \%$ of SBIR products translate into government acquisitions. He sees the need for a better demand signal in the SBIR programs to help companies identify which opportunities to pursue. Access to unique and essential technical facilities for small businesses is also a challenge that needs to be addressed. Finally, the data-sharing requirements included in treaties like the World Meteorological Organization's Resolution 40 need to be modified so that participation requirements don't prohibit sustainable business models for companies whose data is their intellectual property.

Mr. Ian Christiansen, Director of Private Sector Programs at Secure World Foundation, discussed the private foundation's role promoting solutions for space sustainability and the peaceful uses of outer space. The non-profit seeks to facilitate a cooperative global dialogue to create a stable space environment for everyone's use by focusing on space situational awareness, debris mitigation policies, applications use, and data access policies. Mr. Christiansen personally works with the commercial space sector, helping to ensure that regulations and policy evolve to enable new applications and innovations to market. He is also concerned with how the space industry can self-organize to establish best practices, working principles, and guidelines for responsible behavior. Mr. Christiansen noted the large and growing diversity of applications and users in the space environment and the challenge associated with how all the parts interact with governance approaches. He also pointed out that policy and regulation need to be adaptive in order to accommodate new business models. Many groups are thinking about and working on these issues and should be leveraged moving forward. 
Dr. Tanya Ramond, Director of Product Management at Bridgecomm, discussed recent changes to her organization due to the emergence of high-growth markets in terrestrial and airborne communications. Bridgecomm, formerly known as Bridgesat, identified the opportunity to leverage the optical communication solutions developed to support the space ecosystem as solutions for the growing market areas. She explained that, while the optical communication technology is not new, decreasing price points have only recently broadened accessibility beyond the top space organizations like NASA, the European Space Agency, and Japan Aerospace Exploration Agency.

\subsection{Key Themes}

» Gaps in today's space ecosystem supply chain limit innovation and growth.

- Supply chain logistics are a problem for small companies and startups that are trying to compete against established companies. Buying one or two resistors at a reasonable cost is difficult when others are buying thousands.

- Qualification of parts for use in space is a bottleneck for innovation. For example, attempting to develop new high-throughput optical communication technologies is limited by the access to space-qualified, field-programmable gate arrays faster than $1 \mathrm{GHz}$. Piecemeal qualification by individual small companies is too expensive. The NASA radiation qualification process is often prohibitively costly, causing companies to take large risks with unqualified parts. Nontraditional space users are often surprised when they cannot obtain parts or instruments easily accessible for terrestrial applications, limiting cross-sector innovation. New methods to identify and determine what to qualify and pathways to qualification are needed.

- A framework for considering international partnerships is needed to provide clarity on international treaty and policy requirements and on how to balance the potential financial benefits of international partnerships with impacts on the national economy and security.

»Communication technologies and data management

- There is still a problem with persistent communication availability for satellites. There are no off-the-shelf solutions.

- There is a massive amount of data currently available, but the data is not integrated, synthesized, or in standard formats. Additionally, people and organizations generally do not know how to access the data. Addressing these challenges is key to leveraging the resources already in place.

»Small-business challenges and technology gaps

- There is a need to better connect people and organizations currently engaged in space commerce and to provide an entry for new people and organizations to become engaged. Startup organizations are key to this challenge.

- Many solutions to technology gaps are probably already on the shelf, but not recognized. There is currently no comprehensive or even partially comprehensive solution to match on-theshelf solutions to technology gaps. 
- Incubator programs and seed funding for commercial transition help small companies bring technologies to market.

» Space tourism and the human side

- Space tourism is imminent, but most of our understanding of how space travel affects humans is geared toward people selected for space travel in part based on their high level of physical fitness. We do not have a fundamental understanding of the risks to the average human, yet understanding the risks and risk mitigation is critical to space tourism and space travel.

\subsection{Recommendations}

»Assess the status of the space ecosystem supply chain and the needs of small businesses and startups to develop a supply chain roadmap to promote innovation.

» Improve transparency and communication among the space industry community, including the development of industry technology roadmaps and the coordination of standards development.

»Coordinate the exploration of novel financing mechanisms that fit the needs of small and mediumsized manufacturing companies to compete and excel in space commerce.

»Identify and address the unique challenges that small businesses encounter when dealing with cost-intensive problems associated with the space industry.

»Provide mechanisms for small businesses and startups to access one-of-a-kind technical or qualification facilities or high-cost qualification pathways.

»Assess the technology landscape for space commerce, perhaps using an approach like The National Academies Decadal Surveys, to prioritize needs and funding opportunities.

»Develop a matchmaking organization that hunts both sides of the commercialization process to bridge the gap.

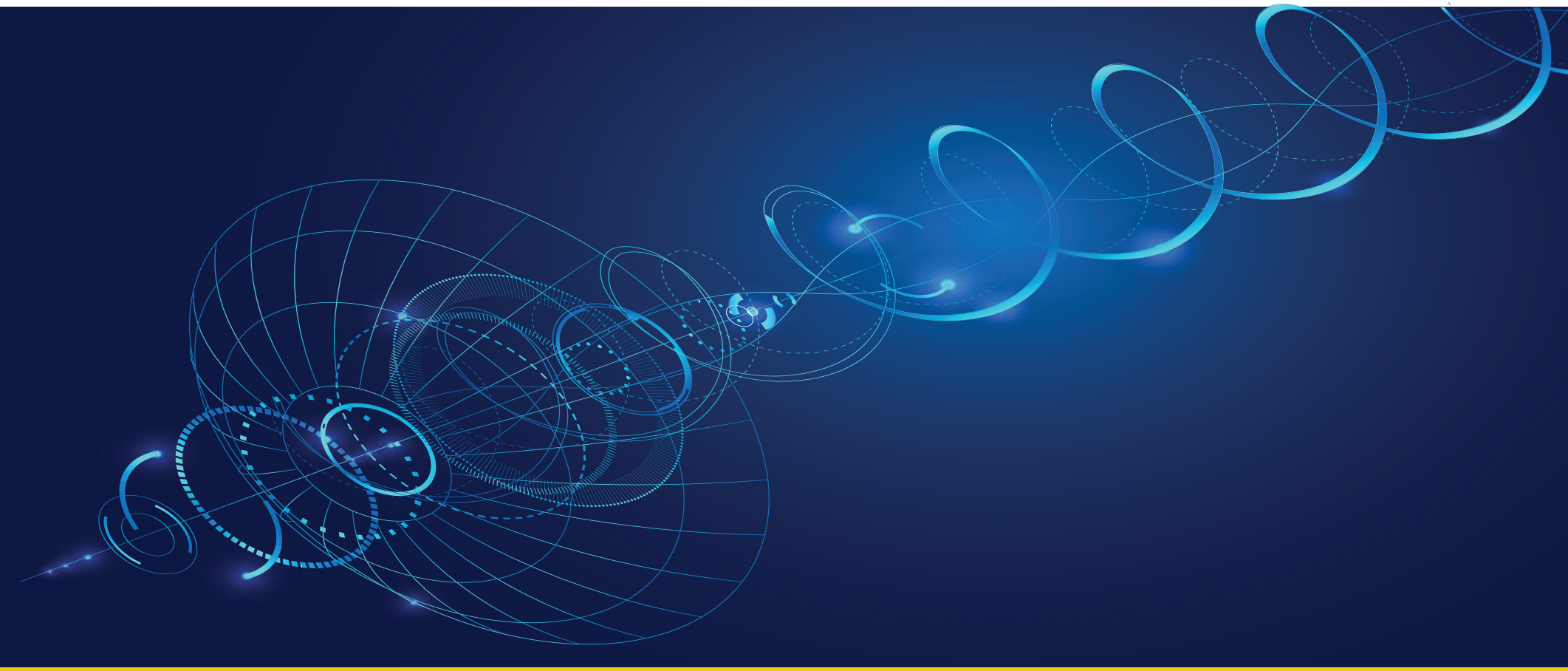





\section{Spectrum for Space Services}

This panel focused on spectrum's vital role in space commerce, and identified technical and regulatory areas where additional research, collaboration, and frameworks could facilitate growth. Each of the panelists presented insightful information on different spectrum issues prior to the audience question-and-answer session.

\begin{tabular}{|c|l|}
\hline \multicolumn{2}{|c|}{ Table 3. Panel members, Spectrum for Space Services } \\
\hline $\begin{array}{c}\text { Mr. Derek Khlopin } \\
\text { (Moderator) }\end{array}$ & $\begin{array}{l}\text { Senior Advisor at the National Telecommunica- } \\
\text { tions and Information Administration, } \\
\text { U.S. Department of Commerce }\end{array}$ \\
\hline Mr. Glenn Feldhake & $\begin{array}{l}\text { Program Manager, NASA International Spec- } \\
\text { trum }\end{array}$ \\
\hline Mr. Jaime Londono & $\begin{array}{l}\text { Vice President, Advanced Programs and Spec- } \\
\text { trum Management, EchoStar Corporation }\end{array}$ \\
\hline Dr. Scott Palo & $\begin{array}{l}\text { Charles Victor Schelke Endowed Professor, } \\
\text { Colorado Center for Astrodynamics Research, } \\
\text { University of Colorado Boulder }\end{array}$ \\
\hline Mr. Barry Noakes & $\begin{array}{l}\text { Chief Engineer Commercial Satellite Solutions, } \\
\text { Lockheed Martin Space Systems }\end{array}$ \\
\hline Dr. Christian Meyer & Vice President of Space Systems, Maxar \\
\hline
\end{tabular}

Mr. Glenn Feldhake, International Spectrum Program Manager at the NASA Glenn Research Center, explained how radio signals propagate between space and the earth, and the impacts of the atmosphere, ice particles, and clutter (rain, trees, building) on radio signals. He discussed how different propagation models can be used to design efficient systems and how others are better for predicting interference; and he provided information on the sources and repositories of propagation models. He identified ongoing challenges in standardizing methods for obtaining data, and in obtaining the data vital for model validation (as some models need 10 years of data). Mr. Feldhake recommended that aligning the interests of funding sources, researchers, and spectrum users would have a significant positive impact on reaching agreement on appropriate propagation models used for regulatory purposes. 
Mr. Jaime Londono, Vice President of Advanced Programs and Spectrum Management at EchoStar Corporation, focused his presentation on emerging spectrum and interference challenges for nongeostationary satellites (NGSOs). The coordination process for spectrum use and interference mitigation between the various satellites and constellations in orbit around the earth at altitudes for geo-stationary satellites, NGSO medium-earth and low-earth orbit satellites, and high-altitude platforms is complicated and three-dimensional amongst the satellites. The aggregate interference issue becomes even more complex when multiple constellations exist, and multiple satellites communicate with multiple receivers. International and domestic regulatory frameworks remain challenging, as does the processes for obtaining needed additional spectrum.

Professor Scott Palo, the Schelke Endowed Professor of Smead Aerospace Sciences at the University of Colorado, provided historical context of the cycles of space innovation and addressed the spectrum challenges presented by the rapid growth of disruptive and small satellite technologies that are garnering huge investments and enabling new business opportunities. He identified a pressing need to expedite regulatory access to spectrum, noting that spectrum licensing and small satellite development timelines remain incompatible, and that small satellites need spectrum to meet their high-data-rates demands. He also encouraged universities and small business to be involved in spectrum-related policy decision making.

Mr. Barry Noakes, Chief Engineer Commercial Satellite Solutions at Lockheed Martin Space Systems, shared technical information for using optical-free space communications (that operate at 198 terahertz, use very narrow beam-widths that get wider as they get closer to the earth, use low power, have ultra-high data rates, and are secure) as an alternative to RF. Mr. Noakes discussed considerations and risks of optical-free space communications related to exacting pointing requirements, degradation by atmospheric impacts, and designing for operations in the extreme environments of space, along with sources of potential interference such as bright objects and optical cross links. He also shared insights on the anticipated evolution and future uses of optical communications.

Dr. Christian Meyer, Vice President of Space Systems at Maxar Technologies, discussed themes and issues facing space commerce owner-operators, including how the enormous growth in satellites for space commerce creates space congestion issues and orders-of-magnitude more challenges for spectrum allocation and deconfliction. He asserted that spectrum interference is a difficult, costly, global problem, for which equitable and economical international solutions are needed. He also noted that current spectrum use and deconfliction needs have outpaced regulatory frameworks and international policy processes. He posited that industry and academia need to drive and work on innovative global-scale solutions.

The panelists shared these additional insights in response to audience questions:

» Technical solutions can exist that address some of the spectrum sharing concerns, but with the long life expectancy of existing satellites, getting solutions into the operational regime is a significant challenge.

» New data that could benefit propagation models includes data from developing countries, especially regarding atmospheric data in remote areas and data on new geometries for propagation from satellites that communicate in all planes: up, down, sideways, etc. Mesh network modeling is also needed. 
» Space weather can affect communications and satellite design, including due to potential data corruption and calculating margins, though small satellite design has inherent advantages due to less path loss than higher orbital satellites. Space weather can also affect atmospheric drag on LEO systems which can also impact the design of large LEOs.

» No license is required for optical links in the U.S. Licensing could become an issue considering the concerns optical communications are creating for astronomers. For regulating federal entities NTIA retains authority to regulate optical frequencies but has chosen not to do so to date. A world radiocommunication conference could also address optical issues in the future. Optical communications are less susceptible to interference than RF due to the line-of-sight and narrowness of the beam.

»Currently, likely less than $5 \%$ of small satellites have propulsion systems, but that is expected to increase and grow as new small satellites are launched. Space debris, security and link concerns, and advances in electric low-power propulsion thrusters will also drive increased inclusion of propulsion capabilities in satellites.

»While not all the currently announced industry plans for new NGSO constellations will likely come to fruition, there will definitely be more non-GEO constellations. When small satellites ride-share for launches, the integrator or aggregator will conduct communications deconfliction with the space craft providers to ensure communications will exist with the small satellites once deployed in the same orbital plane and close together.

NASA is looking at exploring the possibility of using existing fixed and mobile satellite uplinks and downlinks for cross-links.

\subsection{Key Themes}

» The community acknowledges the challenges of increasingly crowded spectrum for space systems.

- The regulatory process for obtaining spectrum, domestically and internationally, is cumbersome. For example, it is not sustainable for spectrum licensing to take twice as long as it does to build a small satellite.

» There is openness to new approaches and tools for addressing spectrum scarcity and spectrum efficiency:

- New spectrum-sharing paradigms

- Adding optical and infrared (198 THz) to RF options

- Identifying new spectrum analysis capabilities to source and share data

- Aligning research topics, industry needs, and funding sources

\subsection{Recommendations}

» Understand new spectrum demands while protecting existing services

» Universities and small businesses are on the front of the evolution of the space industry and need to be considered in policy making.

» Funding sources should be aligned with identified needs. 


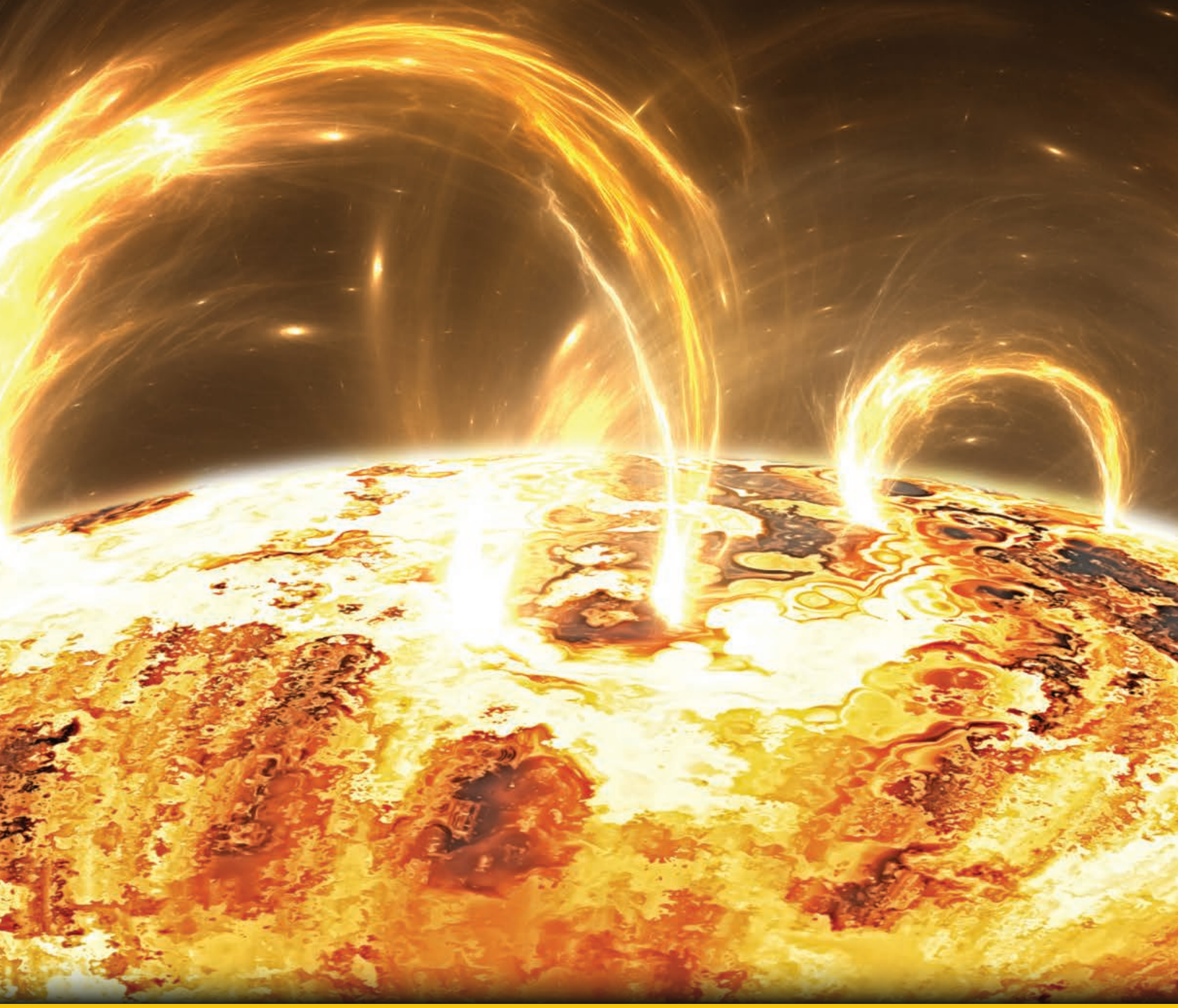




\section{Models and Algorithms for Space Situational Awareness}

The objective of this panel was to review fundamental needs and requirements for successful SSA as seen from a variety of vantages. The panel was designed to include members from the three principal types of entities involved in commercial space, as well as both established and new actors. The contrasting viewpoints and organizational challenges enabled a diversity of comments and serves to underline items that all representatives agreed upon. Established vs. new SSA actors in government (U.S. Air Force vs. NOAA), industry (Lockheed Martin Advanced Technology Center vs. Numerica), and academia yielded particularly insightful observations.

\begin{tabular}{|c|l|}
\hline \multicolumn{2}{|c|}{ Table 4. Panel members, Models and Algorithms for Space } \\
$\begin{array}{c}\text { Situational Awareness } \\
\text { [Moderator] }\end{array}$ & $\begin{array}{l}\text { Associate Professor, Smead Aerospace } \\
\text { Engineering Sciences Department, } \\
\text { University of Colorado Boulder }\end{array}$ \\
\hline Dr. Michele Gaudreault & $\begin{array}{l}\text { Deputy Chief Scientist, Air Force Space Com- } \\
\text { mand }\end{array}$ \\
\hline Dr. Moriba Jah & $\begin{array}{l}\text { Associate Professor, Aerospace Engineering } \\
\text { and Engineering Mechanics Department, } \\
\text { The University of Texas at Austin }\end{array}$ \\
\hline Mr. Bob Rutledge & $\begin{array}{l}\text { Lead, Space Weather Forecast Office, } \\
\text { NOAA Space Weather Prediction Center }\end{array}$ \\
\hline Ms. Marya Andrepont & $\begin{array}{l}\text { Director, Space Security \& Communications, } \\
\text { Lockheed Martin Advanced Technology Center }\end{array}$ \\
\hline Dr. Jeff Aristoff & $\begin{array}{l}\text { Vice President, Space Systems, } \\
\text { Numerica Corporation }\end{array}$ \\
\hline
\end{tabular}

The panel discussion began with a short presentation delivered by Dr. Michele Gaudreault entitled "Space Situational Awareness Science and Technology Challenges." Needs in SSA operations, characterization, challenges, environment, and threats were discussed. Following this briefing an engaging discussion amongst the panel began, summarized below.

To begin, each panelist responded to a question from the moderator, Dr. Marcus Holzinger, Associate Professor in the Smead Aerospace 
Engineering Sciences Department, University of Colorado Boulder: "What top-three fundamental research and technology development needs in models and algorithms for SSA do you view as necessary in civil and commercial space?"

Dr. Jeff Aristoff, Vice President of Space Systems at Numerica Corporation, discussed concerns around scaling algorithms and software capabilities to the magnitude of predicted orbital objects. He noted that the tools will have to ingest data from multiple sources. The solution is more than just a faster computer and parallel computing. Algorithms and models for maneuvering will be needed in order to deal with the increasing number of conjunctions that might happen, as well as false detections. Ways to better verify and validate algorithms and models-for example, standard methods-will also be required.

Ms. Marya Andrepont, Director of Technology Integration at Lockheed Martin Corporation, echoed Dr. Aristoff's concerns and mentioned accuracy versus persistence. Accuracy is needed to ensure correct predictions, while persistent data, such as "watching all the time," is also needed. How this data will be shared and how the quality will be determined is a concern. Today, there is data that is not used at all because there are no standards or metrics to determine the quality of the data.

Dr. Moriba Jah, Associate Professor, Aerospace Engineering and Engineering Mechanics Department, The University of Texas at Austin, echoed previous thoughts, but also brought up the need for accurate models and measurements. True understanding of space environment effects and the impacts on objects (for example accurate drag models or passive charging and interaction with magnetic fields) is needed, but, too often, overly simplified assumptions are used. All the nongravitational perturbations care about the physical properties of the objects. We don't have a scientific taxonomy for human-made objects in space. He also brought up scaling in the context of understanding and predicting maneuvers. How do we recognize objects uniquely and predict how they behave in the future? And finally, Dr. Jah pointed out that there is a cultural aspect to all of this since the designers and operators are human, so it's not just about physics. The cultural aspect impacts, for example, operators' and designers' interpretations of regulations and standards and times that operators are active and communicating with the asset in space to perform maneuvers.

Mr. Bob Rutledge, Lead, Space Weather Forecast Office, NOAA Space Weather Prediction Center, spoke about challenges associated with atmospheric drag characterization and modeling the radiation environment. For drag there is a need for mature weather information and a whole atmosphere model, continuing a partnership with CU and CIRES. For radiation there is a need to provide data to inform anomaly assessment attribution and health. There are relatively good measurements for geostationary orbit, but low and medium earth orbits are under monitored and/or the data are not openly shared. Space weather impacts both real-time operations and design environments at both the norm and the extreme.

Dr. Michele Gaudrealut, Deputy Chief Scientist, Air Force Space Command, commented that the two biggest problems are getting an accurate measurement (we have 400 rulers, but we want a micrometer) and, to echo Bob Rutledge's comments, better drag estimates to help achieve better orbit determination for items that don't maneuver.

This was followed by discussions centered around questions from the audience. 


\subsection{Key Themes}

»Data, quality, validation, and ability to compare algorithm and model outputs

- To improve methods and models, we require precise and persistent sensing using multiple sensors of different types, exhaustive associated metadata, data quality control, and verification and validation of data and algorithms. Benchmark test cases, nominal accepted data processing pipelines, datasets, and/or competitions can help improve the impact of current and future research and development activities.

» Improved awareness and rigorous treatment of systemic and random uncertainty

- For models and algorithms to improve commercial SSA, they must exhibit improved awareness and rigorous treatment of aleatoric and epistemic uncertainties in the objects observed, systemic biases and ambiguities caused by using incorrect models (e.g., unknown object characteristics), and unknown or erroneous local space weather (e.g., charging, atmospheric properties). Additional data and models are needed for under-observed low and medium earth orbit regimes. Derived data from debris object tracks can be useful for inferring some of these things. A move away from using only probability of collision is suggested.

»Cultural-, autonomy-, and astrodynamics-driven actions and perturbations

- Human-in-the-loop or autonomy-in-the-loop systems are difficult to model and predict. Massive constellations of satellites that possess high-cadence autonomous maneuvers will easily lead to incorrect observation associations and erroneous orbits. Under-appreciated elements of astrodynamics perturbations can be misconstrued as maneuvers and lead to lost objects or misclassification of objects as active. Data analytics (also including machine learning) should leverage (and not ignore) known physics and phenomena. Existing results in astrodynamics should be more broadly understood by operators to avoid poor operational practices in orbit regimes that are potentially chaotic or unstable (e.g., medium and geostationary earth orbit graveyard), and additional research in astrodynamics (as applied to Earth and near-Earth orbits) should be conducted to identify safe orbits that efficiently use orbit resources.

\subsection{Recommendations}

»Collaborate with academia to investigate best practices, develop novel technologies, and train professionals.

»Benchmark test cases, nominal accepted data processing pipelines, datasets, and/or competitions will help improve the impact of current and future research and development activities.

» Data analytics (also including machine learning) should leverage (and not ignore) known physics and phenomena.

» Existing results in astrodynamics should be more broadly understood by operators to avoid poor operational practices in orbit regimes that are potentially chaotic or unstable (e.g., medium and geostationary earth orbit graveyard).

» Additional research in astrodynamics (as applied to Earth and near-Earth orbits) should be conducted to identify safe orbits that efficiently use orbit resources. 


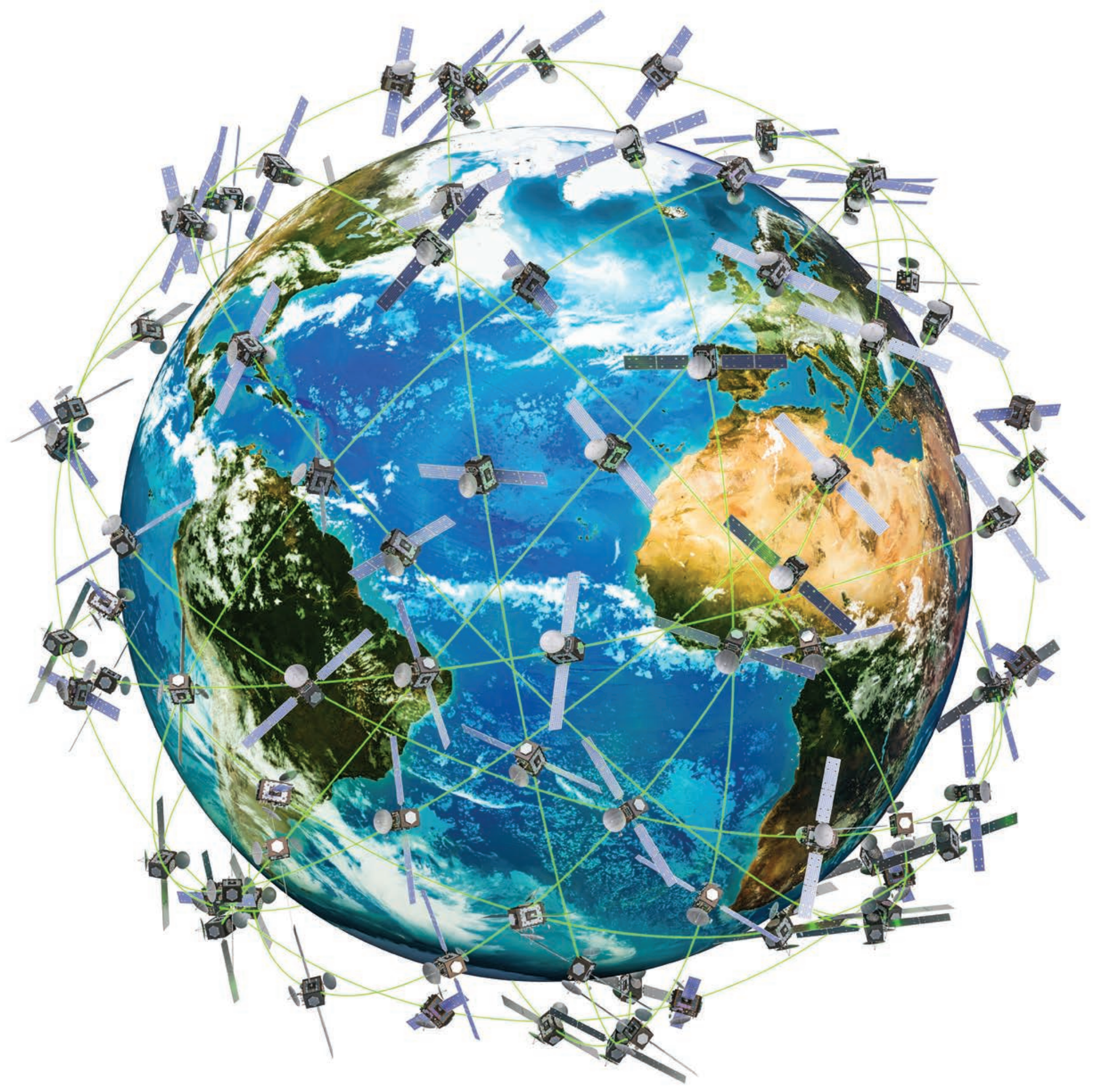




\section{Managing Data for Space Traffic Management}

This panel explored the technical challenges associated with the collection, distribution, analysis, and utilization of SSA data. Panel members represented the DOC, industry, the State Department, academia, and former Air Force operations perspectives. The panelists and their affiliations are listed in Table 5.

Table 5. Panel Members, Managing Data for Space Traffic Management

\begin{tabular}{|c|c|}
\hline $\begin{array}{l}\text { Mr. Scott Rayder } \\
\text { [Moderator] }\end{array}$ & $\begin{array}{l}\text { Senior Advisor to the President, University Corpora- } \\
\text { tion for Atmospheric Research [UCAR] }\end{array}$ \\
\hline Mr. Jim Cooper & $\begin{array}{l}\text { Senior Systems Engineer, Space Situational Aware- } \\
\text { ness, Analytical Graphics, Inc. }\end{array}$ \\
\hline $\begin{array}{l}\text { Ms. Amber } \\
\text { Charlesworth }\end{array}$ & $\begin{array}{l}\text { Foreign Affairs Officer, } \\
\text { State Department Office of Space and Advanced } \\
\text { Technology }\end{array}$ \\
\hline Dr. David Rodvold & Chief Scientist and Co-founder, Bluestaq \\
\hline Ms. Charlie McGillis & $\begin{array}{l}\text { Executive Director of Customer Engagement and } \\
\text { Strategy, Slingshot Aerospace }\end{array}$ \\
\hline Mr. Kevin O’Connell & Director, Office of Space Commerce \\
\hline
\end{tabular}

The panel began with a talk by Mr. Jim Cooper from Analytical Graphics, Inc., "Space Situational Awareness - The Challenges of Space Debris." Mr. Cooper presented a quantitative basis for the urgent need to address STM and SSA needs. Today, over 60 nations are flying satellites with more nations poised to enter the field and many satellite constellations planned. Just two conjunction events, one in 2007 and one in 2009, created 6300 new catalog objects. Meanwhile, with a minimum detectable threshold of $10-20 \mathrm{~cm}$, it is estimated that the current public catalog contains only $4 \%$ of low-earth-orbiting objects greater than $1 \mathrm{~cm}$, a size that can cause significant physical and economic damage to an orbiting satellite. Mr. Cooper highlighted the expected growth of trackable and untrackable objects expected in the near decade, showed quantitative estimates of the increased probability of conjunction, and addressed the "human" aspects intertwined with technical challenges of orbit determination and conjunction assessment. For example, how do we get transparency of collision events and how do we define and enforce responsible space behaviors using best practices? How do we establish best practices? 
In collision avoidance practices decisions could be made based on which satellite was there first, or cost analysis (e.g. fuel vs. mission), or maneuverability. Despite these challenges, there are numerous capabilities already available to start supporting a space traffic management regime.

Ms. Amber Charlesworth from the Office of Space and Advanced Technology at the Department of State discussed U.S. participation in the UN committee on peaceful use of outer space. She acknowledged that STM is global and requires international cooperation. She also acknowledged industry will be a key piece of the solution and their continuing involvement is needed. Many industry best practices are better than that of governments, such as examination of the manufacturing phase before entering orbit to make sure a craft is maneuverable. Ms. Charlesworth discussed the intention to maintain U.S. leadership in this area.

Dr. David Rodvold from Bluestaq used two computer punch cards to illustrate how historical approaches to STM are influencing it today. The data format hasn't changed in decades, and the 80-column limit dates back to the limit on a computer punch card. Yet modern STM requires data be assimilated from many sources with all kinds of information and analyzed in new ways. He described his company's work on a web-based portal that provides quick and easy access to the data. Bluestaq is building an SSA marketplace that allows a user to put out a request, get vendor bids, agree to terms, and get payment. This allows smaller companies that aren't defense contractors to be involved in the marketplace and brings small-company agility to this problem.

Ms. Charlie McGillis from Slingshot Aerospace brought an operator's focus to the discussion by drawing on her previous experience in charge of intelligence at Fourteenth Air Force (14 AF), the Air Force Space Command. She emphasized the need for metadata in addition to the terabytes of information already out there: For example, who owns the satellite and where was it built? What is the influence of culture? Relationships between the data are important, as well. From an operational perspective one needs to 1) ingest data, including metadata, and 2) curate the data, i.e. evaluate data provenance based on who supplied it, who it belonged to, the quality, and any biases. Then one needs to 3) aggregate that data and show patterns of analysis, and 4) develop a prediction capability. Finally, one needs to 5) supply a confidence factor.

Mr. Kevin McConnell began by re-emphasizing that this is an urgent problem of which everyone in the community is aware, and that it must be worked on in a "whole of government" fashion, with agencies working together. He reiterated that the government must harness the power of private industry in order to solve this complex problem. He emphasized the need for a confidence factor associated with predictions in order to avoid operator "warning fatigue," and the need to do a better job with notifications and modernize beyond e-mail. To create the Open Architecture Data Repository, and a marketplace of solutions, the first step is to bring in the Unified Data Library, with 3.5 million pieces of data a day, thousands of users, and a web driven interface, while remembering to pay attention to cybersecurity and data validation. The Office of Space Commerce's goal is to create a platform where people can experiment and innovate. Mr. McConnell remains optimistic that, working together, this problem can be solved.

\subsection{Key themes}

» U.S. industry plays a key role in addressing the urgent problems associated with SSA and STM. Government must foster and leverage the agility of industry.

- New capabilities in the commercial world may disrupt the debris problem. 
- Outdated aspects of STM need to be fused quickly with modern tools. Rely on U.S. industry to do this.

- Creating a market for SSA data is one way to encourage small company participation; look for dynamism in the marketplace.

- Multitudes of companies are bringing diverse capabilities to market: sensors, analytical tools, data management, etc.

- In many instances, industry already has better practices than the government.

» The community needs better definitions of and standards around who curates the data, what data should be brought in, who provides independent and unbiased checks and how, and how a confidence factor can be assigned.

- The data need curation, fusing, and quality control.

- The data need independent and unbiased checks.

- Data coming from multiple sources needs to be distributed, analyzed, and ingested in a timely manner.

- The Air Force has provided independent and unbiased checks and balances for data. Normally the A9 Directorate validates, and they would validate commercial data. The Department of Defense (DOD) will continue but will share with the DOC. DOD and commercial capabilities could be aggregated; for example, a tool that uses physics or artificial intelligence to validate data.

- Commercial services should emerge. For example, a potential commercial service is to determine what to do if there is a predicted conjunction.

- Someone must be keeper of data; secure data, tag it, and show it to who needs it, but otherwise keep it secure.

- Are we storing the right data in the Unified Data Library?

- Data is not the same as information. Data gets fused into information.

- The Unified Data Library needs metric data from the sensors.

- The Unified Data Library is a work-in-progress. Why not bring in validated commercial data? We want raw data so others can process. Think about the Unified Data Library as the first part of the marketplace.

» The human influence on SSA and STM can't be ignored.

- SSA and STM are global challenges, and as such, policy is intertwined with technology.

- There are many legal, policy, and international aspects that must be considered as part of technical solutions.

- Culture matters. Who is operating the satellite is part of the equation.

- The Office of Space Commerce is hearing from industry that they must start thinking about regulatory issues as new owner/operators enter space. The goal is a light touch, using industry best practices and new technology ideas such as beacons and space debris removal. 


\subsection{Recommendations}

» Government must foster and leverage the agility of industry. U.S. industry plays a key role in addressing the urgent problems associated with SSA and STM.

» Better define standards around who curates the data, what data should be brought in, who provides independent and unbiased checks and how, and how a confidence factor can be assigned.

» Do not ignore the human influence on SSA and STM.

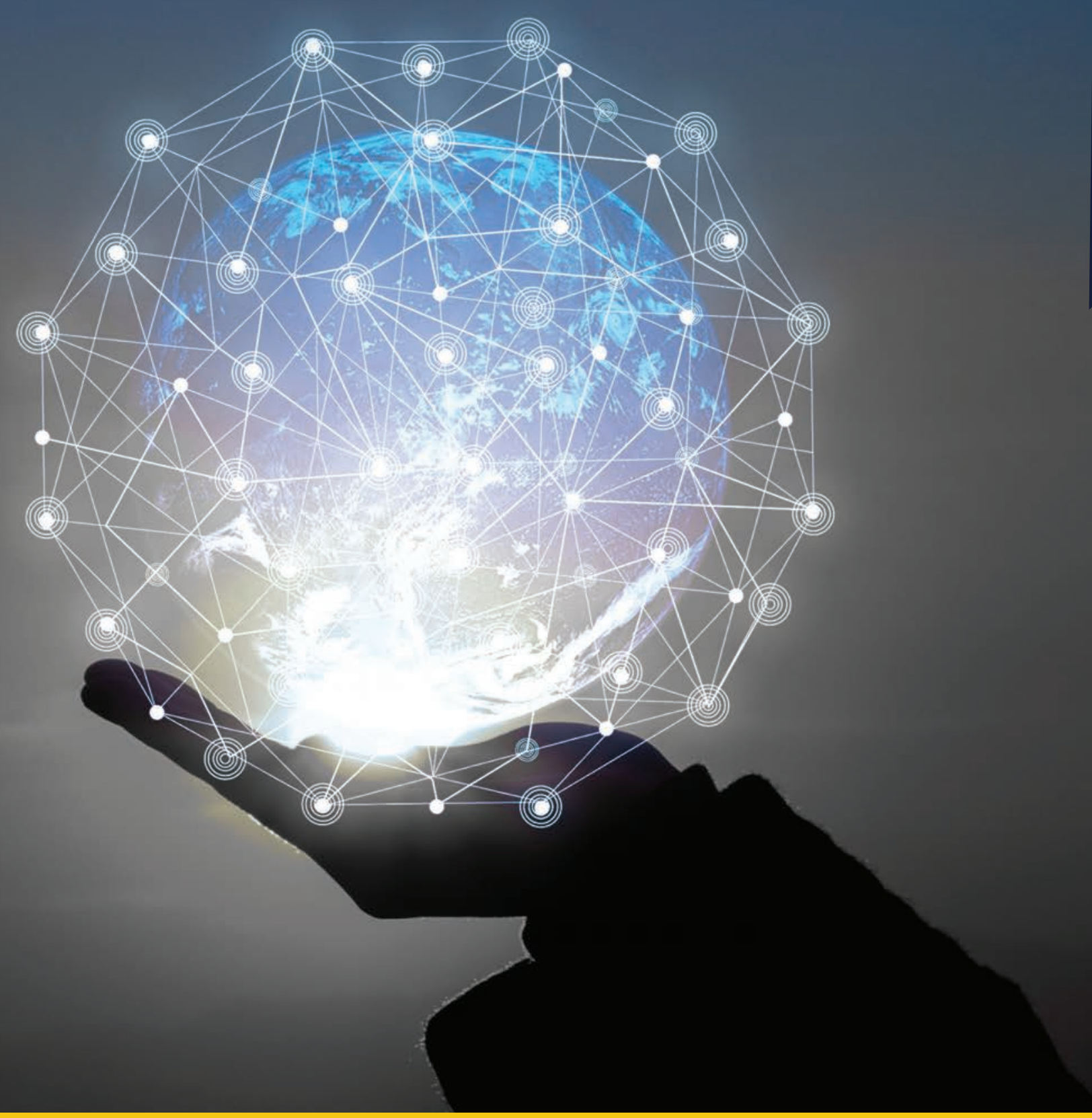




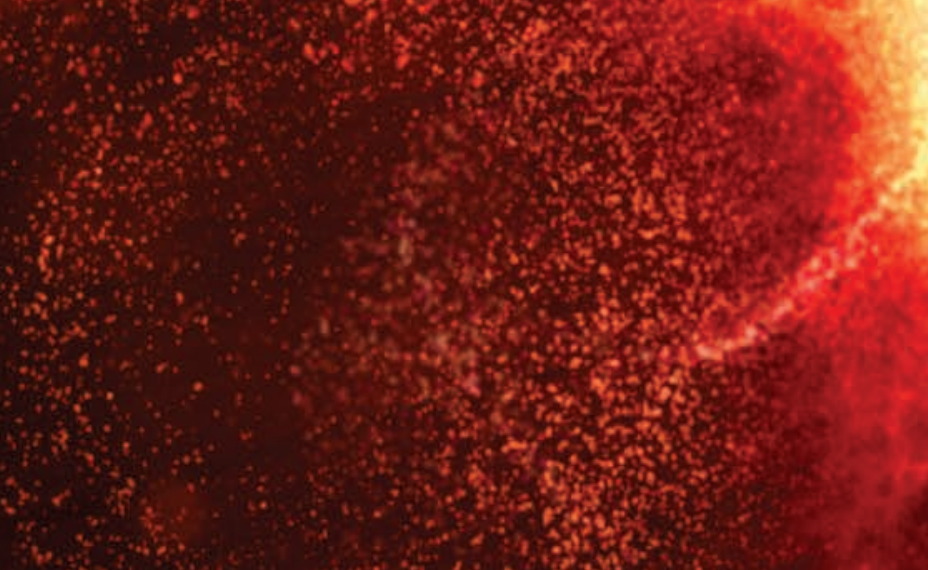

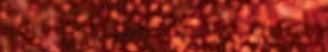

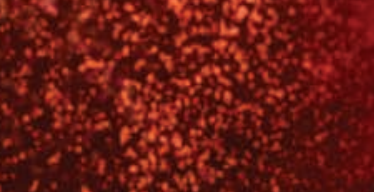

(3)

if:

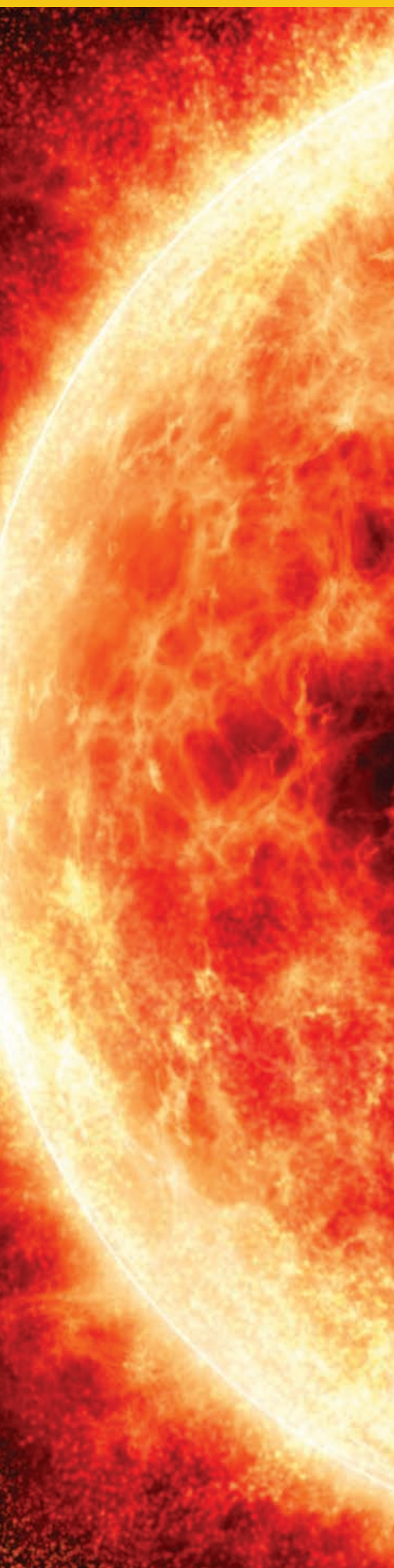




\section{Appendix A: Agenda}

\begin{tabular}{|c|c|}
\hline \multicolumn{2}{|r|}{$\begin{array}{c}\text { Department of Commerce } \\
\text { SPACE COMMERCE WORKSHOP AGENDA }\end{array}$} \\
\hline 7:00 - 8:00 am & Registration and Continental Breakfast \\
\hline \multirow[b]{2}{*}{ 8:00 - 8:20 am } & $\begin{array}{l}\text { Introduction of Kevin O'Connell } \\
\text { Walt Copan, NIST Director }\end{array}$ \\
\hline & $\begin{array}{l}\text { Welcome and Opening Remarks } \\
\text { Kevin O'Connell, Director of the Office of Space Commerce at the } \\
\text { U.S. Department of Commerce }\end{array}$ \\
\hline 8:20 - 9:45 am & $\begin{array}{l}\text { Session 1: Partnerships with DOC } \\
\text { Moderator: Kevin O'Connell, Director, Office of Space Commerce }\end{array}$ \\
\hline 9:45 - 10:05 am & BREAK \\
\hline 10:05 - 11:20 am & $\begin{array}{l}\text { Session 2: Emerging Technologies for Space Commerce } \\
\text { Moderator: Walt Copan, Director, } \\
\text { National Institute of Standards and Technology }\end{array}$ \\
\hline 11:20 - 12:05 pm & $\begin{array}{l}\text { Keynote Address } \\
\text { Bobby Braun, Dean, College of Engineering and Applied Science, } \\
\text { University of Colorado Boulder }\end{array}$ \\
\hline 12:05 - 12:50 pm & LUNCH [On Site] \\
\hline 12:50 - 2:05 pm & $\begin{array}{l}\text { Session 3: Spectrum for Space Services } \\
\text { Moderator: Derek Khlopin, Senior Advisor, Office of the Assistant Secretary, } \\
\text { National Telecommunications and Information Administration }\end{array}$ \\
\hline 2:05 - 3:20 pm & $\begin{array}{l}\text { Session 4: Models and Algorithms for Space Situational Awareness } \\
\text { Moderator: Marcus Holzinger, Associate Professor, } \\
\text { Aerospace Engineering Sceinces Dept., University of Colorado Boulder }\end{array}$ \\
\hline 3:20 - 3:40 pm & BREAK \\
\hline 3:40 - 4:55 pm & $\begin{array}{l}\text { Session 5: Managing Data for Space Traffic Management } \\
\text { Moderator: Scott Rayder, Senior Advisor to UCAR President, } \\
\text { University Corporation for Atmospheric Research }\end{array}$ \\
\hline 4:55 - 5:15 pm & WRAP UP \\
\hline 6:00 - 8:00 pm & $\begin{array}{l}\text { Reception, University of Colorado } \\
\text { SEEC Building, } 4001 \text { Discovery Drive, Boulder, CO }\end{array}$ \\
\hline $\begin{array}{l}\text { Each session will b } \\
\text { opening with short } \\
\text { tool will a }\end{array}$ & $\begin{array}{l}\text { panel discussion with 4-7 panel members. Panel format will vary, with some pa } \\
\text { lks while others will open immediately with introductions and discussion. A real-t } \\
N \text { the audience to ask questions and make comments during each session. }\end{array}$ \\
\hline
\end{tabular}




\section{Appendix B: Participants}

Waleed Abdalati

Mojtaba Akhavan-Tafti

Christopher Allison

Karen Andersen

Marya Andrepont

Brian Argrow

Jeff Aristoff

Will Armijo

Sharra Baeighkley

Carah Barbarick

Nicholas Barbosa

Aaron Bass

Patrick Bauer

Thomas Berger

Steven Bledsoe

Daniel Bodenstein

Jason Boehm

lain Boyd

Robert Braun

Tom Bugnitz

Nicholas Campbell

Roger Carter

Tiffany Chow

lan Christensen

Hyungmin Chung

Robert Cone

Anton Conte

James Cooper, Jr.

Walter Copan

Brian Copello

Kristan Corwin

Fabio da Silva

Matthew Dodge

Marla Dowell

Douglas Engelhardt

John English

Matthew Erskine

Jeremy Eyman

Glenn Feldhake

Frank Francone

Jessica Freitas

Jamie Fritzke

Tim Fuller-Rowell

Edward Garboczi

Oscar Garcia

Michele Gaudreault

Gordon Gillerman

Barbara Goldstein

Steven Gonalez

Josh Gordon

Gretchen Greene
University of Colorado Boulder

University of Michigan

Sierra Nevada Corporation

UCAR

Lockheed Martin Space

University of Colorado

Numerica Corporation

ASTRA, LLC

Stranaska Scientific LLC

Space Foundation

National Institute of Standards and Technology [NIST]

ASRC Federal

Aerospace Corporation

University of Colorado at Boulder Space Weather TREC

Z-RATED.COM INC

Boulder Engineering Studio

National Institute of Standards and Technology [NIST]

University of Colorado

University of Colorado Boulder

Manufacturer's Edge

University of Colorado

Orbital Micro Systems

Secure World Foundation

Secure World Foundation

CSULB

Advanced Space

DOT

Analytical Graphics, Inc. [AGI]

National Institute of Standards and Technology [NIST]

National Institute of Standards and Technology (NIST)

National Institute of Standards and Technology (NIST)

National Institute of Standards and Technology (NIST)

Booz Allen Hamilton

National Institute of Standards and Technology (NIST)

Maxar Technologies

Boulder Engineering Studio

Booz Allen Hamilton

Office of Congressman Ed Perlmutter [CO-07]

NASA

RML Technologies, Inc.

U.S. Department of Commerce

Student

University of Colorado

National Institute of Standards and Technology [NIST]

InterFlight Global

HQ AFSPC/DST

National Institute of Standards and Technology [NIST]/SCO

National Institute of Standards and Technology [NIST]

NASA/JSC

National Institute of Standards and Technology [NIST]

National Institute of Standards and Technology (NIST) 
Katri Hakola

Colby Harper

Dale Hatfield

Chiemi Heil

Chad Hoffmann

Marcus Holzinger

Stephanie Hooker

Michael Hurowitz

Dana Irvin

Joshua Jackson

Moriba Jah

Ruth Janjic

Edgar Johansson

Christopher Johnston

Brandon Jones

Kathleen Karika

Leah Kauffman

Jaclyn Keshian

Derek Khlopin

Sharon King

Jon Kolb

William Kowalski

Travis Langster

Conrad Lautenbacher

Jay Lindell

Jer Chyi Liou

Jaime Londono

Alexander MacDonald

Arthur Maples

Joseph Marney

Dallas Masters

Gay McGillis

Duncan McGillivray

Kevin McWilliams

Christian Meyer

Melissa Midzor

Shawn Miller

Harrell Moore

Christopher Muldrow

William Murtagh

Annie Oatman-Gardner

Karri Palmetier

Scott Palo

Tanya Ramond

Scott Rayder

Jillian Redfern

Kimberly Robertson

Christian Rocken

David Rodvold

Robert Rutledge

Alexander Salter
Challenger Point Engineering, Strategy and Consult LLC

Pathfinder Wireless Corp.

University of Colorado at Boulder

DOT

NORAKEnterprises

University of Colorado Boulder

National Institute of Standards and Technology [NIST]

Orbital Micro Systems

Longbow Software

Shift9 Laboratories LLC

The University of Texas at Austin

Boulder SBDC/TechSource

LASP

Keysight Technologies

Millennium Engineering and Integration Company

Maxar

National Institute of Standards and Technology [NIST]

White House Office of Science and Technology Policy

NTIA

Boulder SBDC

Omitron

Atomos Space

AGI

GeoOptics, Inc

CO OEDIT

NASA

EchoStar

Spire Global, Inc.

NASA

Catalyst Campus

Spire Global, Inc.

Slingshot Aerospace

National Institute of Standards and Technology [NIST]

Boulder Engineering Studio

Maxar Technologies

National Institute of Standards and Technology [NIST]

Raytheon

Stephenson Stellar Corporation

University of Colorado Boulder

NOAA Space Weather Prediction Center

U.S. Senator Michael Bennet's Office

Palmetier Law, LLC

University of Colorado Boulder

BridgeComm

University Corporation for Atmospheric Research

Southwest Research Institute

Boulder Engineering Studio

GPS Solutions/Hexagon PI

Bluestaq LLC

NOAA Space Weather Prediction Center

Rawls College of Business, Texas Tech University 
Melissa Sampson

Brian Sanders

Mary Saunders

Matthew Scholl

David Simmons

Roger Simpson

Frederick Slane

Steven Smith

James Spann

Donald Speedy

Charles Spillar

Jason Stauch

Michelle Stephens

Matthew Taylor

Jeffrey Thayer

Carroll Thomas

Jack Waldorf

Debra Wilcox

Adam Wunderlich

Jia Yue
Ball Aerospace

Orbital Micro Systems

American National Standards Institute

National Institute of Standards and Technology [NIST]

Rocky Mnt Innovation Partners (RMIP)

Omitron

Space Infrastructure Foundation

SAIC

NASA

Trimble Inc.

MITRE

Slingshot Aerospace

National Institute of Standards and Technology (NIST)

Raytheon

University of Colorado

National Institute of Standards and Technology (NIST) MEP

University of Colorado Office of Government Relations

The 3D Printing Store

National Institute of Standards and Technology [NIST]

Hampton University 


\title{
Appendix C: Presentations
}

\section{Space Debris: A Law and Economics Analysis of the Orbital Commons}

\author{
Alexander William Salter \\ Texas Tech University
}

\section{Introduction}

- Space debris: "all man-made objects in orbit around the Earth which no longer serve a useful purpose." (NASA)

- 300,000 pieces large enough to destroy a satellite

- Low probability of collision, <1/1000

- BUT significant costs, conditional on collision: \$30 million immediately, \$200 million from future collision

- Kessler syndrome (snowballing effect)

- Space economy: $\$ 350$ billion, \$130 billion satellite services (2017) 


\section{Timeline}

- 1957-first piece of space debris, rocket body from Sputnik I

-1961-first manufactured space vehicle explodes in orbit

-2007-China anti-satellite test

-2009-Iridium/Russia satellite collision

-2019-India anti-satellite test

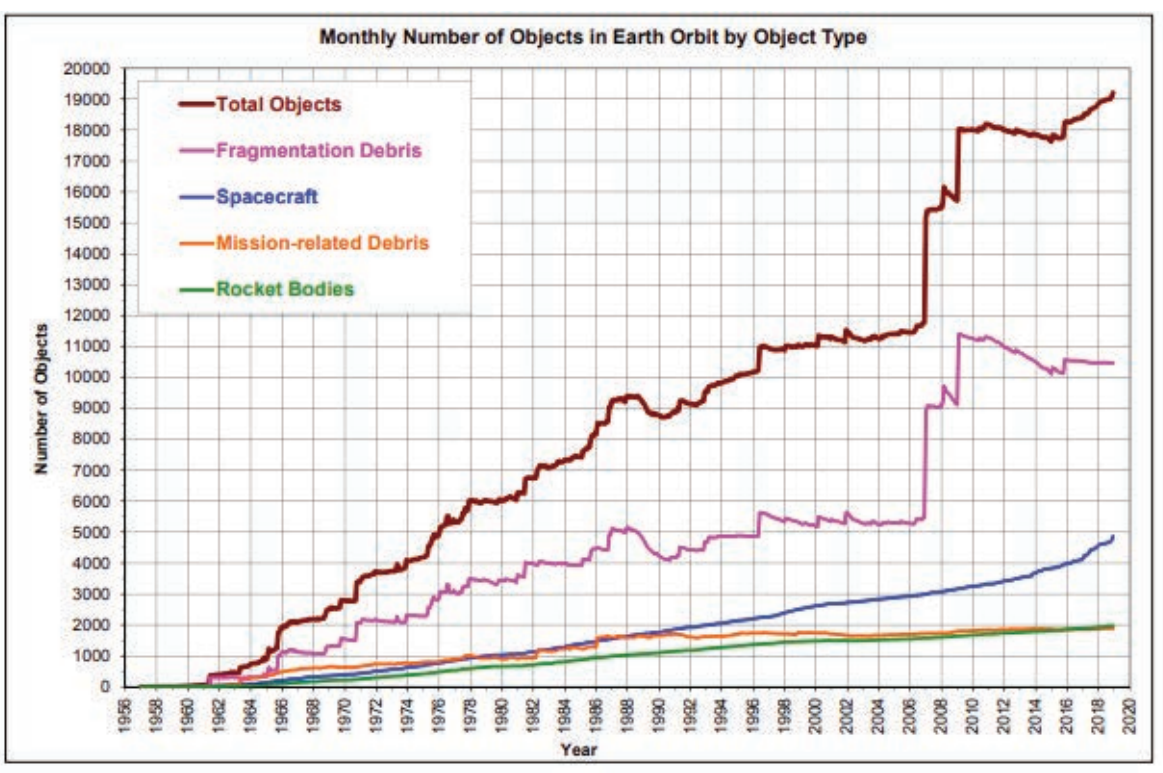

Source: ARES Orbital Degree Office, May 2019 
Number of rocket launches since the start of the space age in 1957:

About 5450 (excluding failures)

Number of satellites these rocket launches have placed into Earth orbit:

About $\mathbf{8 9 5 0}$

Number of these still in space:

About $\mathbf{5 0 0 0}$

Number of these still functioning:

About 1950

Number of debris objects regularly tracked by Space Surveillance Networks and maintained in their catalogue:

About 22300

Estimated number of break-ups, explosions, collisions, or anomalous events resulting in fragmentation:

More than $\mathbf{5 0 0}$

Total mass of all space objects in Earth orbit:

More than 8400 tonnes

Number of debris objects estimated by statistical models to be in orbit:

34000 objects $>10 \mathrm{~cm}$

900000 objects from $1 \mathrm{~cm}$ to $10 \mathrm{~cm}$

128 million objects from $1 \mathrm{~mm}$ to $1 \mathrm{~cm}$

Source: European Space Agency, 2019

\section{An Economic Typology}

- Are orbital access and specific orbits public goods?

- Public good: nonrival and nonexcludable

- Orbital access

- Common pool resource: rival and nonexcludable

- Specific orbits, esp. LEO

- Excludability problem $\rightarrow$ "tragedy of the commons" in space 


\section{Corrective Policy}

- A. C. Pigou (1932) - tax negative externalities

- Great in theory, very difficult in practice

- Information and incentive problems

- R. Coase (1960) - externality problems are property rights problems

- Property rights solutions seem infeasible

- ...But what about legal liability assignment?

- Efficiency and legal rules-who is the least-cost avoider?

- Allocating rights/responsibilities to maximize wealth

\section{Legal Burden and Efficiency}

- Hypothetical rule: burden for coping with space debris entirely on private parties

- Will this work well? Probably not

- More robust spacecraft, maneuverability, insurance, etc.

- Total costs of debris mitigation and removal almost certainly lower with assistance of public policy

- Stricter deorbiting rules, user fees, etc. 


\section{Mitigation vs. Removal}

- Different problems

- One estimate: remove five large pieces per year for 100 years $\rightarrow$ orbital access and LEO stabilized

- But current int'l law makes this difficult

- 1967 OST, Article VII: nation-states retain jurisdiction over space objects

- Space agencies can't remove other countries' stuff w/o their consent

- Debris may be valuable: useful materials already in orbit

- Also: is it really debris? Nat'I security considerations

- 1972 Liability Convention: gov't "absolutely liable" for damage to Earth objects; at-fault liable for damage to space objects

- Removal missions 'gone bad' could be quite costly

\section{Public vs. Private Responses to Removal}

- Public: clarify 'rules of the game'

- Ex: declare 'law of salvage' applies to debris

- Costs and benefits? Incentive problems?

- Public-private: contracts for removal of debris

- Auction off rights

- Beware rent seeking! Auction design

- More meaningful solutions require int'l cooperation, clarifying/amending public int'I space law 


\section{Conclusion}

- Nature of problem such that 'bottom-up' solutions infeasible; some amount of 'top-down' required

- Mitigation is important, but removal needed too

- Not public or private; public and private

\section{Law, Economics, and Space Policy}

"Space Debris: A Law and Economics Analysis of the Orbital Commons." Stanford Technology Law Review 19(2) 2016: 221-238

"Celestial Anarchy: A Threat to Outer Space Commerce?" Cato Journal 34(3) 2014: 581-596 [with P. Leeson]

"Ordering the Cosmos: Private Law and Celestial Property Rights." Journal of Air Law and Commerce 82(2) 2017: 311-332

"The Other Space Race: Some Law and Economics of Celestial Resource Appropriation." Georgia Journal of International and Comparative Law 47(1) 2018: $1-20$

"Settling the Final Frontier: The ORBIS Lease and the Possibilities of Proprietary Communities in Space." Journal of Air Law and Commerce, forthcoming 


\section{ANSI's Role in Standards Coordination to}

\section{Support Emerging Technologies and}

\section{National Priorities}

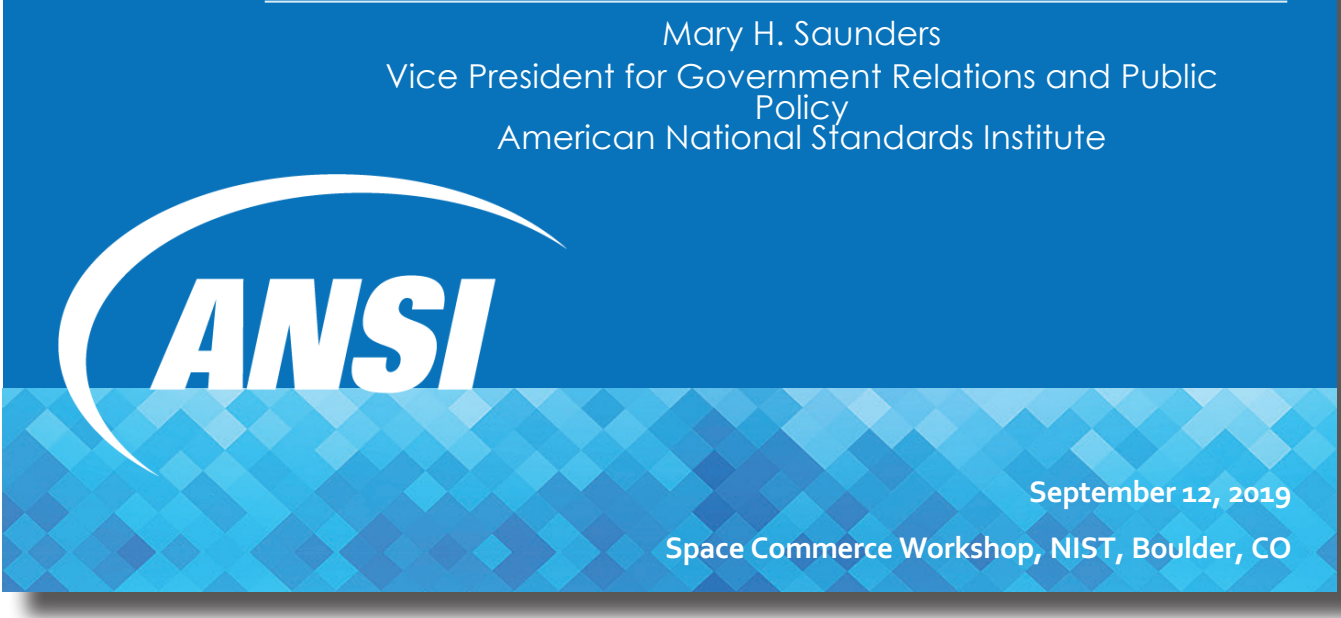

Today, more than ever, standards are an imperative undertaking.

Standards are the building blocks for innovation and competitiveness.

Our nation's ability to compete and lead in a rapidly changing global economy is closely related to our leadership in the development and effective use of standards and standardization processes.

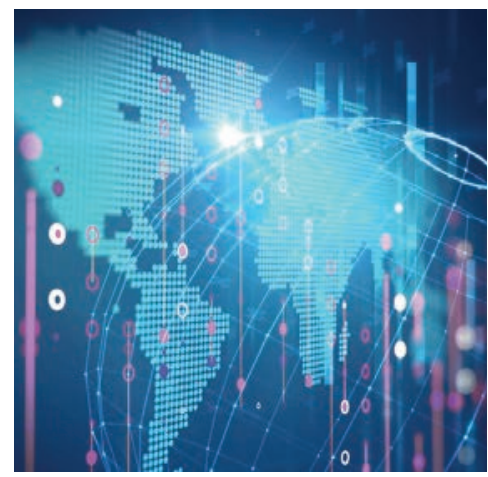

Standards provide the common language that keeps domestic and international trade flowing. It is difficult to overestimate their critical value to both the U.S. and global economy.

Source: Patrick Gallagher, Former Director of the National Institute of Standards and Technology, United States Standards Strategy, December 2, 2010

\section{ANSI}




\section{U.S. Standardization System comparison with many other economies}

- Emphasizes private-sector standards solutions

$\checkmark$ Relies on private-sector compliance verification (conformity assessment) for both regulatory and non-regulatory functions

- Provides a strong voice and greater authority to standards users and individual stakeholders

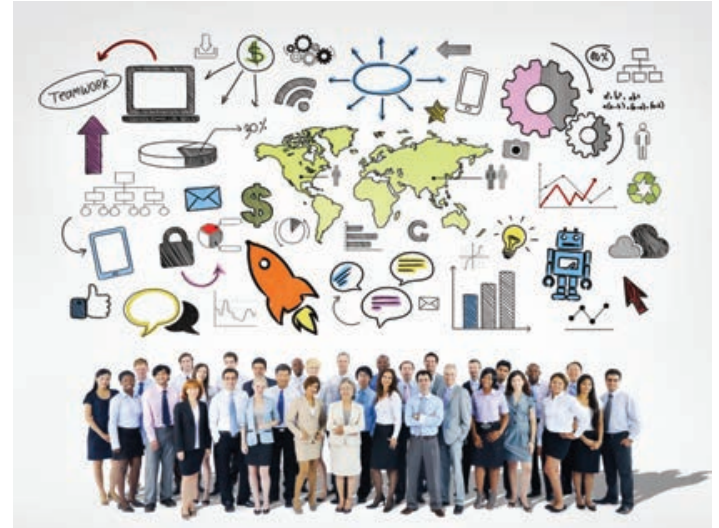

\section{ANSI}

\section{U.S. Standardization System}

\section{guiding principles}

- Standards should meet societal and market needs and should not be developed to act as barriers to trade

- The U.S. endorses the globally accepted standardization principles of the World Trade Organization Technical Barriers to Trade Agreement

- Transparency

- Openness

- Impartiality

- Effectiveness and relevance

- Consensus

- Performance-based
- Coherence

- Due process

- Technical Assistance

- Flexible

- Timely

- Balanced
WORLD TRADE ORGANIZATION

\section{ANSI}




\section{U.S. Standards System different tools for globally relevant standards}

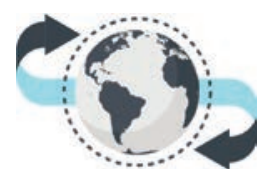

\begin{tabular}{l|l|l}
$\begin{array}{l}\text { National Participation } \\
\text { (one country one vote) }\end{array}$ & Direct Participation & Consortia \\
\hline $\begin{array}{l}\text { Treaty Organizations } \\
\text { Non-Treaty } \\
\begin{array}{l}\text { Organizations } \\
\text { Examples }\end{array}\end{array}$ & $\begin{array}{l}\text { Nationally Accepted } \\
\text { Accepted }\end{array}$ & \\
\hline ISO, IEC, ITU, CODEX, etc. & $\begin{array}{l}\text { Examples } \\
\text { ASTM International, } \\
\text { SAE, IEEE, etc. }\end{array}$ & $\begin{array}{l}\text { W. Wamples } \\
\text { Consortium, etc. }\end{array}$
\end{tabular}

\section{ANSI}

ANSI's Role in Standards Coordination $\quad$ Oे 2019 Slide 5

\section{U.S. Standardization System}

The public-private partnership

Agencies engage in standardization in a wide range of missionspecific roles

- Decisions about which standards are most appropriate for specific needs are left to the discretion of individual agencies

- National Technology Transfer and Advancement Act (NTTAA) Public Law 104-113

- Federal agencies are encouraged to seek existing private-sector standards that are appropriate for their purposes and missions

- Federal agencies are responsible for evaluating the efficacy of their conformity assessment activities. Each agency must coordinate its activities with those of other appropriate agencies and the private sector.

\section{ANSI}

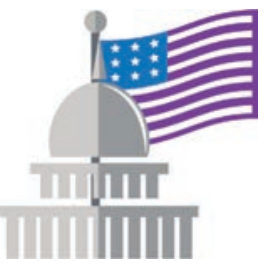




\section{American National Standards Institute (ANSI)}

- Founded in 1918, ANSI is a private non-profit membership organization whose mission is to enhance U.S. global competitiveness and the American quality of life by promoting, facilitating, and safeguarding the integrity of the U.S. voluntary standardization system

- ANSI represents and serves the diverse interests of more than 270,000 companies and organizations and 30 million professionals worldwide

- businesses, professional societies and trade associations, SDOs, government agencies, consumer and labor organizations

- Official U.S. representative to the International Organization for Standardization (ISO) and, via the U.S. National Committee, the International Electrotechnical Commission (IEC)

\section{ANSI}

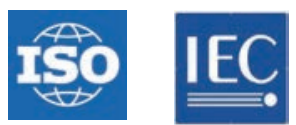

\section{ANSI's Roles}

- Represents U.S. globally

- Accredits standards developing organizations (SDOs) and approves American National Standards

- Accredits / approves technical advisory groups (mirror committees) for ISO / IEC technical work

- Accredits conformity assessment bodies
- Provides education and training services

- Offers neutral forum for discussing standards needs and priorities

- Serves as a bridge between U.S. public \& private sectors

- Ensures integrity of the standards and conformity assessment system

ANSI doesn't develop standards

\section{ANSI}




\section{ANSI Coordination and Harmonization Activities}

- ANSI Standards Panels, Collaboratives, and Workshops are cross-sector coordinating activities established to promote the development and compatibility of voluntary consensus standards and conformity assessment programs necessary to support emerging technologies and national/global priorities

- Coordinate the efforts of the private and public sectors

- Identify existing standards, standards in development, and compliance programs

- Define where gaps exist based on stakeholder needs

- Recommend additional work needed, timelines for its completion, and organizations that can perform the work

- Helps to inform resource allocation for standards participation, avoid duplication of effort, and drive coordinated standards activity

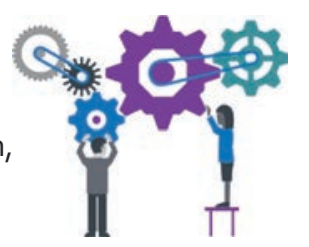

\section{ANSI}

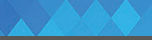

ANSI's Role in Standards Coordination

(c) 2019 Slide?

\section{ANSI Standardization Collaboratives}

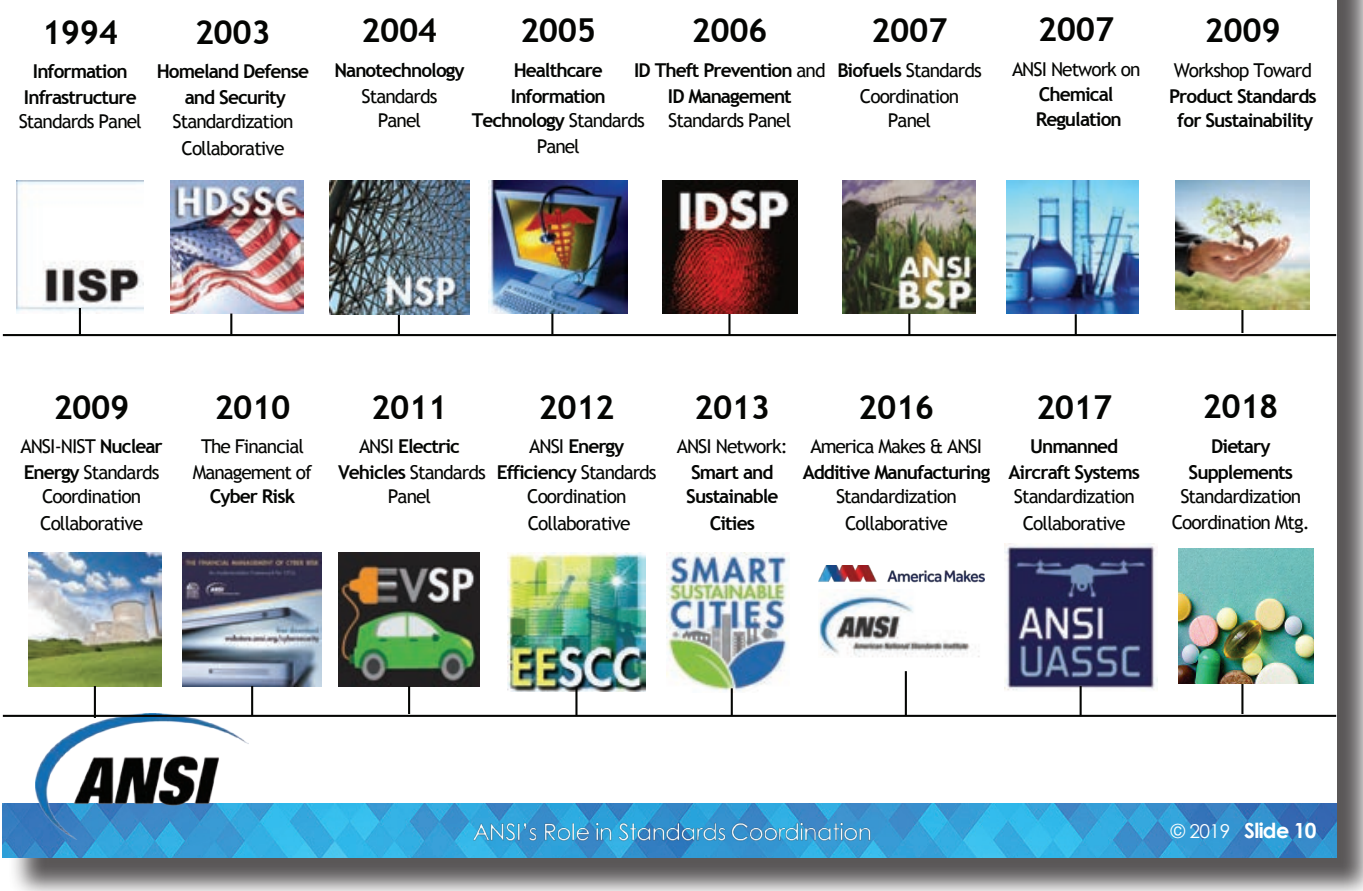




\section{America Makes \& ANSI Additive Manufacturing Standardization Collaborative (AMSC)}

- Launched in March 2016 to coordinate and accelerate the development of industry-wide additive manufacturing ( $\mathrm{AM}$ a/k/a $3 \mathrm{D}$ Printing) standards and specifications to help facilitate the growth of the AM industry

- National Institute of Standards and Technology (NIST), U.S. Department of Defense (DoD), Federal Aviation Administration (FAA) and several SDOs were instrumental in its formation

- Before AMSC there was no process for identifying priorities and interdependencies in the development of standards and specifications for additive manufacturing

- A number of SDOs are engaged in standards-setting for various aspects of $A M$, prompting the need for coordination to maintain a consistent, harmonized, and non-contradictory set of AM standards and specifications

\section{ANSI}

\section{A. AmericaMakes}

\section{AMSC Deliverable}

- Standardization Roadmap for Additive Manufacturing, Version 2.0 (June 2018)

- Identifies existing standards and specifications, as well as those in development, assesses gaps, and makes recommendations for priority areas where there is a perceived need for additional standardization

- Standards Landscape

- A list of standards that are directly or peripherally related to the issues described in the roadmap

- Available as free downloads at www.ansi.org/amsc

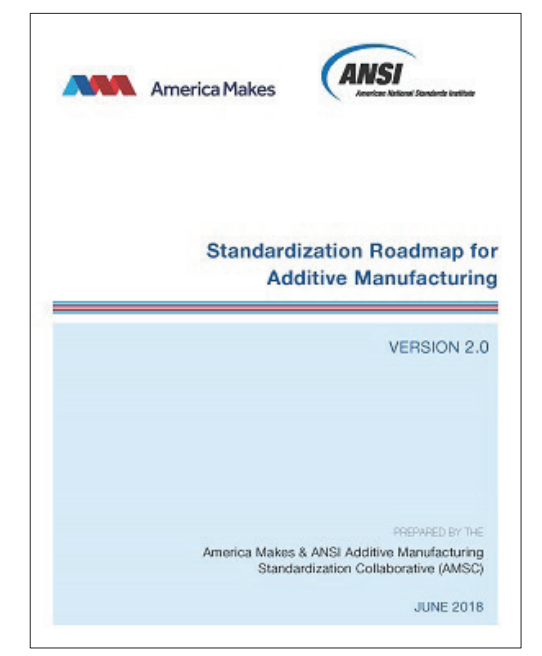

\section{ANSI}




\section{ANSI Unmanned Aircraft Systems Standardization Collaborative (UASSC)}

Launched in September 2017 to coordinate and accelerate the development of the standards and conformity assessment programs needed to facilitate the safe integration of unmanned aircraft systems (UAS a/k/a drones) into the national airspace system of the United States, with international coordination and adaptability

- Federal Aviation Administration (FAA), Association for Unmanned Vehicle Systems International (AUVSI), and many other public- and private-sector stakeholders participated in a May 2017 exploratory meeting which indicated broad-based support to establish UASSC

- Focus is to support the growth of the UAS market with emphasis on civil, commercial, and public safety applications

\section{AN'SI}

\section{UASSC Deliverable}

A comprehensive roadmap v1.o published in December 2018 describing the current and desired standardization landscape for UAS

- 6o gaps (no published standard) identified w/accompanying recommendations

- Available as a free download at www.ansi.org/uassc

- Roadmap version 2.0 kick-off meeting taking place 9/12/2019

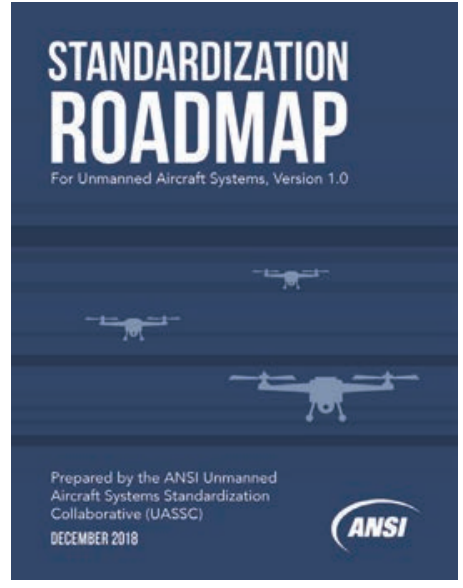

\section{ANSI}




\section{Participation}

- More than 300 individuals from 175 public- and private-sector organizations involved in AMSC and UASSC

- Participation is open to stakeholders that have operations in the U.S.

- Membership in ANSI is not a prerequisite

$\checkmark$ Members include:

- Original Equipment Manufacturers (OEMs)

- User Stakeholders - Industry and Government

- R\&D Community - Academia and Government

- SDOs

\section{ANSI}

\section{ANSI Collaboratives - Ingredients for Success}

- Demonstrated need for coordination

- Broad stakeholder support

$\checkmark$ Clearly defined objectives, timelines and deliverables

- Committed leadership and participants

- Stable funding mechanism

\section{ANSI}




\section{Consider ANSI a Resource}

We're happy to offer similar coordination in relation to space commerce standardization!

Thank You

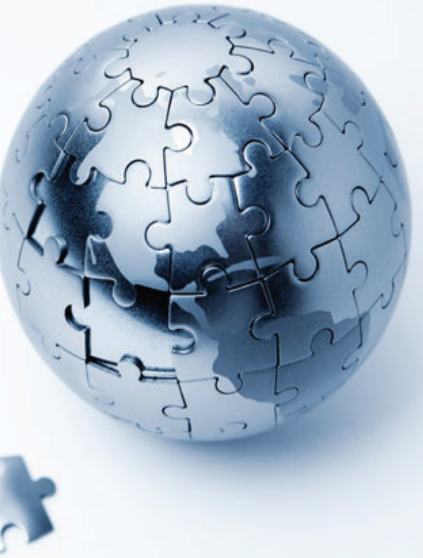

\section{ANSI}

For More Information

Mary H. Saunders

Vice President for Government Relations and Public Policy

202-331-3610

msaunders@ansi.org

Jim McCabe

Senior Director, Standards

Facilitation

212-642-8921

jmccabe@ansi.org
American National Standards Institute

Headquarters

1899 L Street, NW

11 th Floor

Washington, DC 20036

T: 202.293 .8020

F: 202.293 .9287
New York Office

25 West 43rd Street

4th Floor

New York, NY 10036

T: 212.642 .4900

F: 212.398 .0023

\section{www.ansi.org}

webstore.ansi.org 


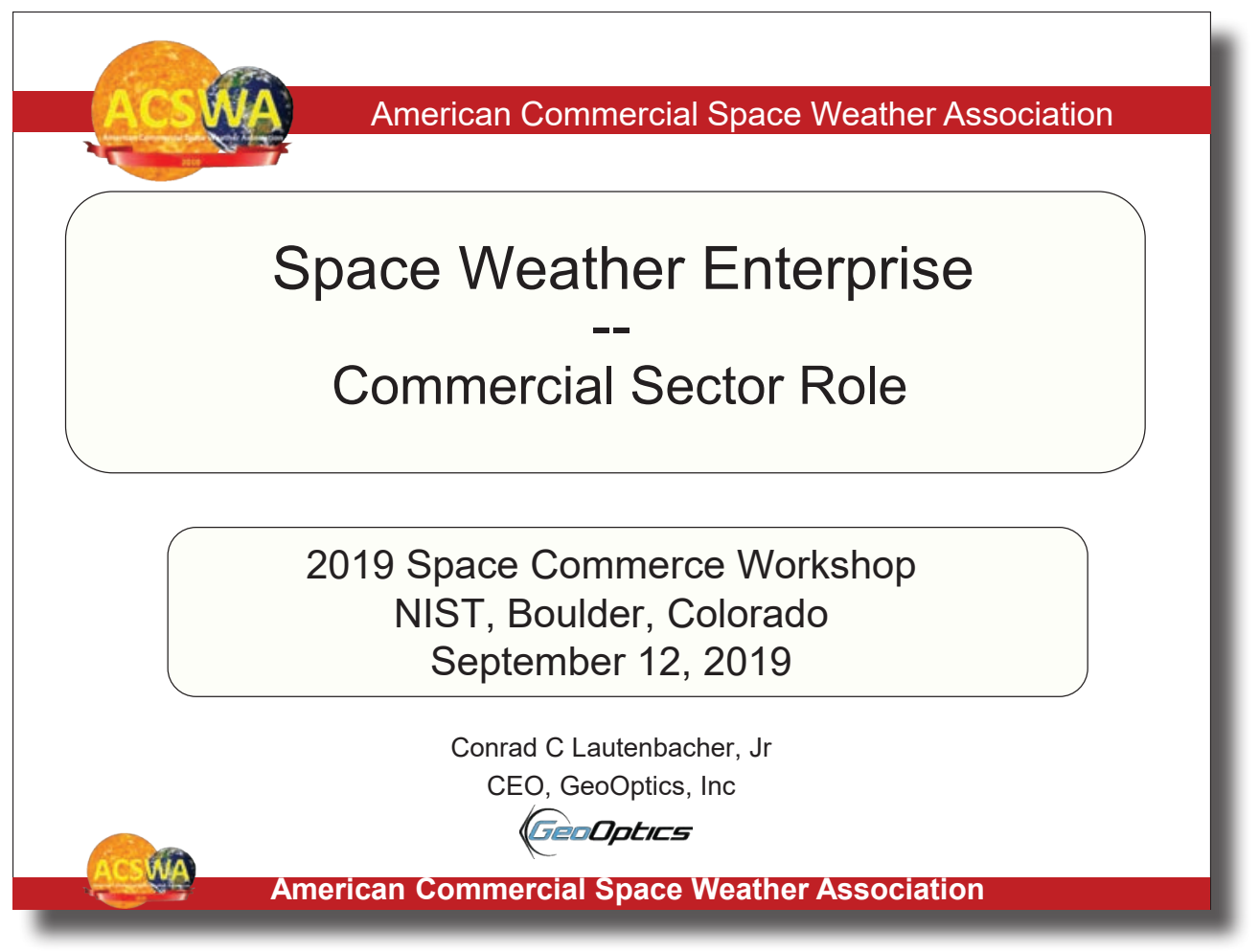

\section{The Space Weather Enterprise}

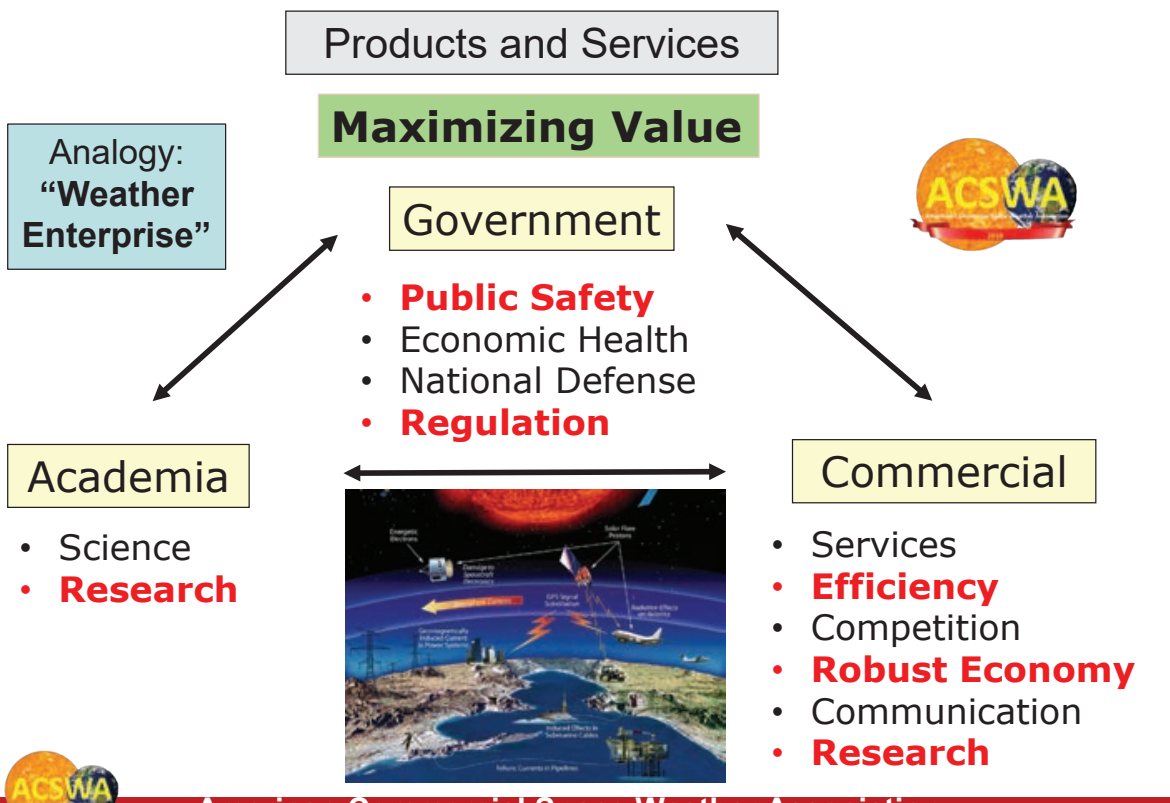

American commercial space Weather Association 

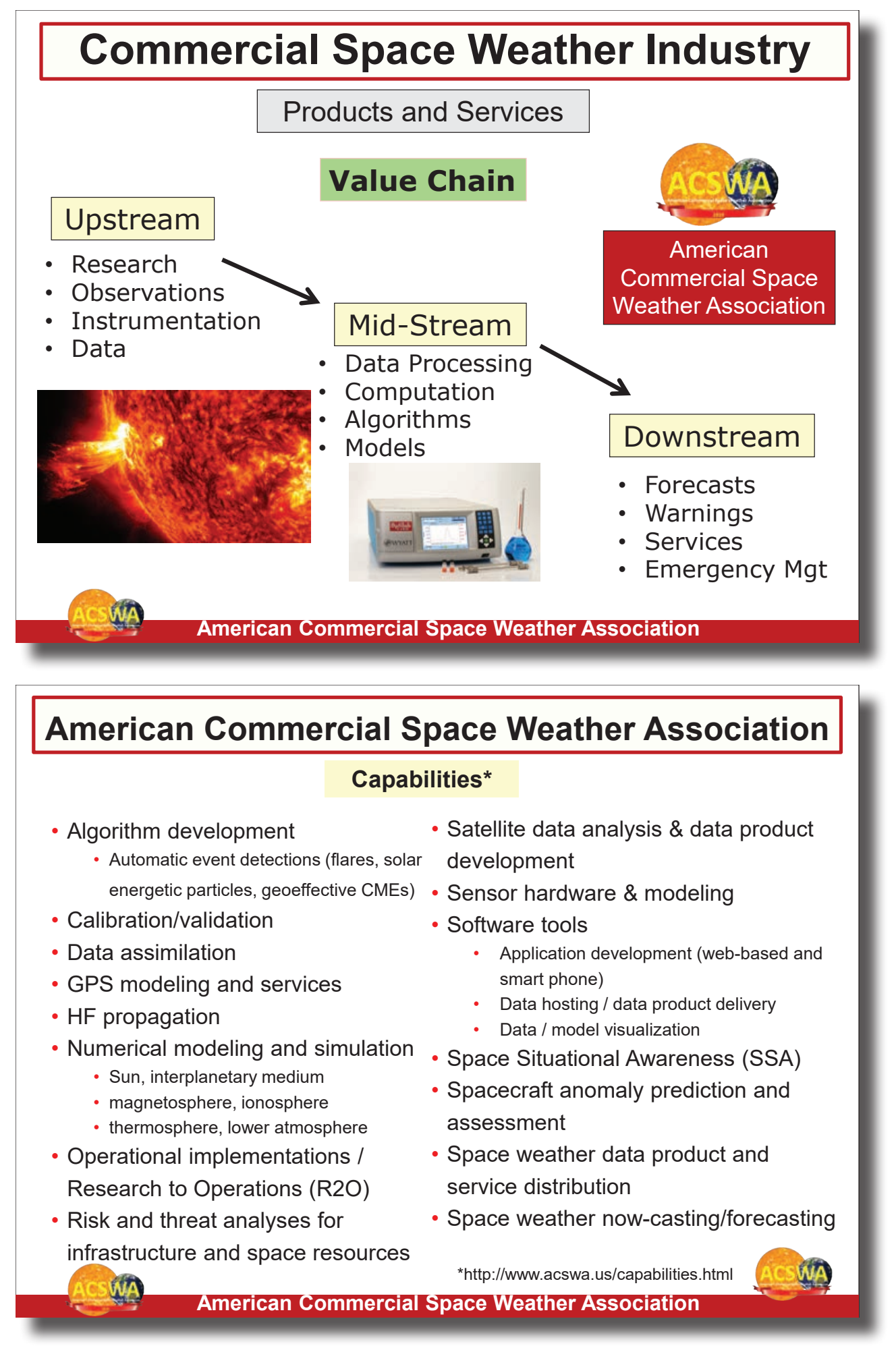


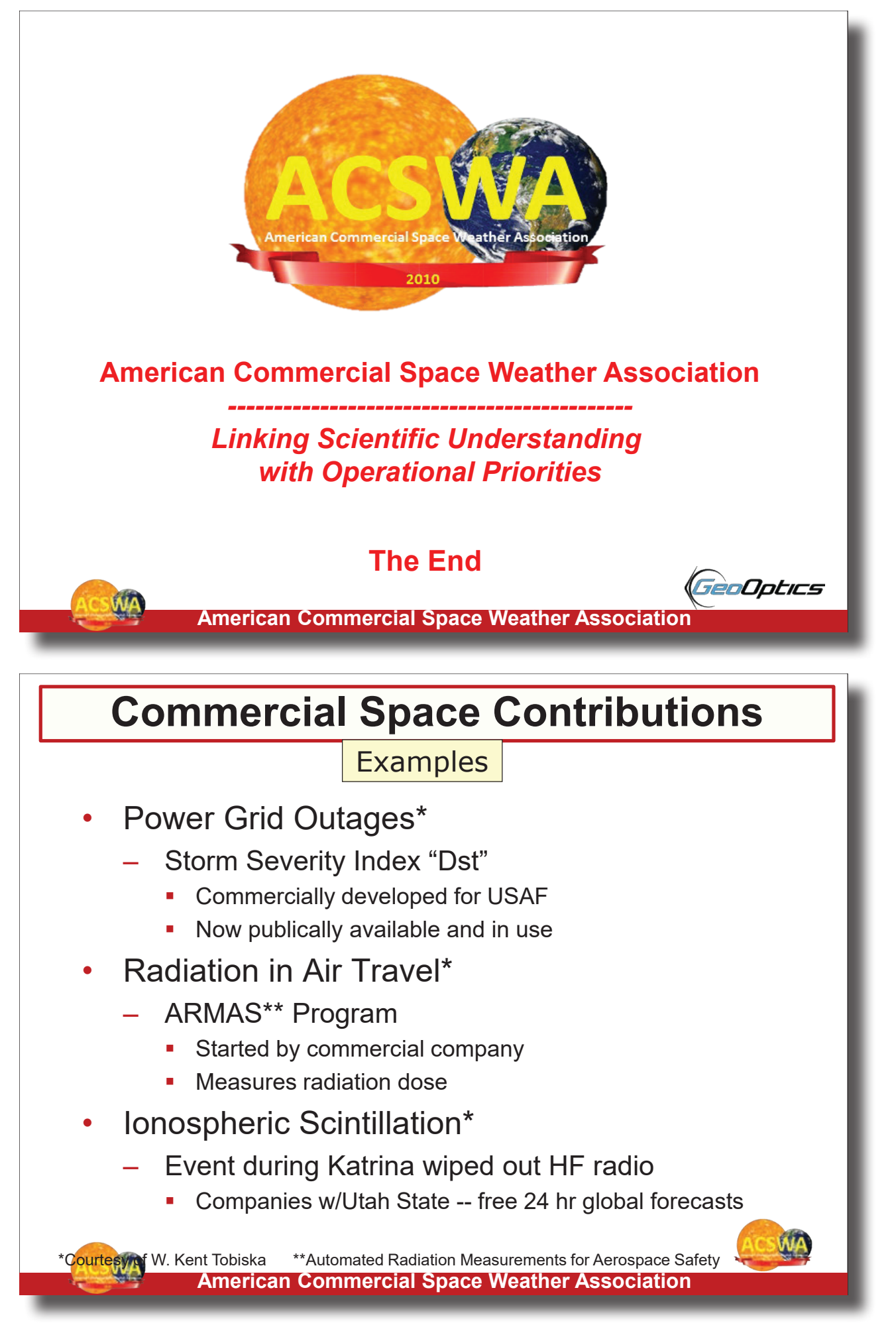




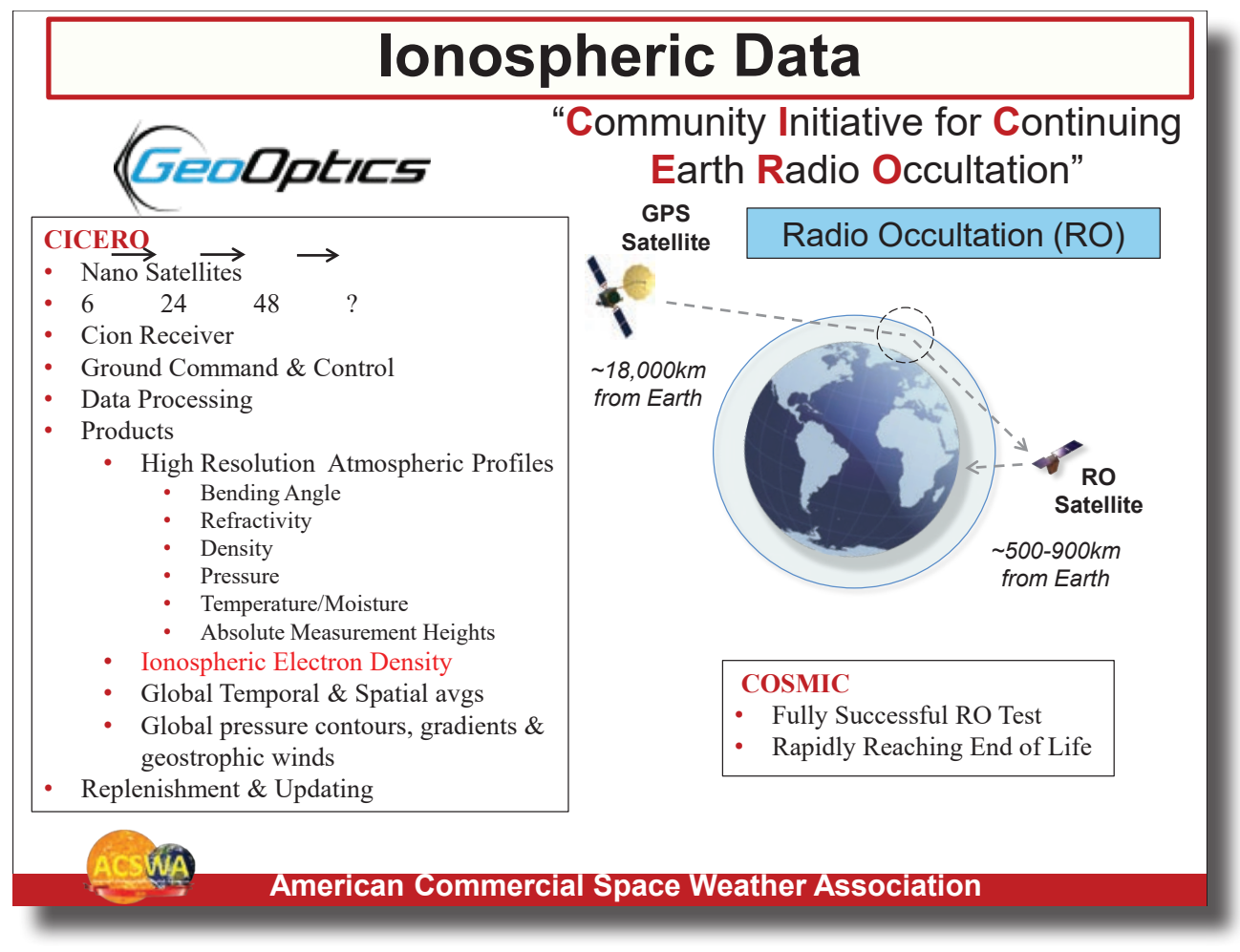

\section{Technology Transfer and Innovation for Space Commerce}

Walter G. Copan, Ph.D.

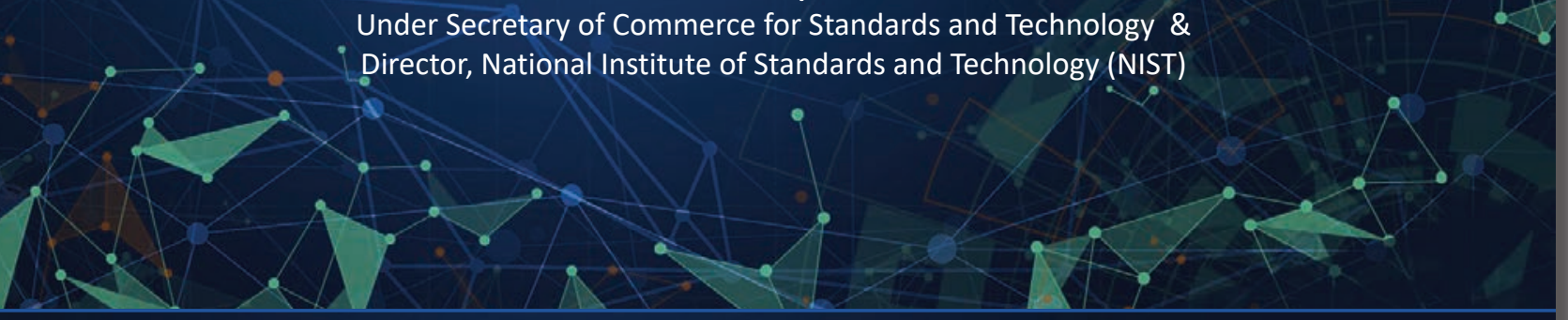

Space Commerce Workshop Boulder, CO

September 12, 2019 


\section{Technology Convergence: Accelerating Innovation NGT}

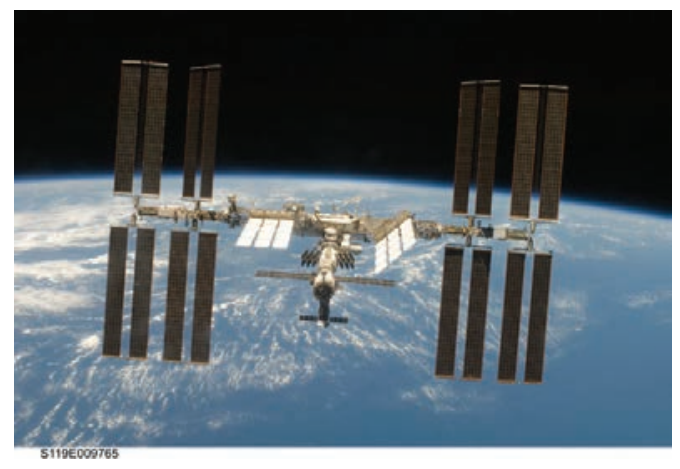

Invention and Innovation

Humans + Computation + Data + Machines + Sensing + Networks + Al / ML + Supply Chains + ...
- Advanced Communications

- Smart Manufacturing

- IoT $\rightarrow$ loEverything

- Autonomous Vehicles / Transport

- Quantum

- Materials Genome

- Biosciences

- Measurement Dissemination

- Smart Homes

- Personalized \& Remote Medicine

- Modern Agriculture

- Space Commerce

\section{Metrology, Standards \& Technology}

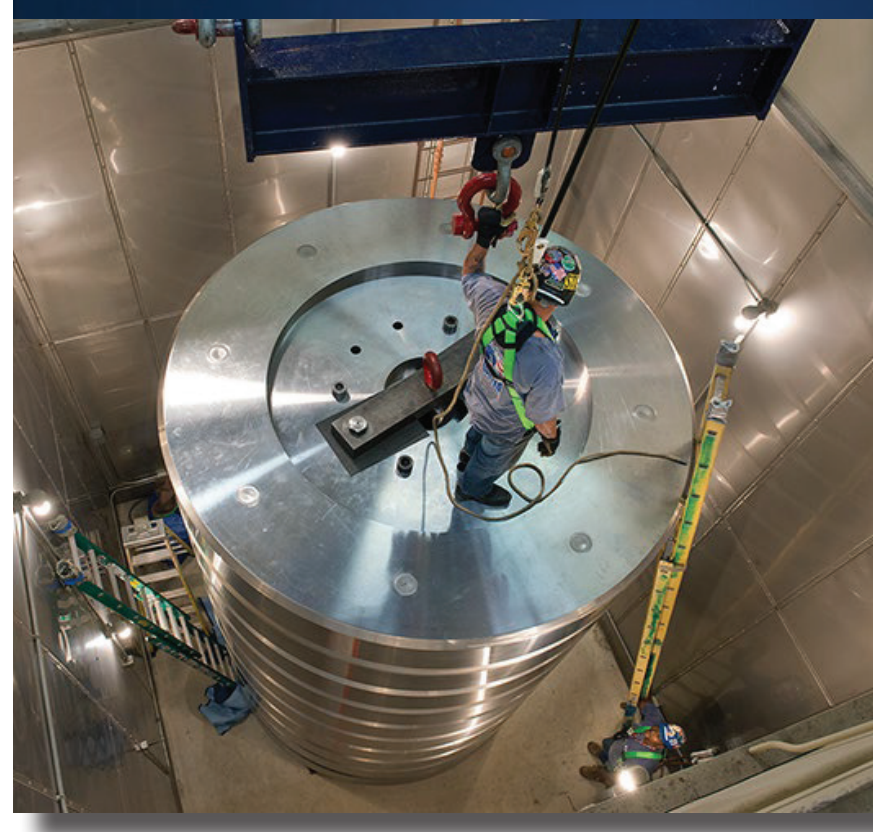

\section{Metrology}

- "To measure is to know"

- Calibrated equipment is essential

- Deliver traceability to the International System of Units (SI)

\section{Standards Matter}

- Standards: innovation enabler

- NIST coordinates U.S. government engagement in standards

- Approach led by U.S. private sector 


\section{NIST in Space - A Long History}

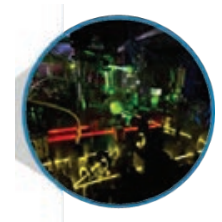

NIST / Atomic Clock Technologies

Economic Impact: \$1.4 Trillion (10 sectors)

- GPS Navigation

- Telecommunications

Accuracy: 1 Second in 33 Billion Years

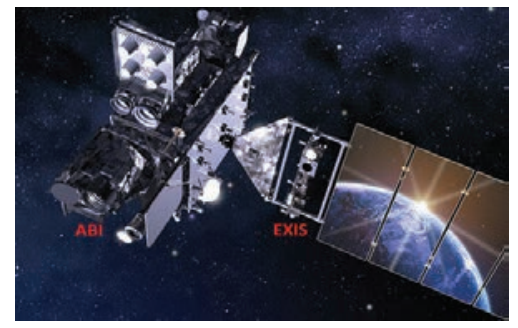

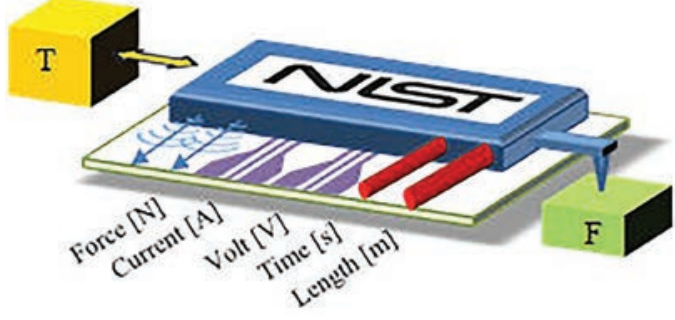

NIST on a Chip - Quantum Devices, Intrinsic Calibration
Satellite Instruments \& Calibrations (GOES-R)

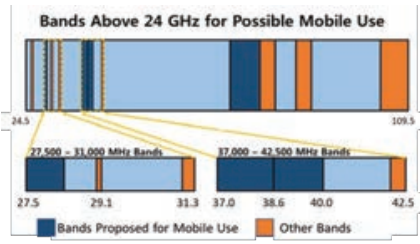

Spectrum Metrology and Standards

\section{John F. Kennedy - September 12, 1962}

NGT

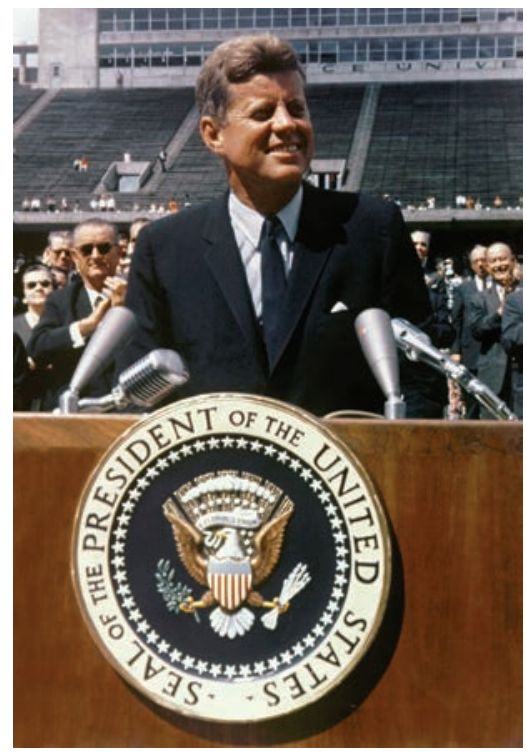

We set sail on this new sea because there is new knowledge to be gained, and new rights to be won, and they must be won and used for the progress of all people. For space science, like nuclear science and all technology, has no conscience of its own. Whether it will become a force for good or ill depends on man, and only if the United States occupies a position of pre-eminence can we help decide whether this new ocean will be a sea of peace or a new terrifying theater of war.

John F. Kennedy, Speech at Rice University 


\section{Public Sector Research}

Public-private partnerships advance the innovation pipeline

U.S. industry, government and academia collaboration

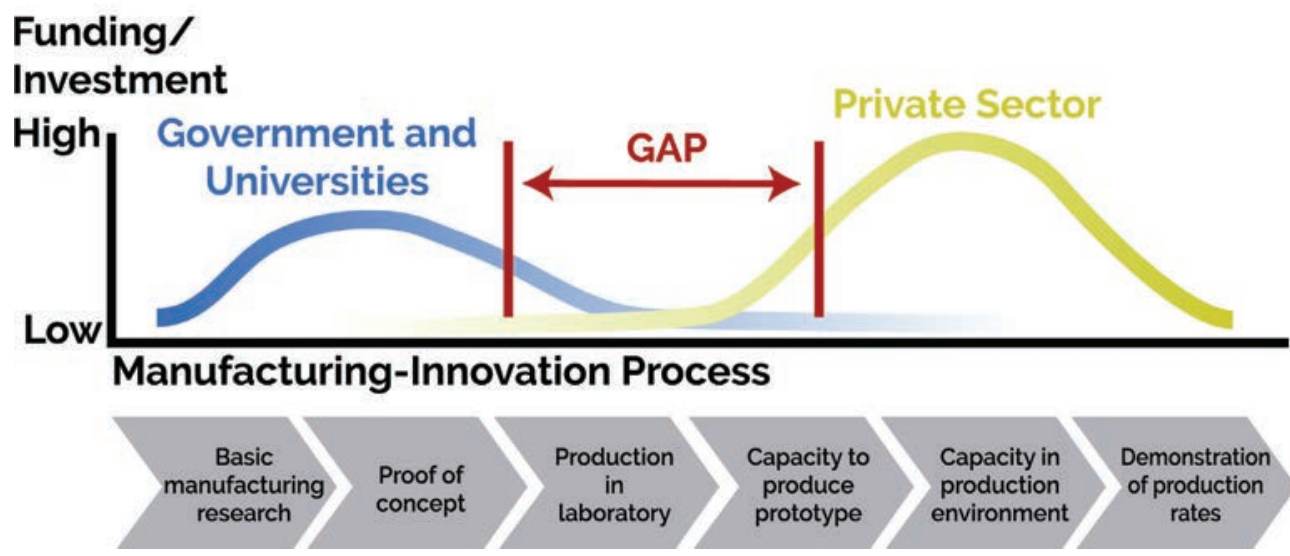

Manufacturing Readiness Levels (1-10)

\section{Future of Technology Transfer}

We've come a long way since $1980 . .$.

Federal government, universities, Federal labs, research organizations, entrepreneurss, investors remain at the heart of innovation ecosystems

Technology transfer - processes by which knowledge, facilities and capabilities developed under Federal research and development (R\&D)

funding are used to fulfill public and private need

Enable evolving paradigms and models of U.S. innovation and Lab-to-Market system 


\section{ROI Initiative Vision and Goal}

\section{NGT}

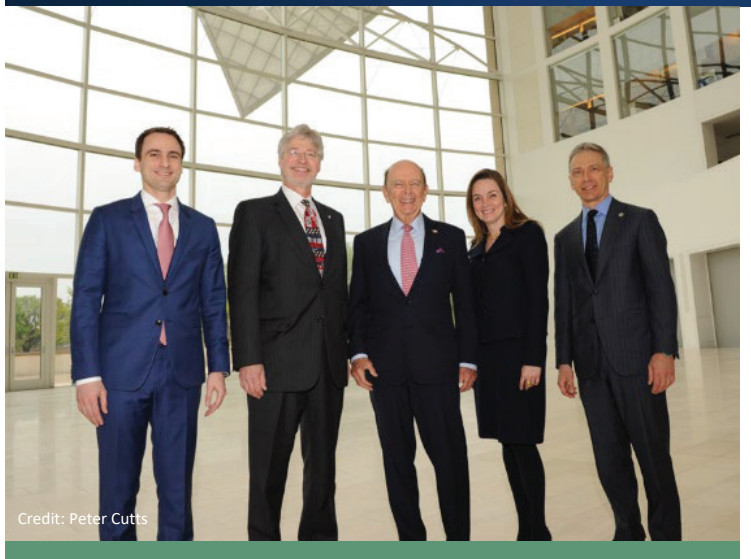

(L to R): Michael Kratsios (WH/OSTP), Walter Copan (U/S NIST), Wilbur Ross (Commerce Secretary), Margaret Weichert (Deputy Director OMB), and Andrei lancu (U/S USPTO)

\section{VISION: Unleash the innovation power of America into our economy}

GOAL: Maximize the transfer of federal investments in science and technology into value for America

Meet current and future economic and national security needs in a rapidly shifting technology marketplace and enhance U.S. competitiveness globally

Attract greater private sector investment to create innovative products, processes, services, as well as new businesses and industries

\section{Lab-to-Market CAP Goal Strategies}

Identify regulatory impediments and administrative improvements in Federal technology transfer policies and practices

Illi

Increase engagement with private sector technology development experts and investors

Build a more entrepreneurial R\&D workforce

Support innovative tools and services for technology transfer

Improve understanding of global science and technology trends and benchmarks. 


\section{ROI Final Green Paper}

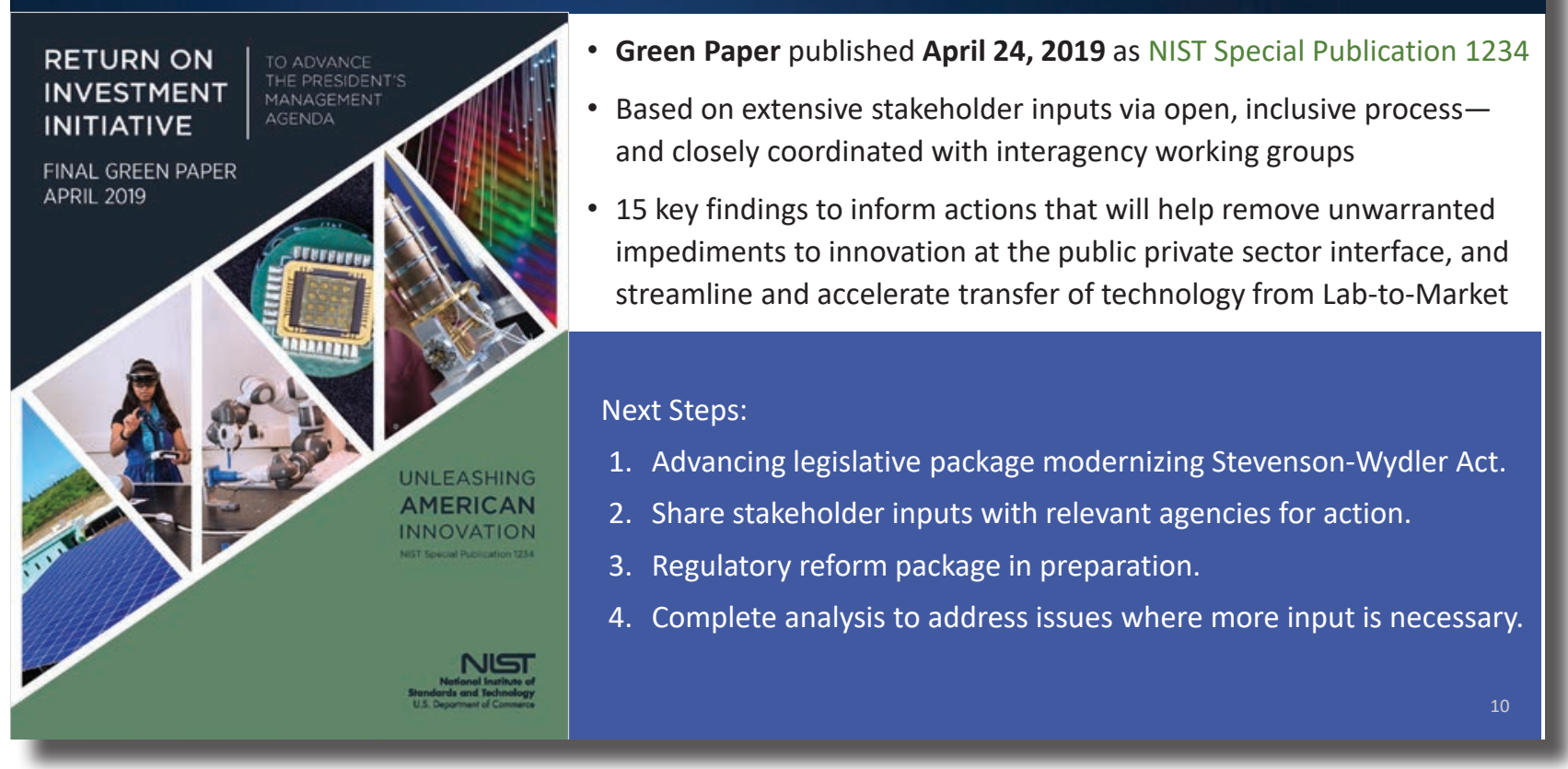

\footnotetext{
NUكT
}

\section{Thank you!}

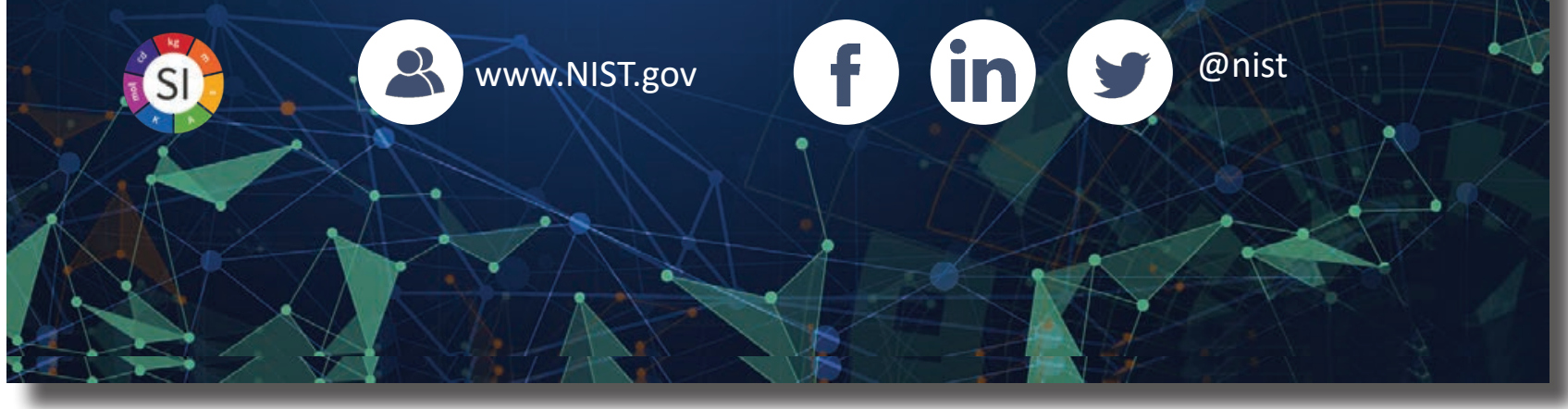




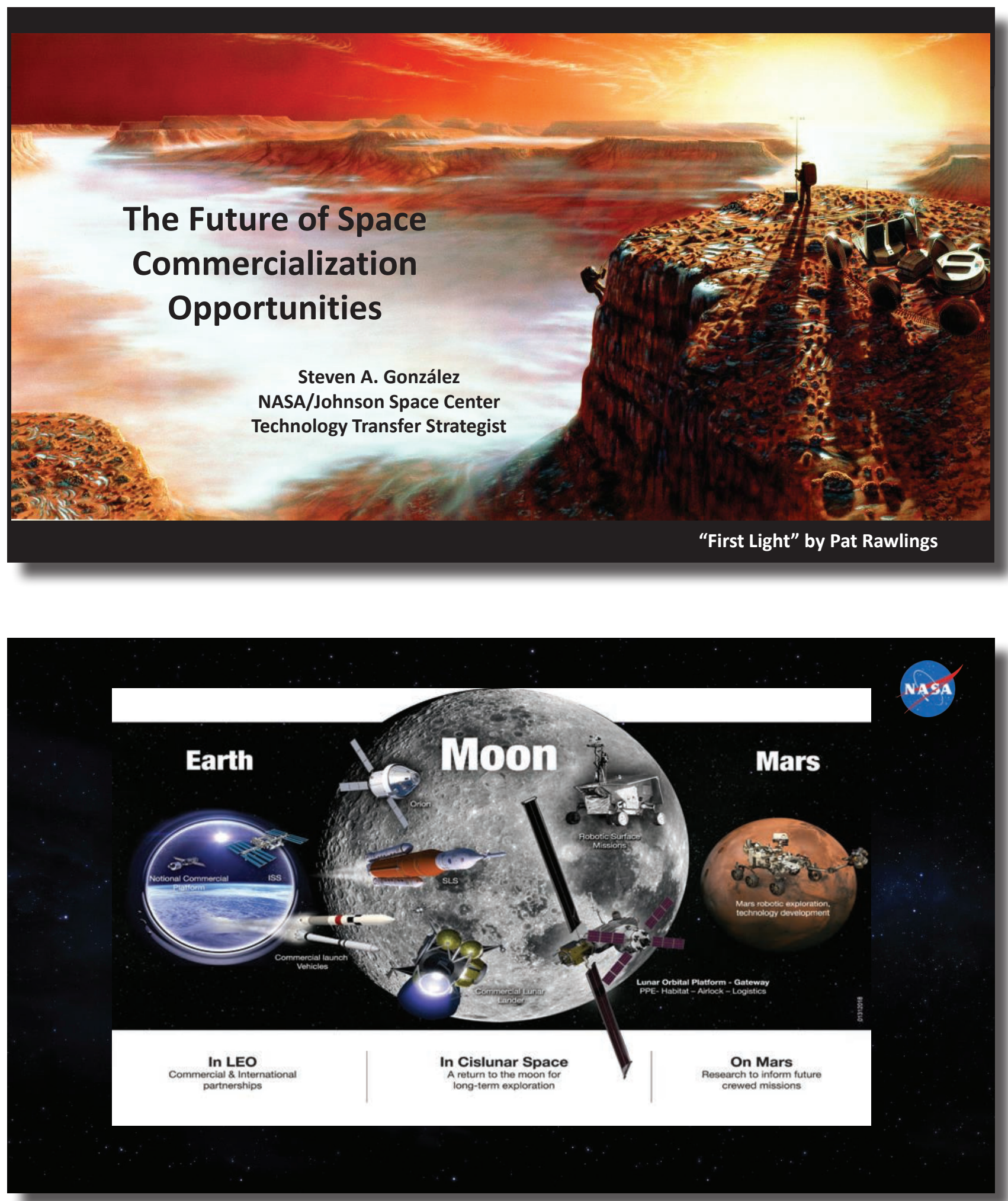




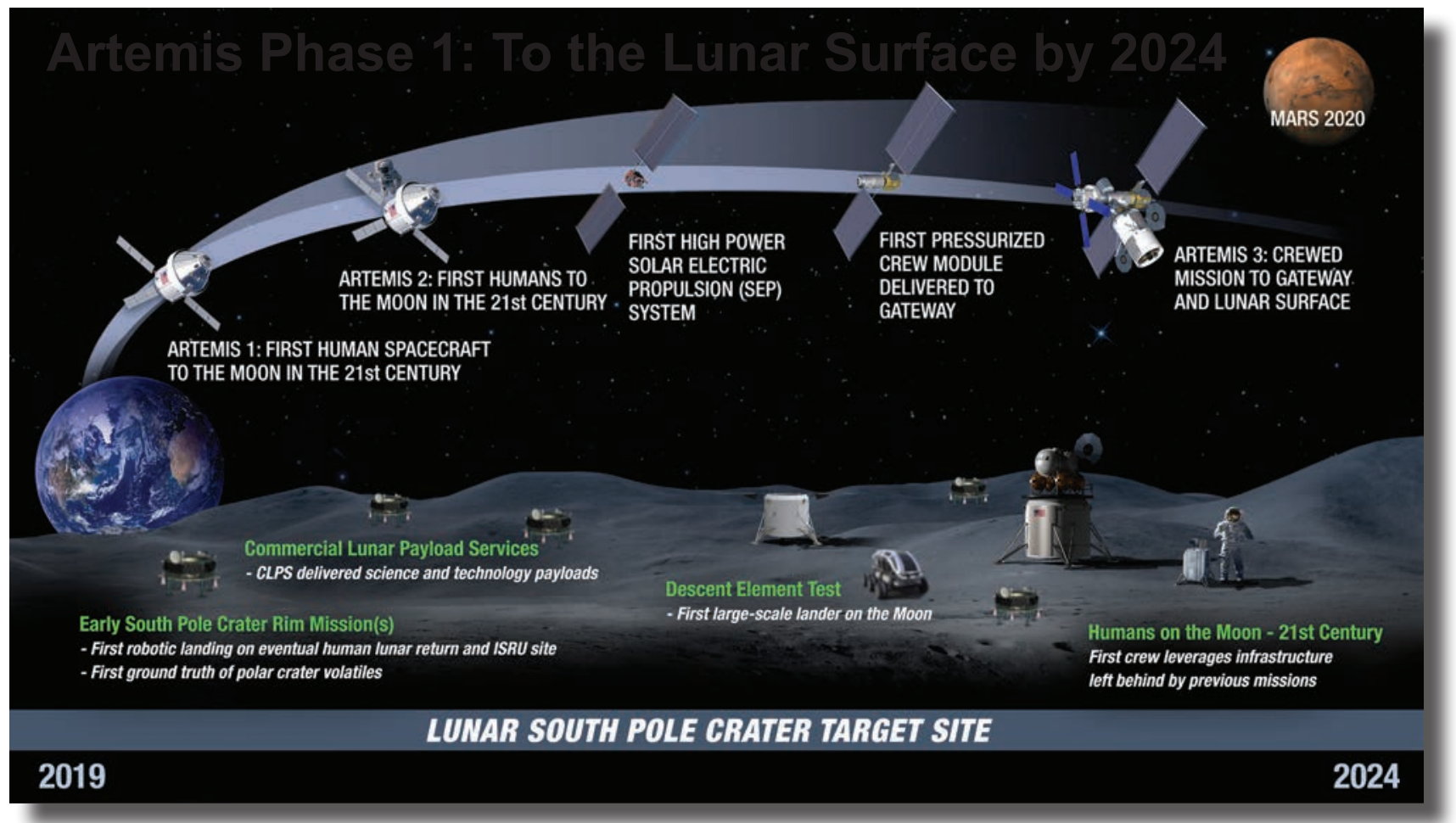

\section{NASA's Commercial Lunar Payload Services (CLPS)}
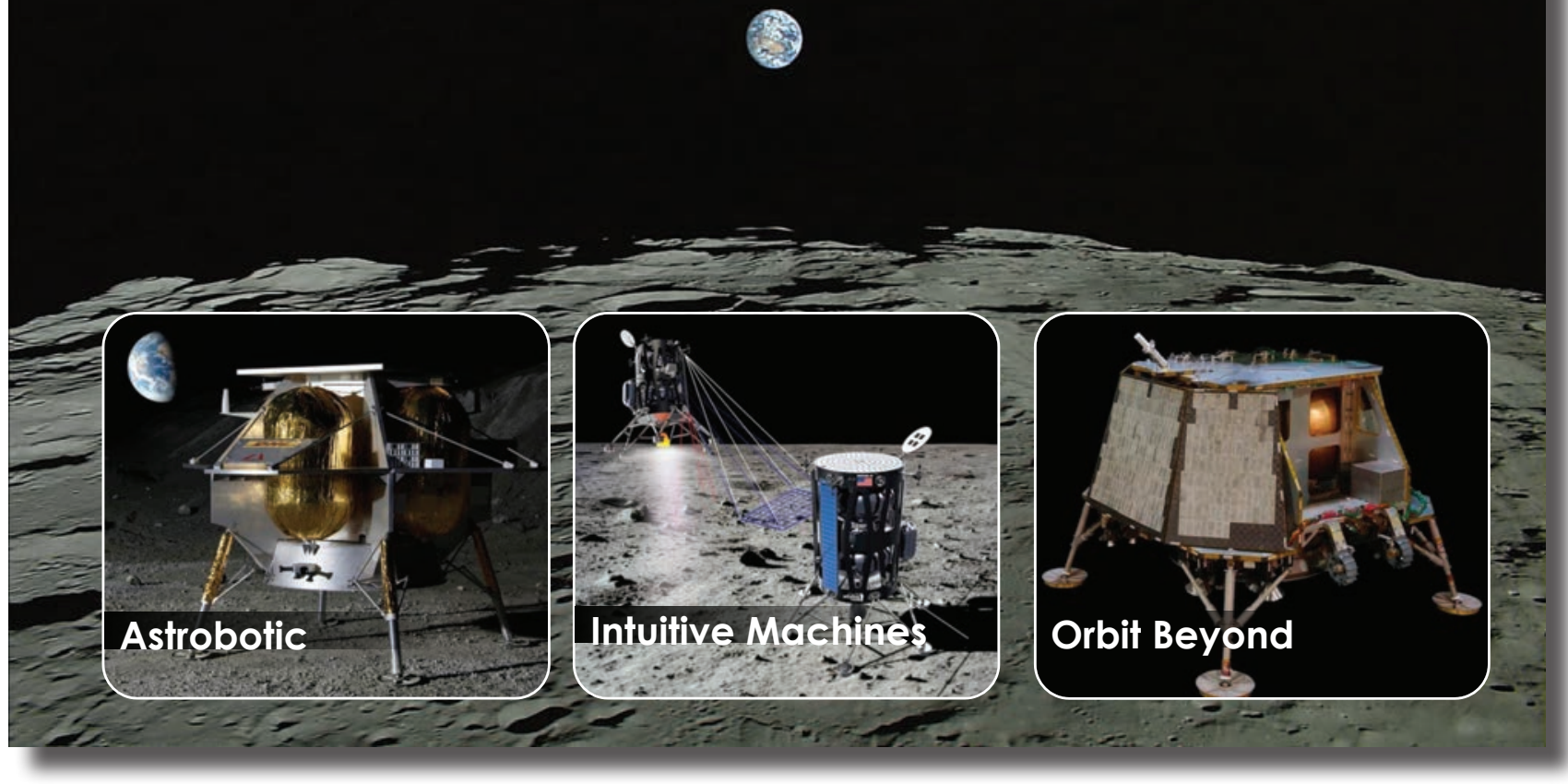

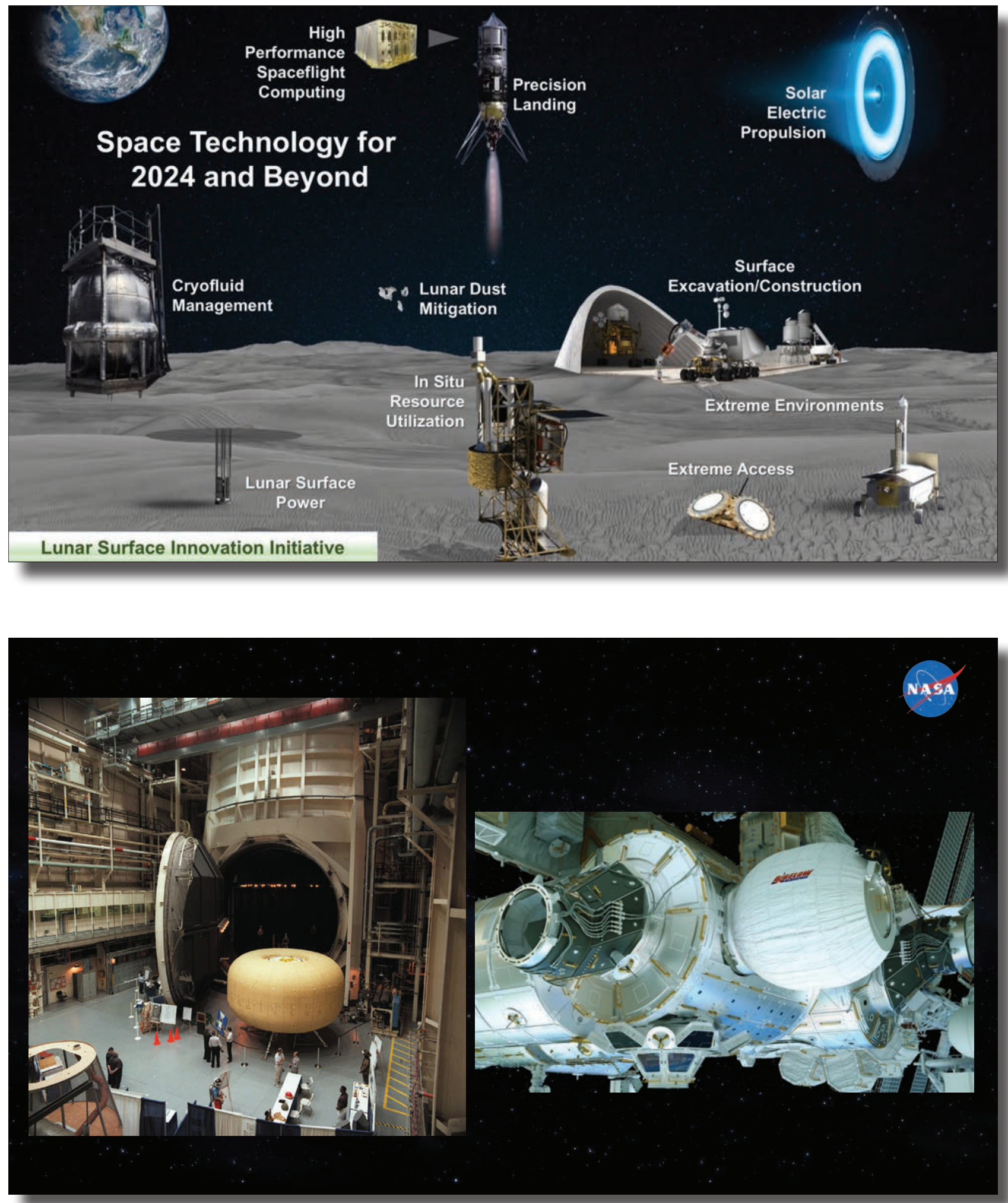


\section{NASA's Patent Portfolio}

"Untapped potential to seed more space commerce startups"

400 NASA has 1405 Active Patents \& Apps
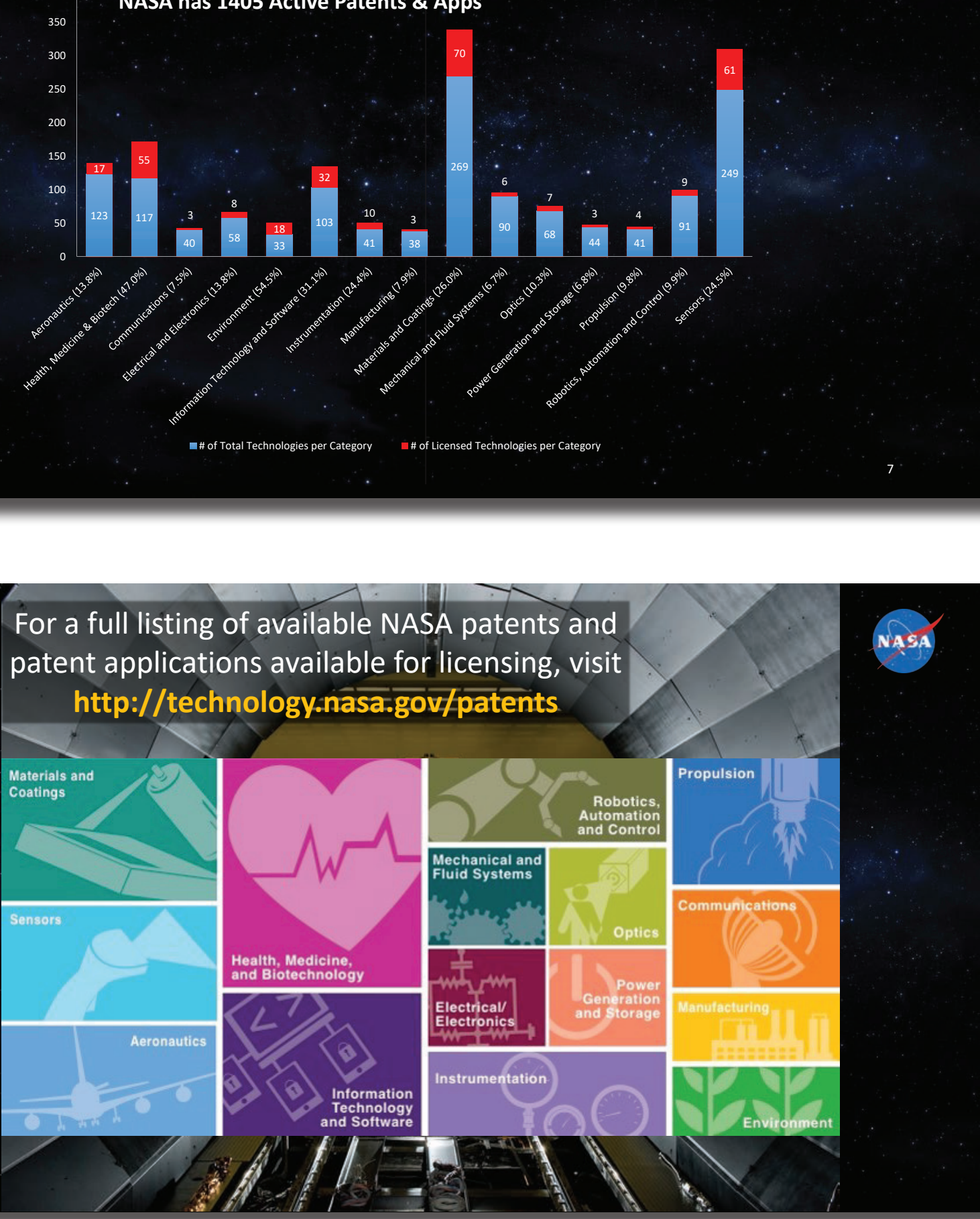


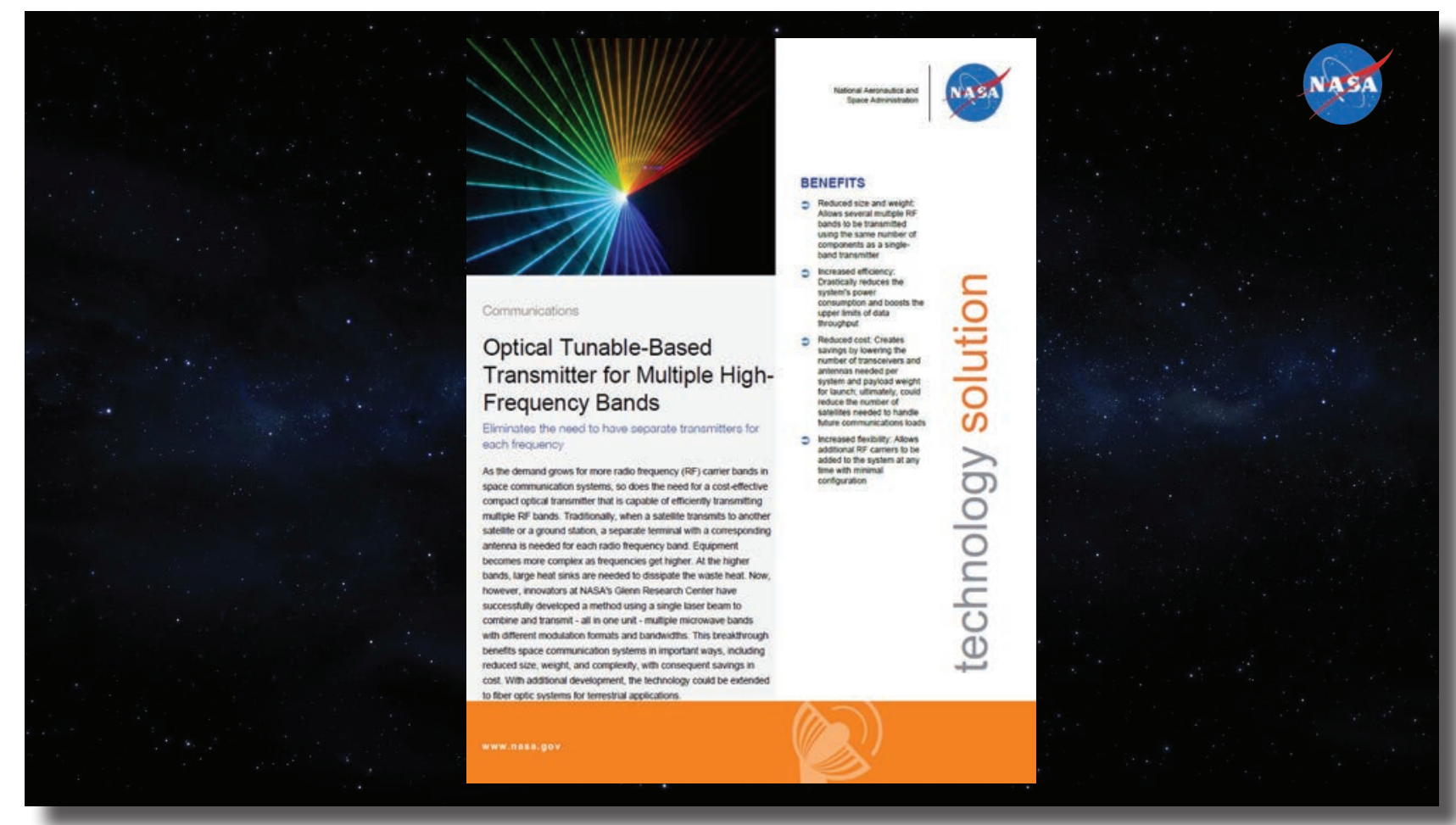

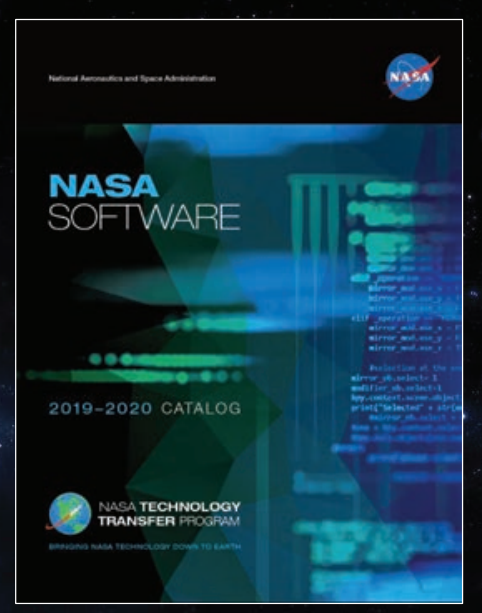

For free access to over 1,000 NASA software programs, visit http://software.nasa.gov
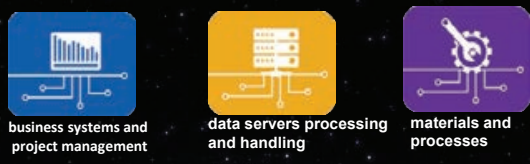

NAS9A and handling
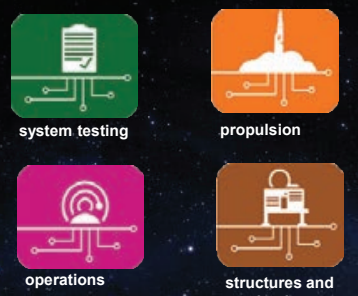
processes

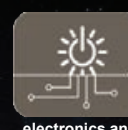

electronics and
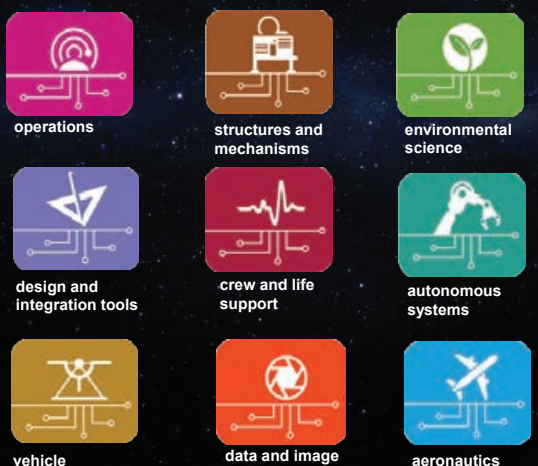

vehicle vehicle

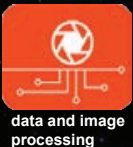
processing
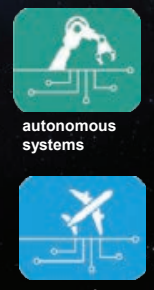

aeronautic 


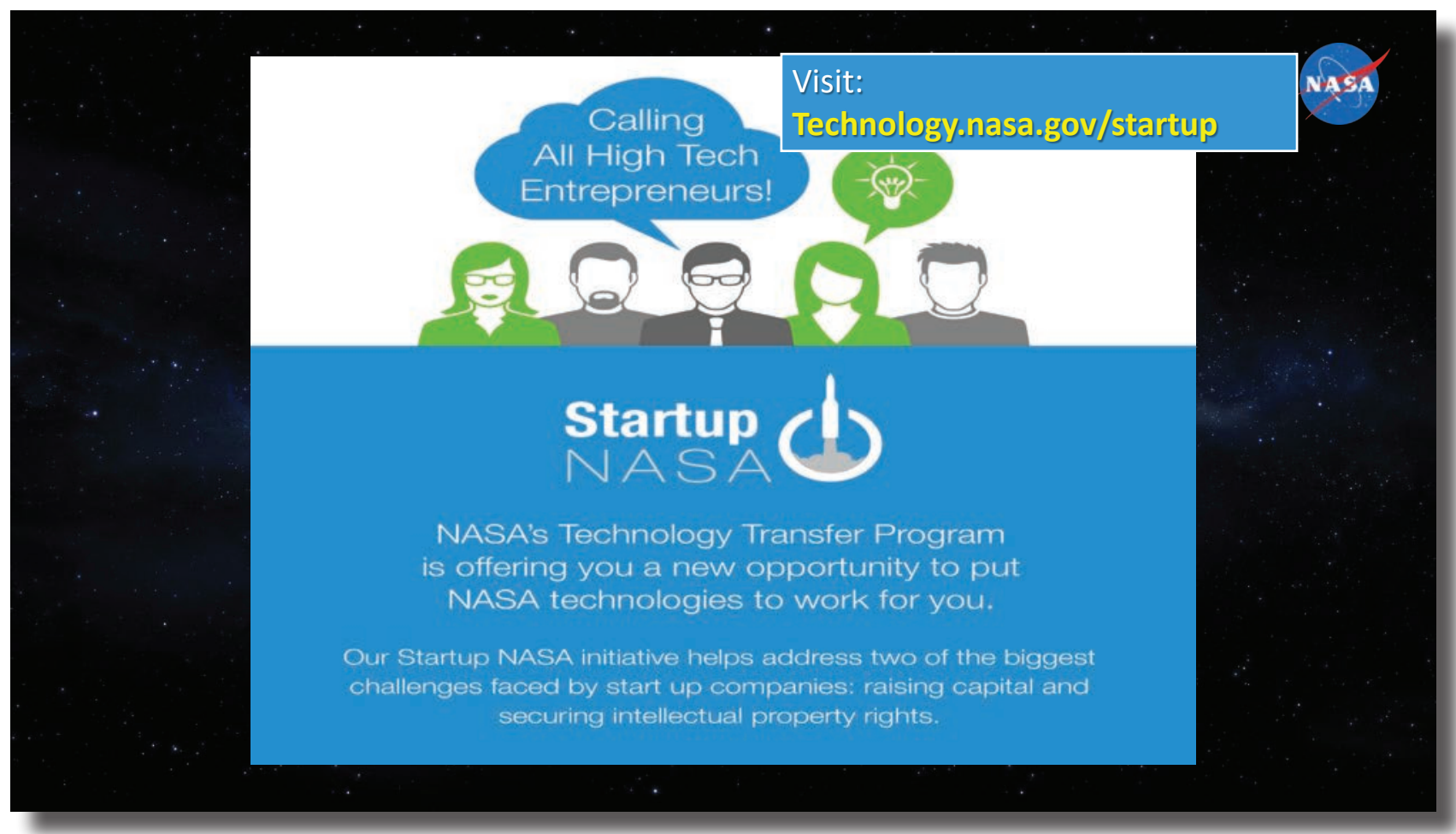

\section{SBIR/STTR Investment}

\begin{tabular}{|l|l|}
\hline SBIR and STTR & \multicolumn{1}{|c}{ SBIR Only } \\
\hline DOD - \$1,000M & USDA - \$18M \\
\hline HHS - \$697M & DHS - \$16M \\
\hline NASA - \$191M & ED - \$13M \\
\hline DOE - \$184M & DOT - \$8M \\
\hline NSF - \$153M & DOC - \$7M \\
\hline & EPA - \$4M \\
\hline
\end{tabular}

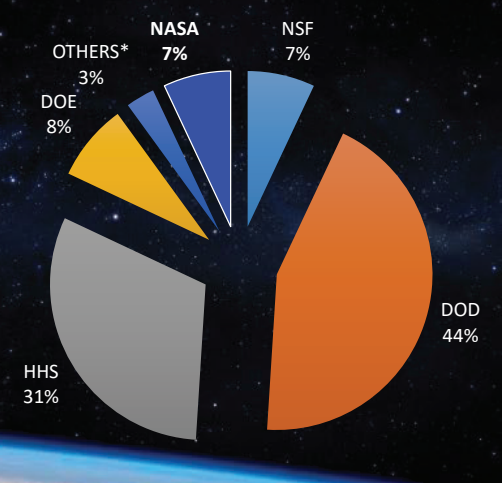



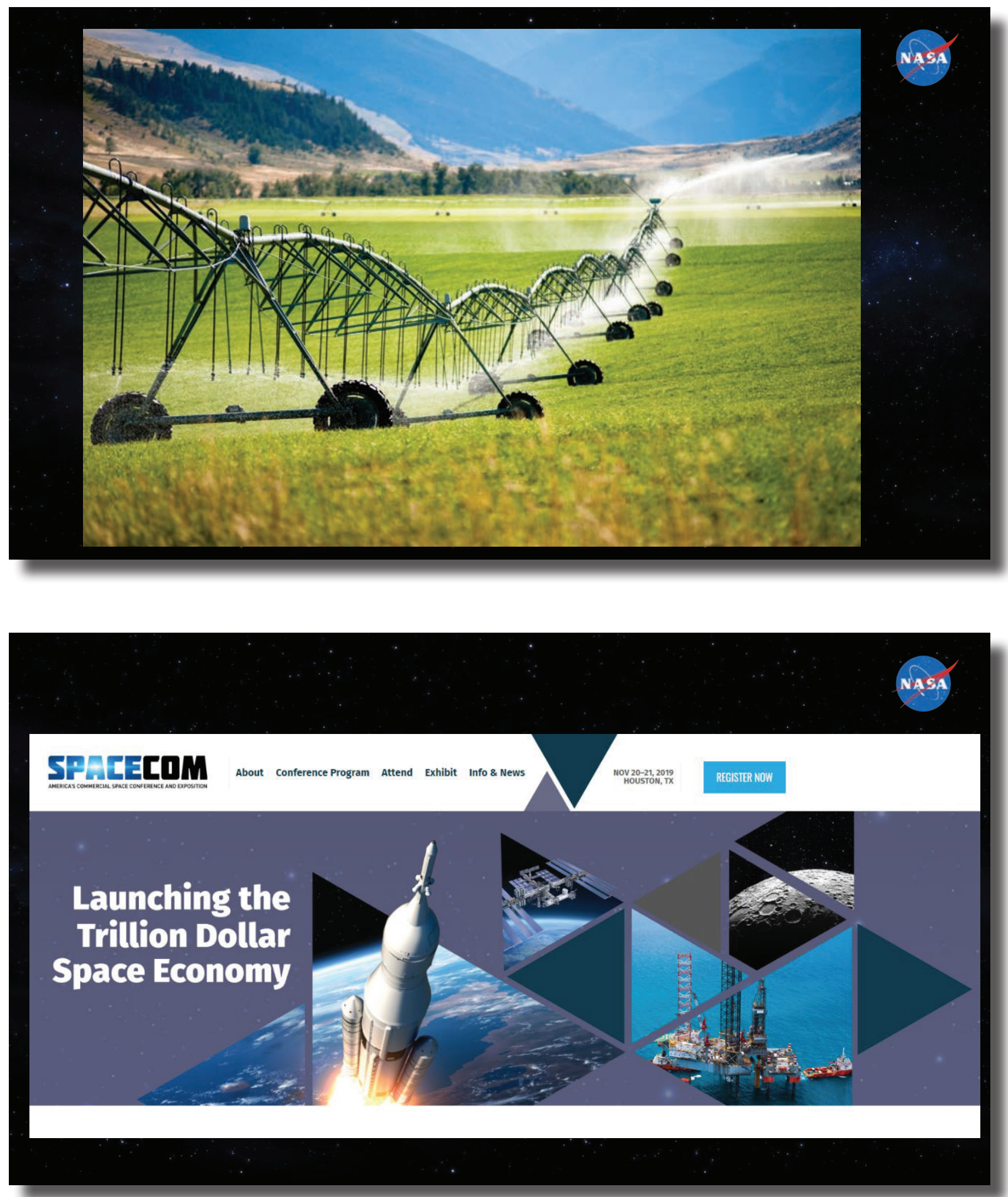


\section{Contact}

Steven González Technology Transfer Strategist 2101 NASA Parkway Mail Code XT

Houston, TX 77058 steven.a.gonzalez@nasa.gov Or visit
http://technology.jsc.nasa.gov http://technology.nasa.gov

Or visit for SBIR/STTR www.sbir.nasa.gov

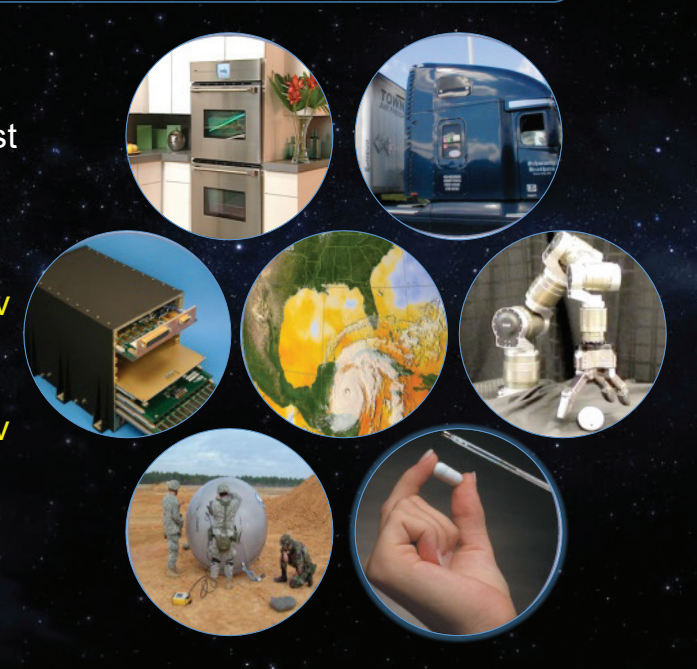

\section{Enabling Space Commerce}

September 12, 2019 - Space Commerce Workshop

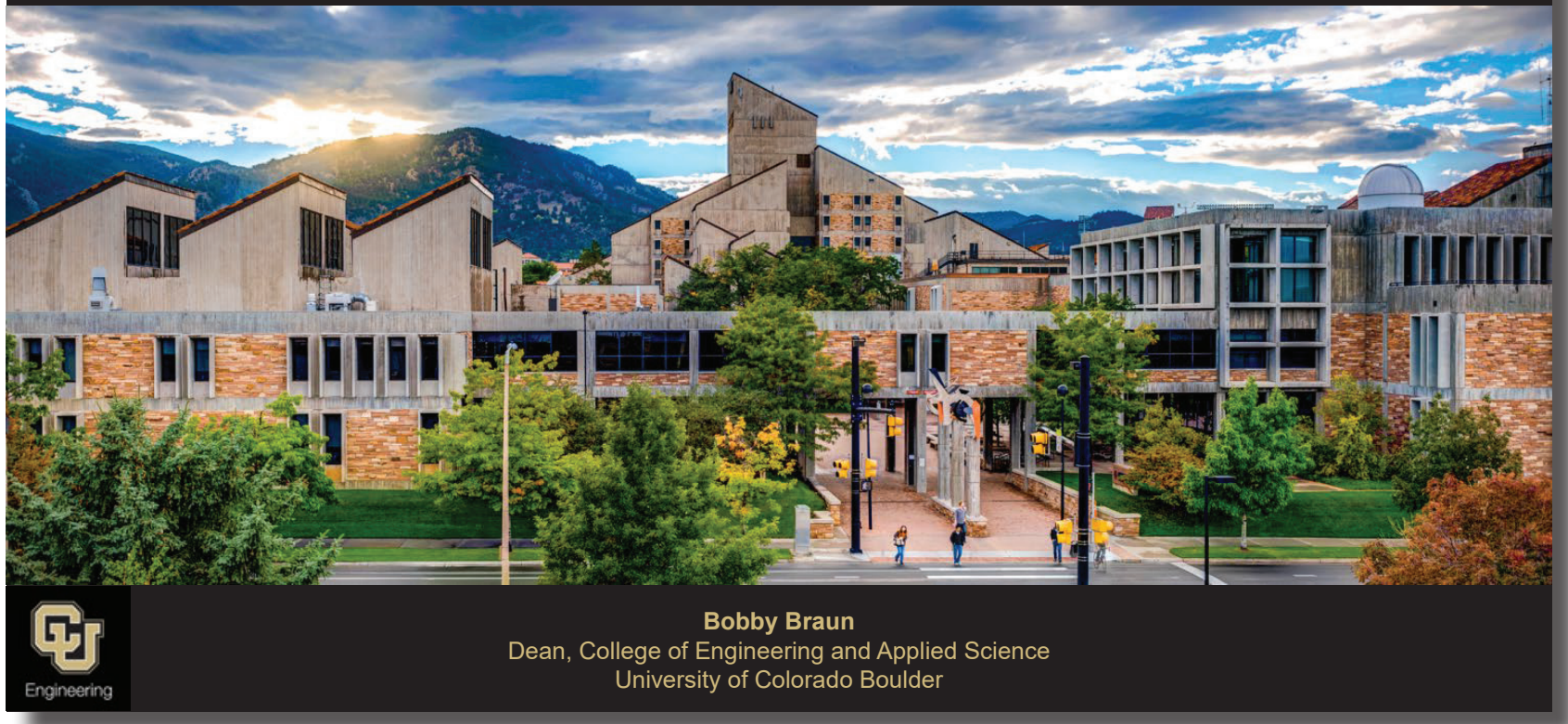




\section{CU Engineering Snapshot}

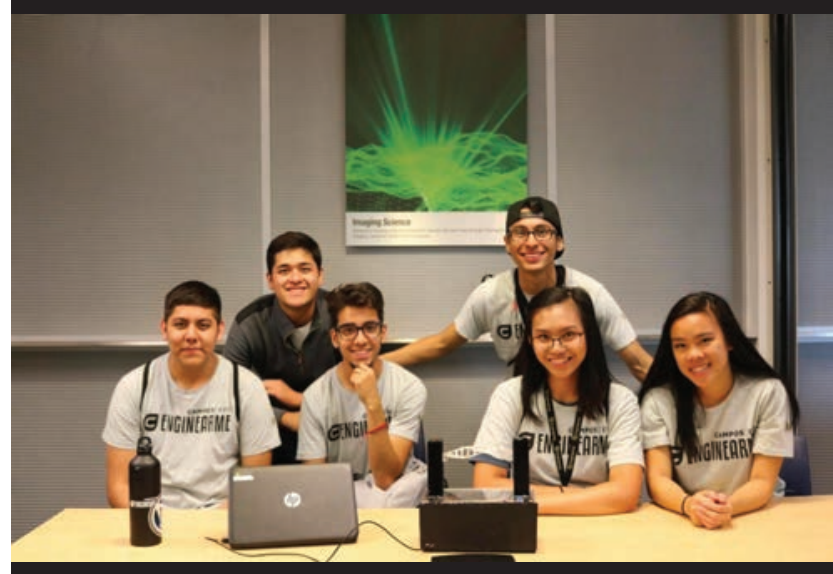

막
6 Departments and 8 Programs

$7,500+$ students (including $2250+$ grad students)

Over 350 faculty and 300 staff

Over $\$ 100$ million in annual research expenditures that drive economic competitiveness, advance national security and quality of life

Strong engagement across the state and ROI for the state

\section{Endowment of over $\$ 150$ million}

Largest, most diverse and fastest growing engineering college in the Rocky Mountain region

\section{Engineering}

\section{Research Strengths}

- Aerospace and Defense

- Quantum

- Materials

- Energy and Water

- Autonomous Systems

- Imaging Science

- Biomedicine

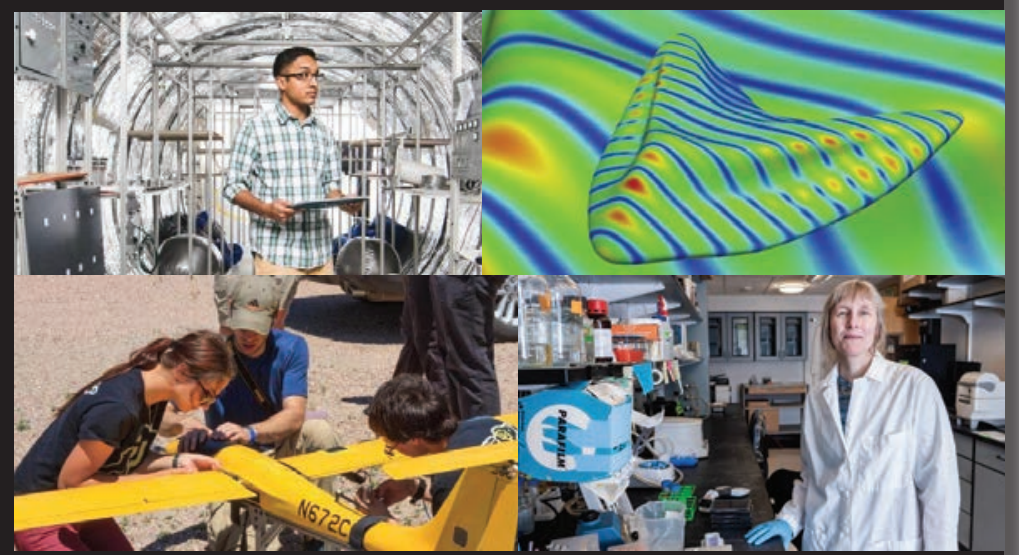

I. Vibrant collaborations across campus, Colorado and the Nation in these areas 


\section{Research Translation is Our Strength}

Monitoring methane $\left(\mathrm{CH}_{4}\right)$ emissions from oil \& gas with NIST Nobel Prize-winning dual frequency comb spectrometer.

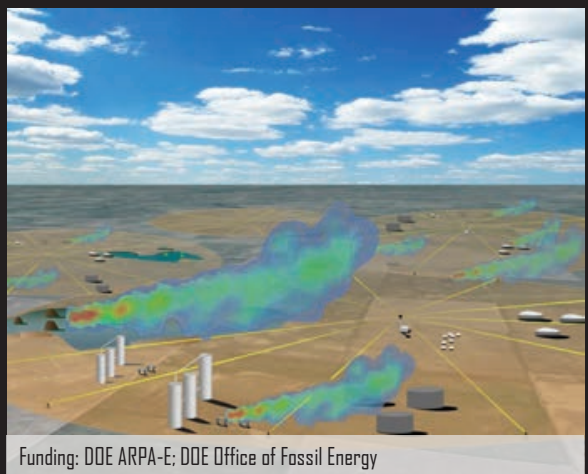

Discovering surprisingly high-temperature superconductivity in plated gold/rhenium layers.

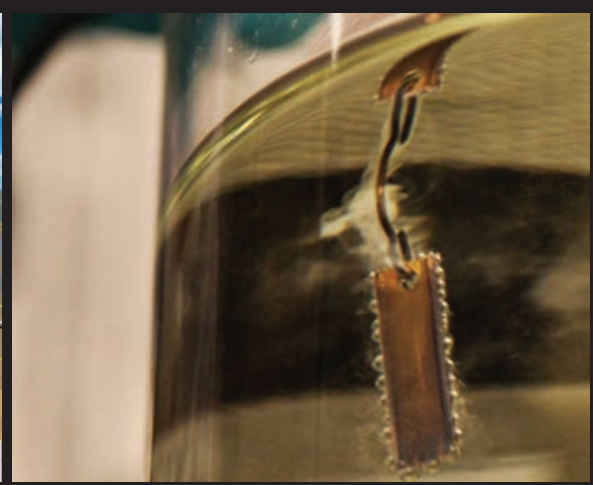

With: Rieker Lab (CU Boulder), Jan Hall (NIST); Dave Pappas (NIST)

\section{CU Boulder: The Space University}

- CU Boulder is the No. 1 public university for NASA funding.

- CU Boulder has been to every planet including Pluto, either with standalone spacecraft or with instruments built here.

- CU developed biological payloads fly on nearly every commercial cargo mission to the International Space Station - and, through a mission control center on campus, we collaborate with astronauts in operation of these experiments.

- There are 20 University of Colorado affiliated astronauts

- Our Space Minor is open to all majors

- We graduate more space-oriented Ph.D. students than any other university

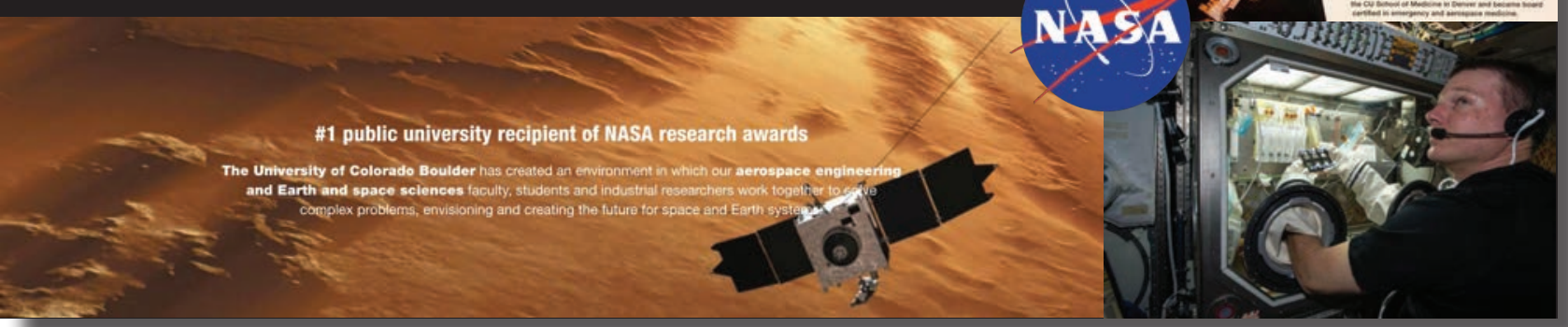




\section{Colorado: The Space State}

- Colorado ranks 1 st in private-sector aerospace employment and $2^{\text {nd }}$ for largest space economy in the U.S.

- Colorado is home to 500+ aerospace-related companies and suppliers supporting nearly 200,000 direct and indirect jobs while pumping more than $\$ 15$ billion into the economy each year.

- Colorado is the U.S. center for military space, including U.S. Space Command, NORAD, U.S. Northern Command, the USAF Academy, and three space-oriented AF bases.

- Colorado's aerospace industry is anchored by nine large space and defense organizations:

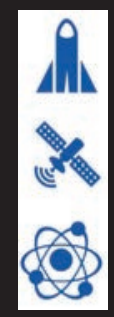

I7
- Ball Aerospace

- The Boeing Company

- Harris Corporation

- Lockheed Martin

- Northrop Grumman

- Maxar

- Raytheon

- Sierra Nevada Corporation

- United Launch Alliance

\begin{tabular}{|c|c|}
\hline Diroct Employment & 21,090 \\
\hline Companies & 130 \\
\hline Five-Year Employment Growth (2012-2017) & $7.3 \%(6.1 \%)$ \\
\hline One-Year Employment Gromth (2017) & $5.5 \%(4.7 \%)$ \\
\hline Direct Employment Concentration (2017) & $0.9 \%(0.8 \%)$ \\
\hline Average Whage & $\$ 129,730$ \\
\hline Emplopment Concentration Ranking & , \\
\hline
\end{tabular}

More than $50 \%$ of Colorado aerospace companies employ 10 or fewer people, reflecting the entrepreneurial and innovative culture of our state.

\section{다 Engineering}

UNIVERSITY OF COLORADO BOULDER

\section{당 ELASP \\ Laboratory for Atmospheric and Space Physics} University of Colorado Boulder

\section{JILA}

\section{CU Boulder Space Ecosystem}
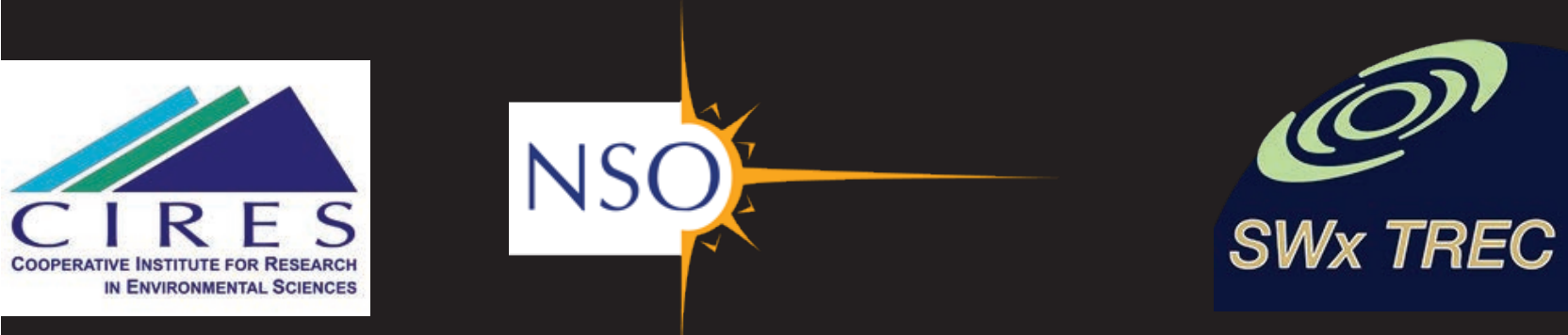


\section{New Aerospace Engineering Sciences Complex}

Newly-opened 175,000 sq. ft. complex located next to relevant research activities at LASP, CIRES and the Department of Atmospheric and Oceanic Science, includes:

- Mission Control

- Payload Operations Center for students and faculty working in real-time with astronauts in space.

- Space Technology Development

- Autonomous systems, Space Communications, PNT.

- Bioastronautics High Bay

- Designing, constructing and testing payloads, spacecraft habitats, and life support systems for human spaceflight.

- Machine Shops, Maker Spaces \& Entrepreneurship Incubator

- Advanced CNC machines, 3D printers, a composites oven and smallsat development labs.

- Space Weather and SSA Research Activities

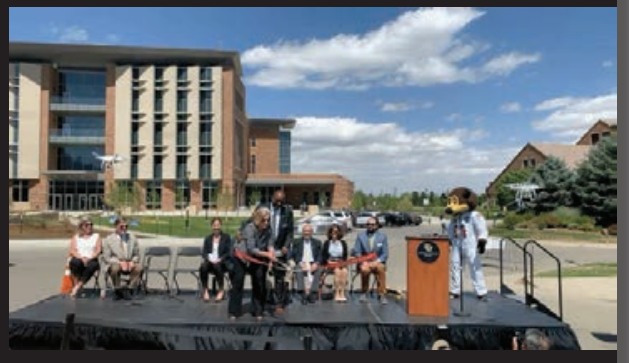

\section{Space Situational Awareness and Space Traffic Management}
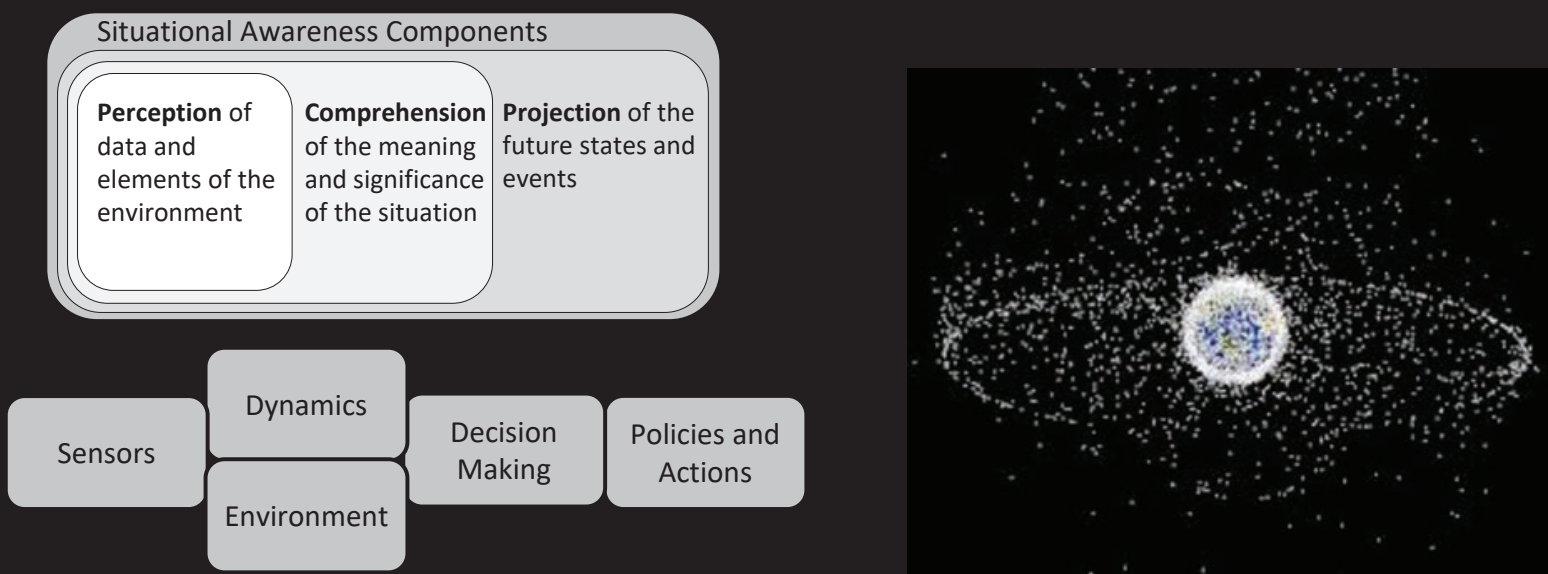

- Rapid growth in operators, capabilities and applications makes SSA and space traffic management (STM) more critical than ever for commerce and security

- Critical area for partnerships across academia, government and industry

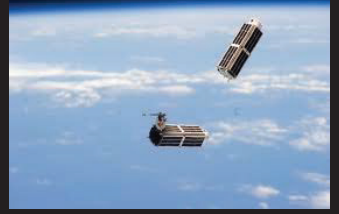




\section{Space Weather Technology, Research, and Education Center}

Envisioning the Future of Space Weather Operations
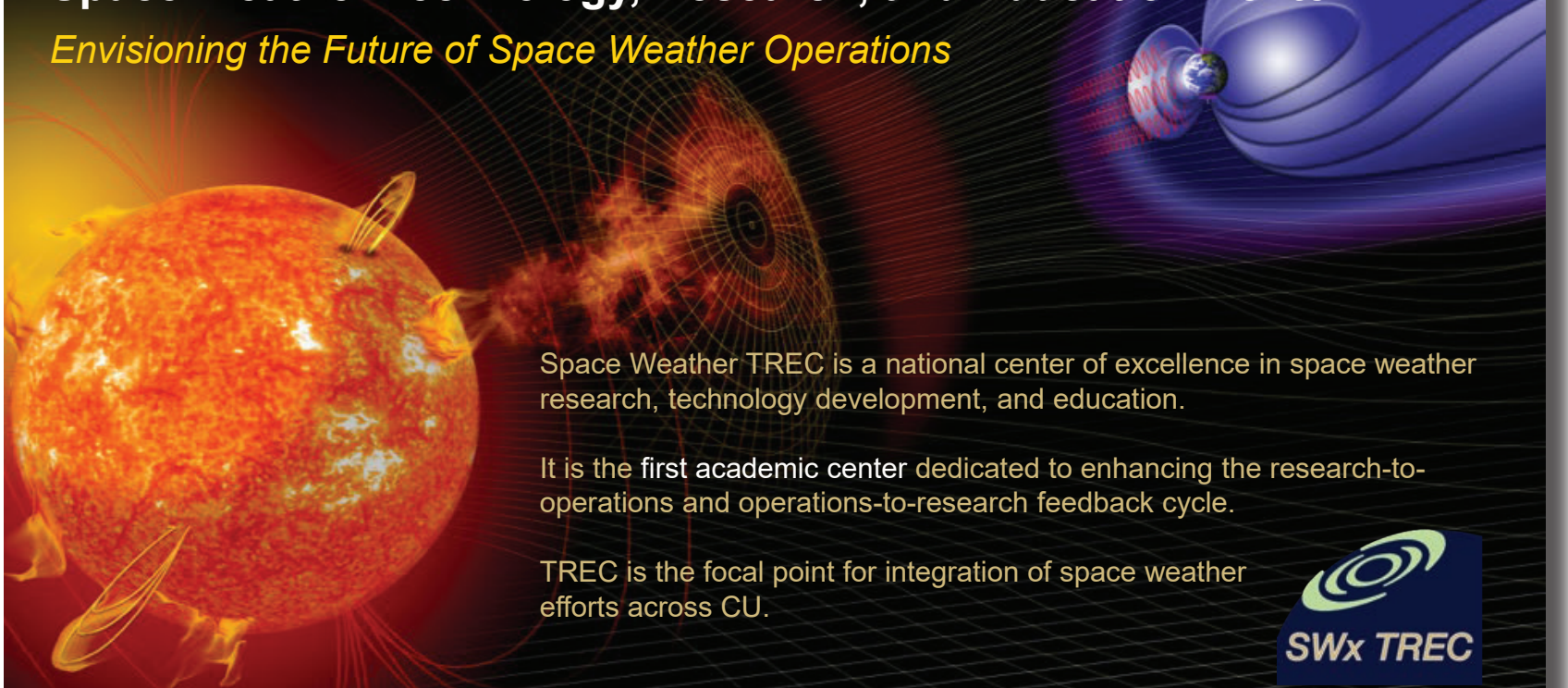

Space Weather TREC is a national center of excellence in space weather research, technology development, and education.

It is the first academic center dedicated to enhancing the research-tooperations and operations-to-research feedback cycle.

TREC is the focal point for integration of space weather efforts across CU.

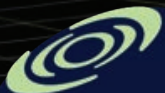

SWX TREC

\section{Human Spaceflight Research}

\section{Bioastronautics research areas:}

- Human space physiology

- Countermeasures

- Environmental control and life support

- Habitat design

- Extravehicular activity

- Human factors

- Microbial and plant growth

- Payload development and operations

\section{Ty}

(8) Jim Bridenstine 8

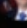

Took a tour of the BioAstronautics High Bay @CUBoulder with technology that's able to simulate lunar landings and safety test conditions for pilots.

Thank you to former astronaut and @CUEngineering Professor Col. Voss for showing me.

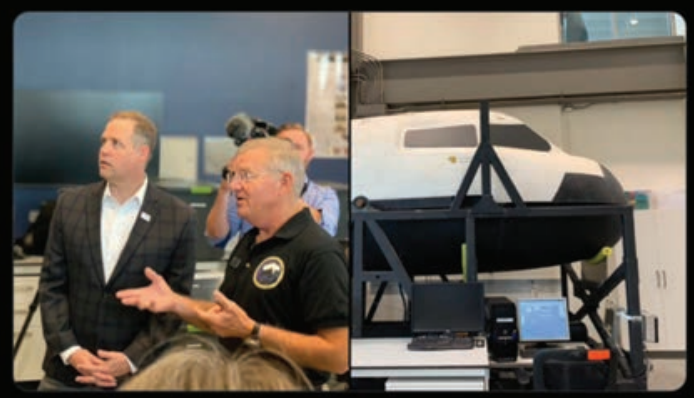

60 


\section{Laboratory for Atmospheric and Space Physics}

A world-class laboratory dedicated to the advancement of space science through the development and operation of advanced space instruments and space missions. LASP is the world's only research institute to have sent instruments to all eight planets and Pluto.

- Planetary Science

- Space Physics

- Solar Science

- Atmospheric Science

- Engineering

- Mission Operations \& Data Systems

\section{당 CLASP}

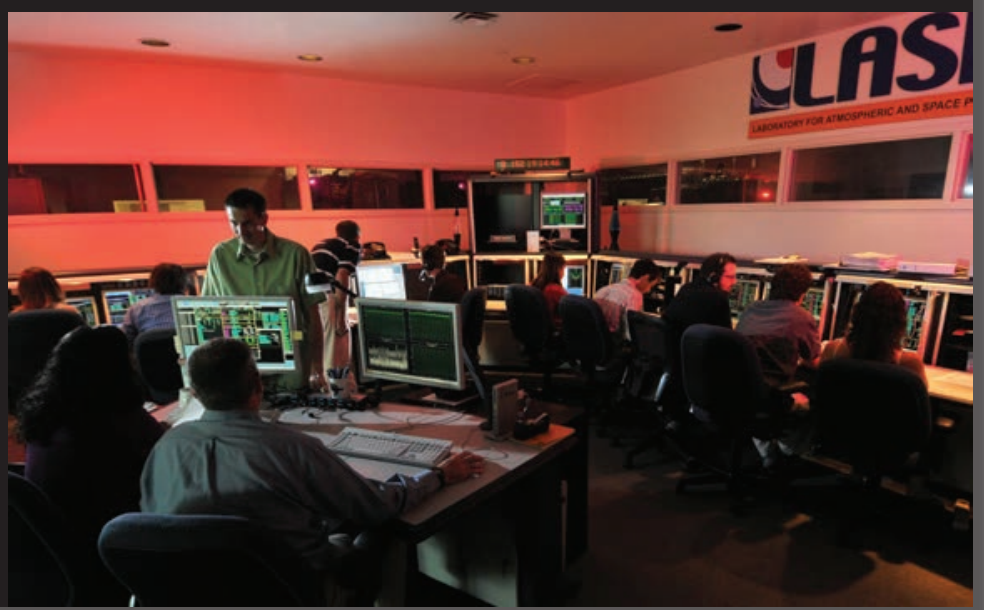

\section{Cooperative Institute for Research in Environmental Science (CIRES)}

Mission: To conduct innavative research that advances our understanding of the glabal, regional, and lacal enviranments and the human relationship with those enviranments, for the benefit of saciety. 


\section{Direct Support of NOAA's Mission}

For example, CIRES:

- Supports NOAA's long-term measurement of greenhouse gases, in collaboration with NIST (standards)

- Develops and implements innovations in terrestrial weather forecasting

- Studies drought, the changing cryosphere, air quality, wildfire, the carbon cycle...

- $\quad 30$ CIRES scientists work in NOAA's Space Weather Prediction Center, improving modeling, understanding

- Several more space weather experts work in the NOAA National Centers for Environmental Information on satellite data, instrumentation, research

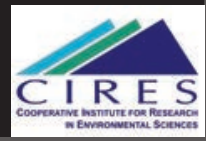

\section{The Cooperative Institute structure provides and supports:}

- A flexible and agile workforce

- Alignment with mission

- Discovery-based research

- Mission-fueled discovery and discovery that benefits mission

- Unique education for future generations of scientists

- Substantial leveraging 


\section{Areas for Future Research Collaborations}

- Space Situational Awareness

- Space Weather

- Space Traffic Management

- Spectrum Management

- Space Technology

\section{- Sensors}

- Communications

○ PNT

- Materials and Coatings

- Manufacturing

- Servicing/Resupply

- In-situ Resource Utilization

- ECLSS

- Transportation \& Tourism

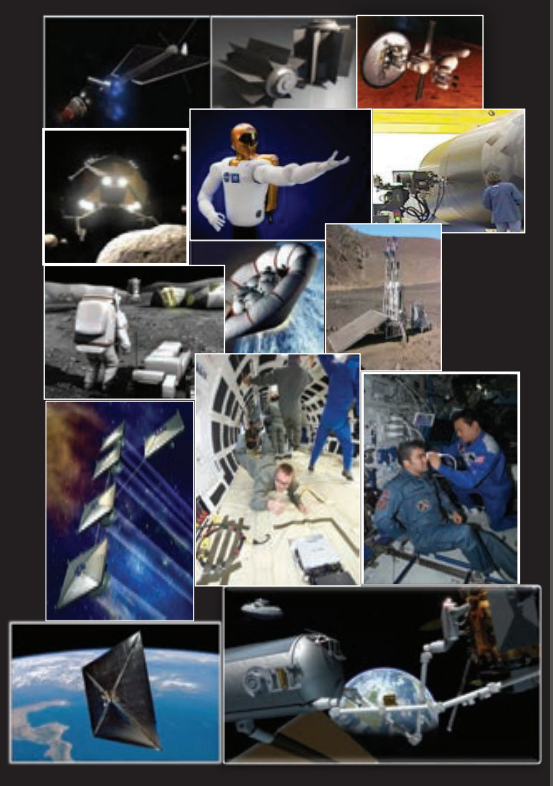

\section{To Grow A Space Economy}

- Government must foster an environment conducive to new commercial entrants and build partnerships that have the possibility to scale.

○ Academia must focus on translation of basic research into commercial applications, engaging entrepreneurial start-ups, established industry and government labs.

○ Industry must take informed risk to continually reinvent itself.

o Perhaps the Cooperative Institute model with a strong emphasis on commercialization could catalyze the growth we are seeking. 


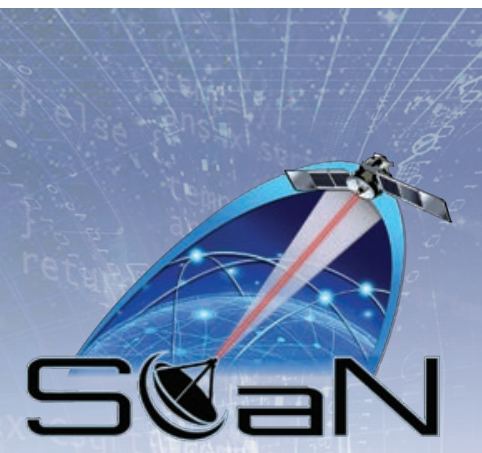

\section{Space Communications \& Navigation}

Propagation Considerations in the Development of

Space Commerce

$>$ Presented By: Glenn Feldhake

$>$ NASA, International Spectrum Program Manager

\section{Propagation Considerations - Current Status}

- Models, models everywhere

- Single effect (e.g., rain attenuation) vs. multiple effect (e.g., rain+cloud+water vapor+oxygen)

- Static calculations vs. Dynamic simulations

- Path specific vs. Path general

- Closing the link vs. Possibility of interference (Opposite ends of the probability distribution curve)

- Repositories of models

- Peer reviewed technical journals

- Professional societies

- Commercial proprietary

- ITU-R Study Group 3 - Propagation

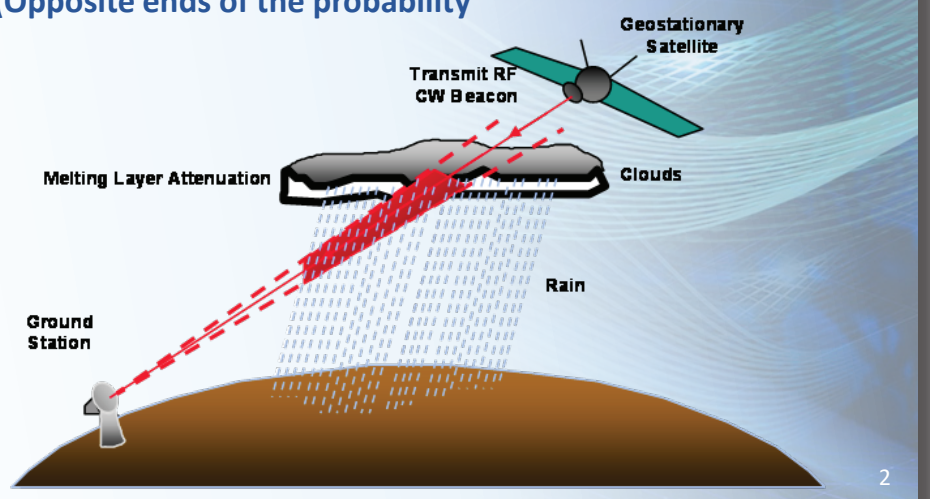




\section{Propagation Considerations - Projections of next milestones}

- Typical sequence of events - takes time

- Identify where a new model or an extension of an existing model is needed

- Develop theory for the model

- Gather data to validate the model - For natural phenomena this may take years

- Publish, if possible, the results in academic journals

- Provide the model to appropriate standardization organizations

- ITU-R Study Group 3 - Propagation

- Meets once per year typically at ITU Headquarters in Geneva, Switzerland

- Work divided into four Working Parties

- Each Working Party maintains a Work Plan

- The Great Race to be \#2!

\section{Propagation Considerations - Obstacles to achieving those milestones}

- Data for model validation

- Theory is not enough to develop propagation models

- Many models have (an) empirical correction(s)

- Unvalidated or extrapolated models give inconsistent results

- Standardization of how validation data is collected and processed

- Competing interests in studies

- What does academia want to study?

- What does industry want studied?

- What are the priorities for those funding the studies?

- Putting it all together

- Atmospheric considerations

- Building entry \& clutter losses

- Bi-static surface scattering

- Path specific vs Path general models

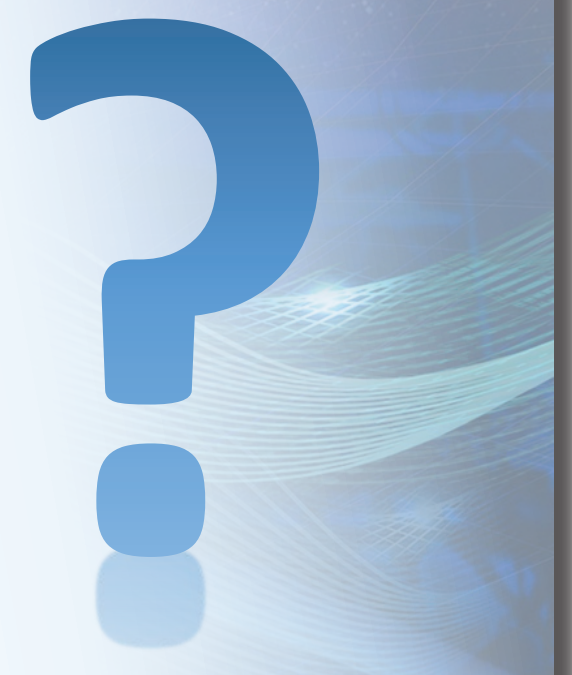




\section{Propagation Considerations - Efforts to identify/develop solutions}

- New propagation prediction methods:

- Must be developed as new frequencies, operating environments, and geometries are considered, but...

- There is no current, long-term plan associating radio wave propagation modeling and commercial space commercialization

- Remember: Propagation is agnostic to technology

- It's the physics happening between the antennas

- Keeping politics out of propagation

- Aligning the priorities of researchers, users of the research, and funding sources for the research

- Contributions to ITU-R Study Group 3 and its Working Parties

- Development of the commercial space industry will require action form the international regulatory community

- The propagation models need to be agreed within the international regulatory community

NGSO v GEO

\section{SPECTRUM NEEDS}

AND INTERFERENCE/PROTECTION

Presented By : Jaime Londono

EchoStar Corporation

VP Advanced Programs \& Spectrum Management

12 September 2019 


\section{Emerging Technologies and Spectrum Demand}

Emerging and Evolving Technologies are enabling new applications, such as

- Internet of Things (IoT)

- Smart Cities

- Connected Cars

New technologies will require new enhanced connectivity that can deliver improved coverage and greater capacity, resulting in higher demand for spectrum.

\section{Enhanced connectivity are enabled by the following factors}

$>$ Development of cost-effective platforms for NGSO constellations facilitated by advances in technology such as Nano- and Cube- satellites

$>$ New NGSO systems have received a new wave of investment from key players, both from within and outside the traditional satellite industry.

$>$ Lower satellite launch costs. (Multiple satellites on one launch vehicle).

These emerging and evolving technologies will need increased spectrum resources. Regulators must, understand the spectrum demand, and ensure that frequency resources are made available while protecting existing services.

\section{Challenge: Meet Spectrum Demands}

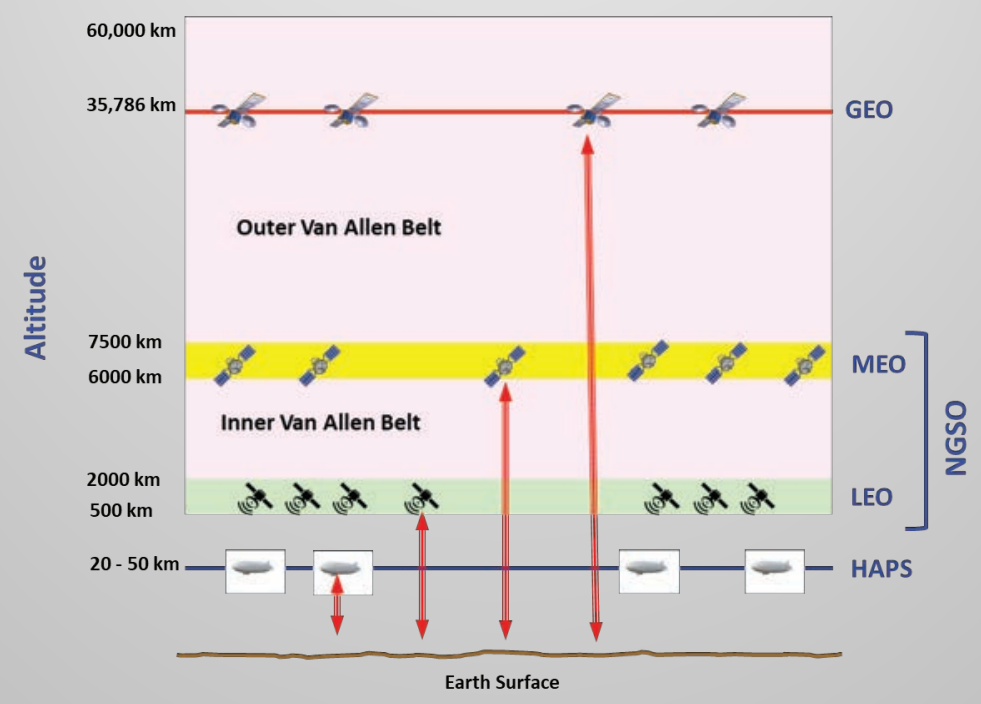




\section{Spectrum Demands: Potential Interference Conflicts}

Non-geostationary satellites (NGSOs) operate at lower orbital altitudes than GSOs: will require multiple satellites to allow for continuous coverage.

$>$ NGSO systems are under development, with plans to launch hundreds or possibly thousands of satellites.
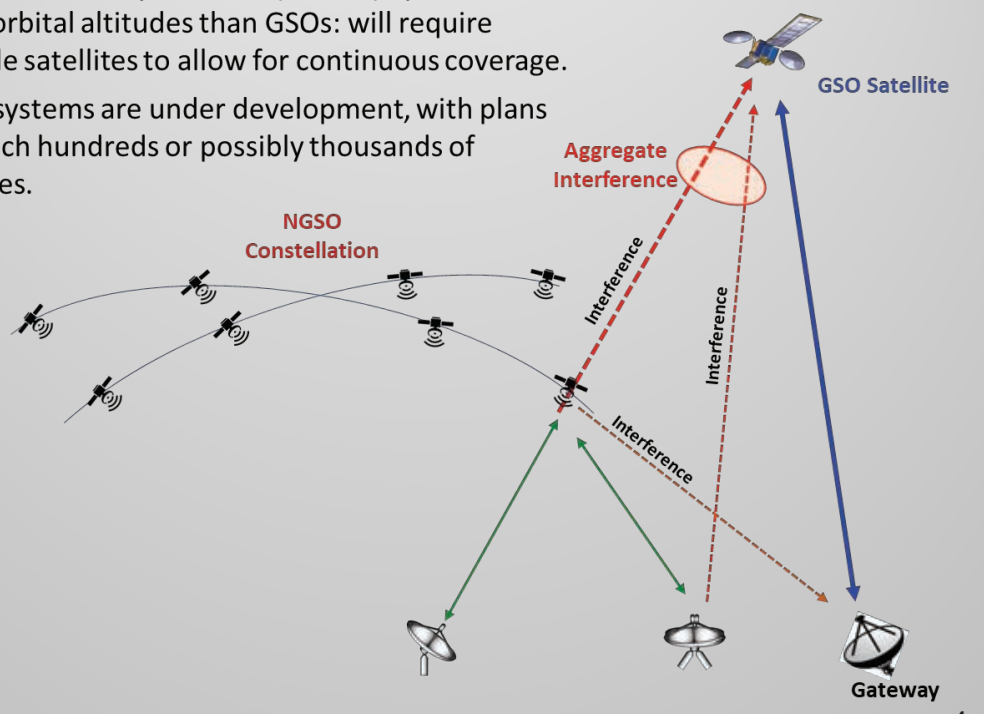

NGSO: congested space

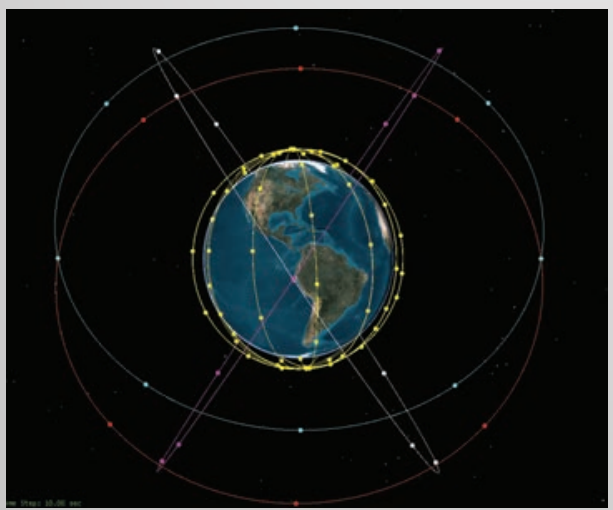

Illustration provided for only one MEO constellation with 28 satellites and one LEO system.

> Reality: Introduction of multiple new proposed NGSO systems to co-exist with existing operational LEO, MEO an GEO systems will be a major challenge.

- Extensive Analysis required to insure compatibility and interference-free environment between the operational systems and the new proposed systems. 


\section{ITU WRC-2019 NGSO Rules Review}

The ITU World Radiocommunication Conference 2019, WRC-19, will be reviewing the current NGSOs rules and will evaluate whether any changes are needed to ensure the most efficient use of the orbital resource address

$>$ The ITU Radio Regulations provide the regulatory framework for coordination of satellite networks, including for NGSO networks.

$>$ Operators apply the regulatory framework established by the ITU to enable the NGSO constellations to coexist with GSO and terrestrial networks. This might imply complying with established operational transmit levels as set by the ITU Radio Regulations.

\section{ITU WRC-2019 NGSO 40/50GHz Spectrum}

Present Situation for the GSO Satellite networks:

NGSO/GSO: The ITU Radio Regulations has an established regulatory process that will allow full protection to GSOs in certain frequency bands.

ITU WRC-2019 agenda item 1.6 spectrum access for NGSO systems

Regulatory framework for the introduction of NGSO systems in the 40/50

$\mathrm{GHz}$ Frequency bands, while protecting GSO systems.

InterAmericas proposal for the ITU WRC-2019 agenda item 1.6

Methodology to ensure protection of GSO. The methodology establishes a mandatory coordination process among NGSO operators to comply with agreed protection criteria for GSO.

\section{Potential Obstacles at the ITU WRC-2019}

Applicants for new NGSO constellations will request further relaxation of the rules. 


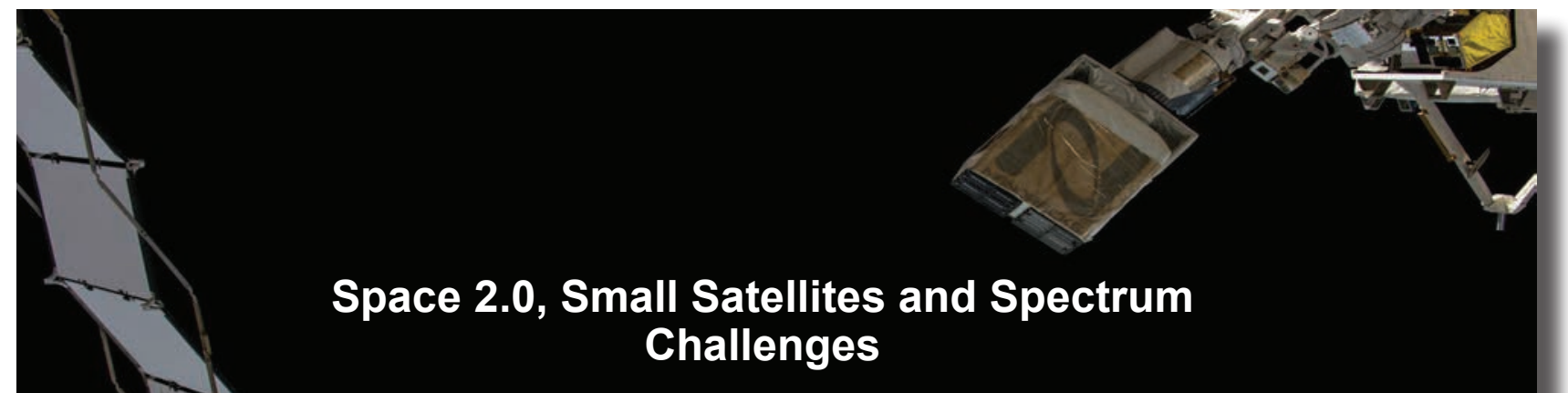

\section{Professor Scott Palo*}

Charles Victor Schelke Endowed Professor

Ann and HJ Smead Aerospace Engineering Sciences Department

University of Colorado Boulder

Director - Space Technology Integration Lab (STIg)

Co-Director - Active Remote Sensing Lab (ARSenL)

Chair - AIAA Small Satellite Technical Committee

\section{Rapid Growth}

Nano/microsatellite launch history and forecast

Projections based on announced and future plans of developers and programs indicate as many as 3,000 nano/microsatellites will require a launch from 2016 through 2022.
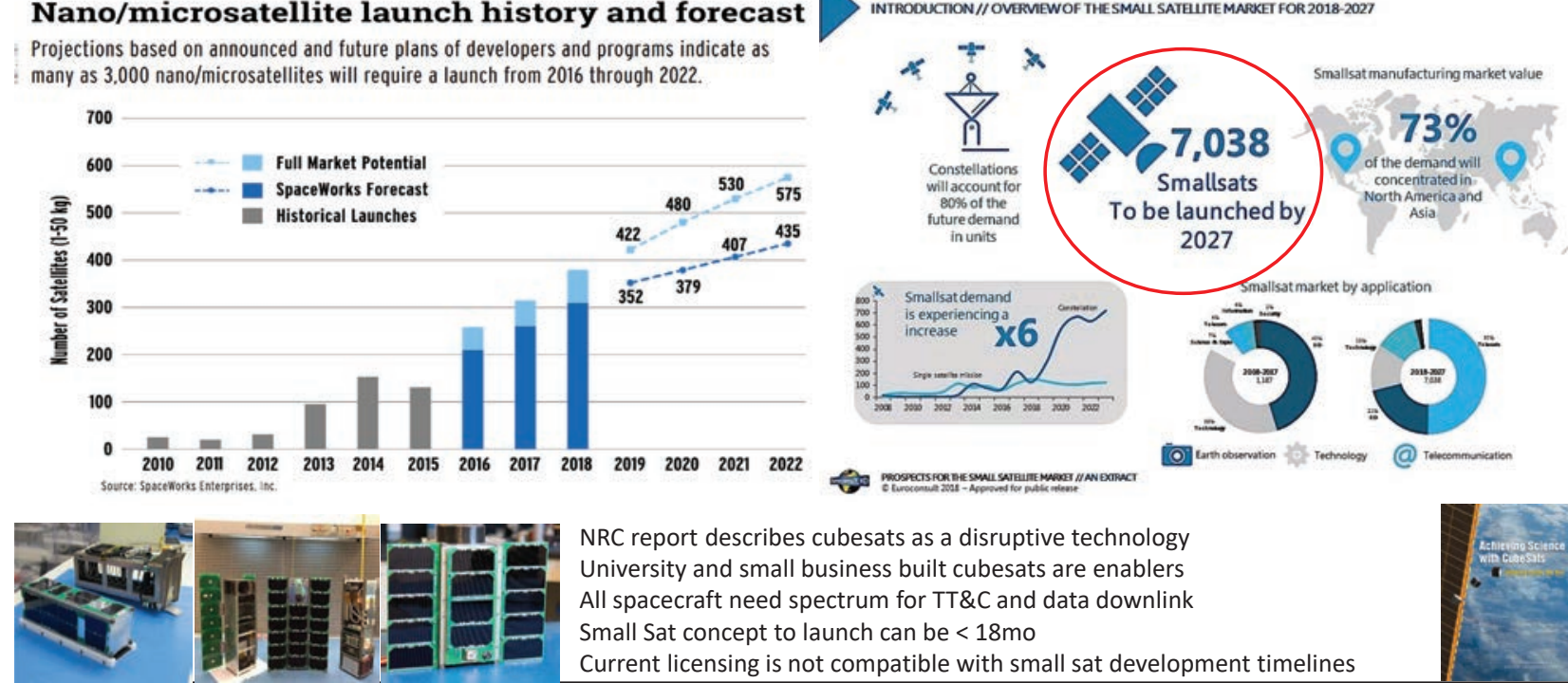

NRC report describes cubesats as a disruptive technology University and small business built cubesats are enablers All spacecraft need spectrum for TT\&C and data downlink Small Sat concept to launch can be $<18 \mathrm{mo}$

Current licensing is not compatible with small sat development timelines

5. Smead Aerospace

UNIVERSITY OF COLORADO BOULDER 


\section{Emerging Small Satellite Companies}

planet.

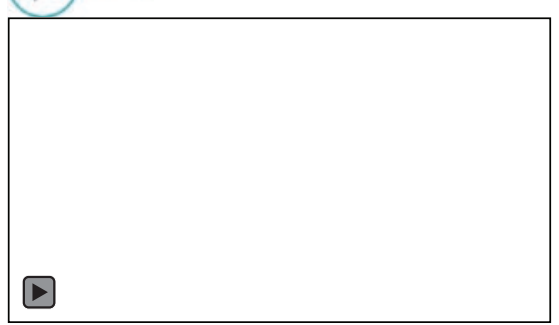

Planet Labs Gets \$168 Million in Funding and Launching More Satellites
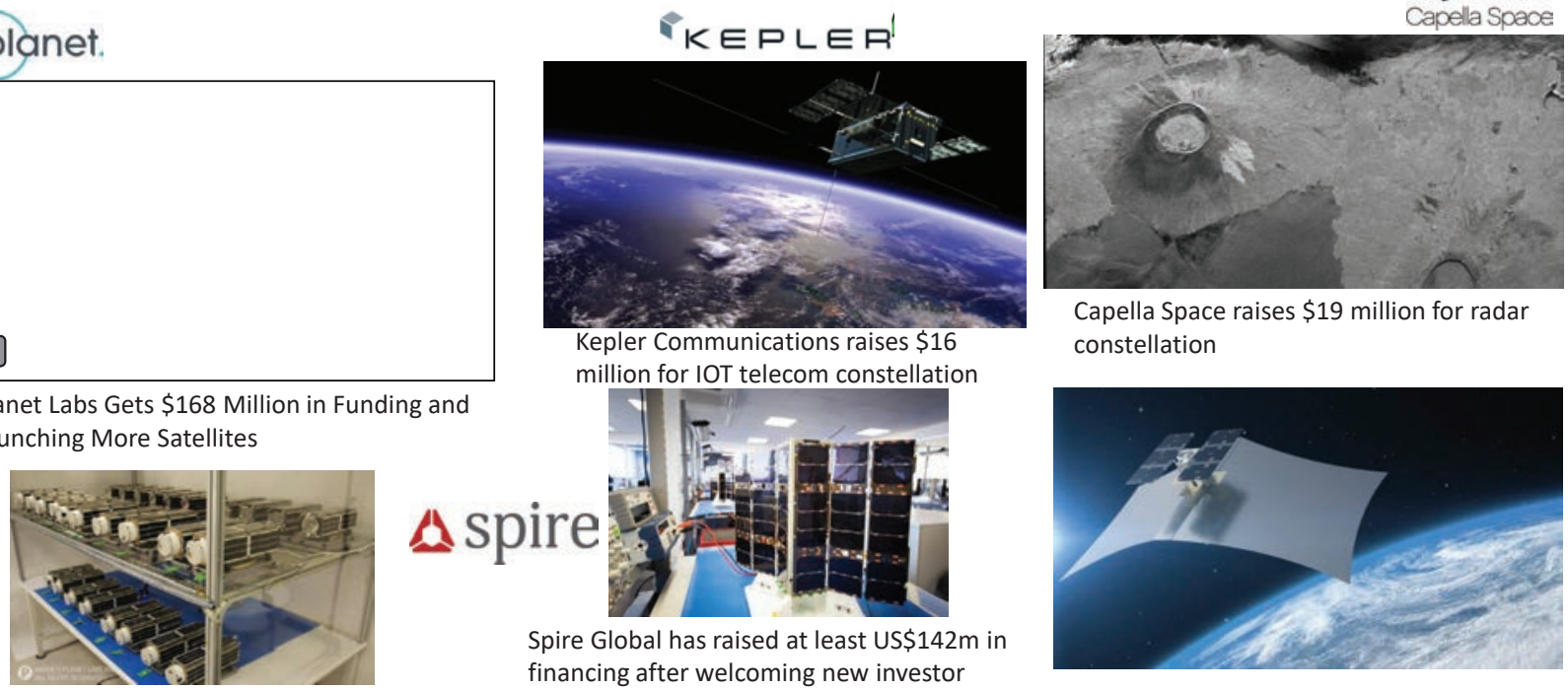

Capella Space raises $\$ 19$ million for radar constellation

million for IOT telecom constellation

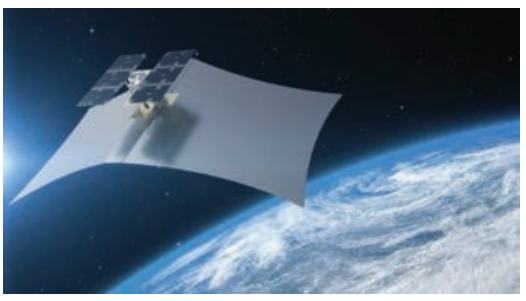

\section{Spire Global has raised at least US\$142m in \\ financing after welcoming new investor \\ spire

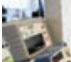

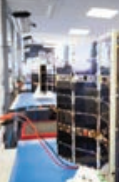

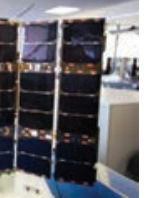

\section{If Smead Aerospace}

UNIVERSITY OF COLORADO BOULDER

\section{SpaceX}

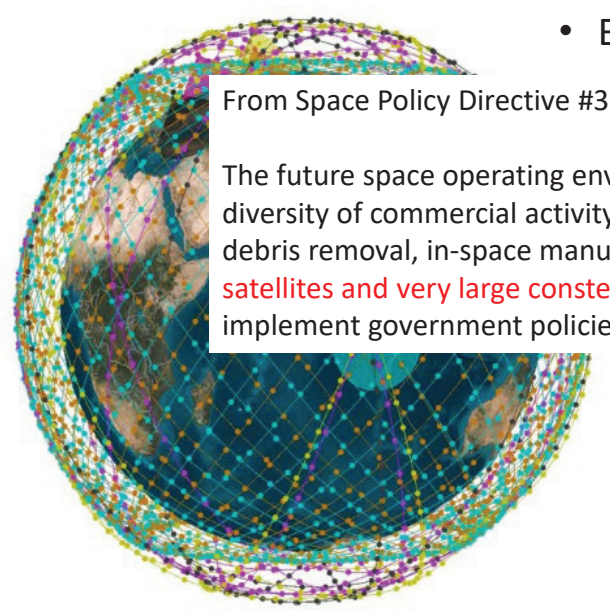

https://www.nytimes.com/2019/06/01/science/starlink-spacex-astronomers.htm

From Space Policy Directive \#3 (6/18/2018) : National Space Traffic Management Policy implement government policies and processes to address these new activities.

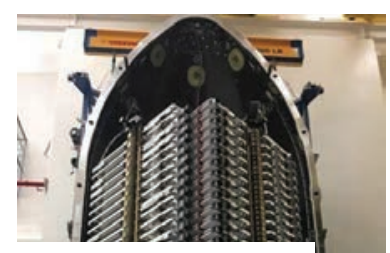

4,425 Satellites in 83 planes

- $386 \mathrm{~kg}$ each

- Block 1 did not include cross-links

The future space operating environment will also be shaped by a significant increase in the volume and diversity of commercial activity in space. Emerging commercial ventures such as satellite servicing, debris removal, in-space manufacturing, and tourism, as well as new technologies enabling small satellites and very large constellations of satellites, are increasingly outpacing efforts to develop and

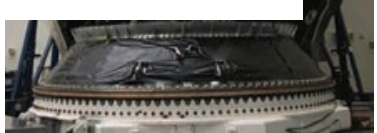

60 SpaceX satellites on Falcon Heavy Launched May 23, 2019 
FCC FACT SHEET*

Streamlining Licensing Procedures for Small Satellites

Report and Order, IB Docket No. 18-86

\section{Background}

The Commission's part 25 satellite licensing rules, primarily used by commercial systems, group satellites into two general categories - geostationary-satellite orbit systems and non-geostationary-satellite orbit (NGSO) systems-for purposes of application processing. The Commission's satellite licensing rules, in particular those applicable to commercial operations, were generally not developed with small satellite systems in mind, and uniformly impose fees and regulatory requirements appropriate to expensive, long-lived missions. However, the Commission has recognized that smaller, less expensive satellites, known colloquially as "small satellites" or "small sats," have gained popularity among satellite operators, including for commercial operations. Therefore, in 2018, the Commission adopted a Notice of Proposed Rulemaking that proposed to develop a new authorization process tailored specifically to small satellite operations, keeping in mind efficient use of spectrum and mitigation of orbital debris.

\section{What the Report and Order Would Do:}

- Create an alternative, optional application process within part 25 of the Commission's rules for smal satellites. This streamlined process would be an addition to, and not replace, the existing processes for satellite authorization under parts 5 (experimental), 25 , and 97 (amateur) of the Commission's rules.

- This new streamlined application process could be used by applicants for satellites and satellite system meeting certain qualifying characteristics, such as:

- 10 or fewer satellites under a single authorization.

- Total in-orbit lifetime of satellite(s) of six years or less.

- Maximum individual satellite wet mass of $180 \mathrm{~kg}$.

- Propulsion capabilities or deployment below $600 \mathrm{~km}$ altitude

Ability to share use of authorized frequency band with current operations and without

materially constraining future satellite entrants seeking to use the band.

- Relatively low risk from an orbital debris perspective, as assessed through additional clearly ascertainable characteristics.

May 24, 2018 - Space Policy Directive \#2 : Streamlining Regulations on Commercial Use of Space

\section{If Smead Aerospace}

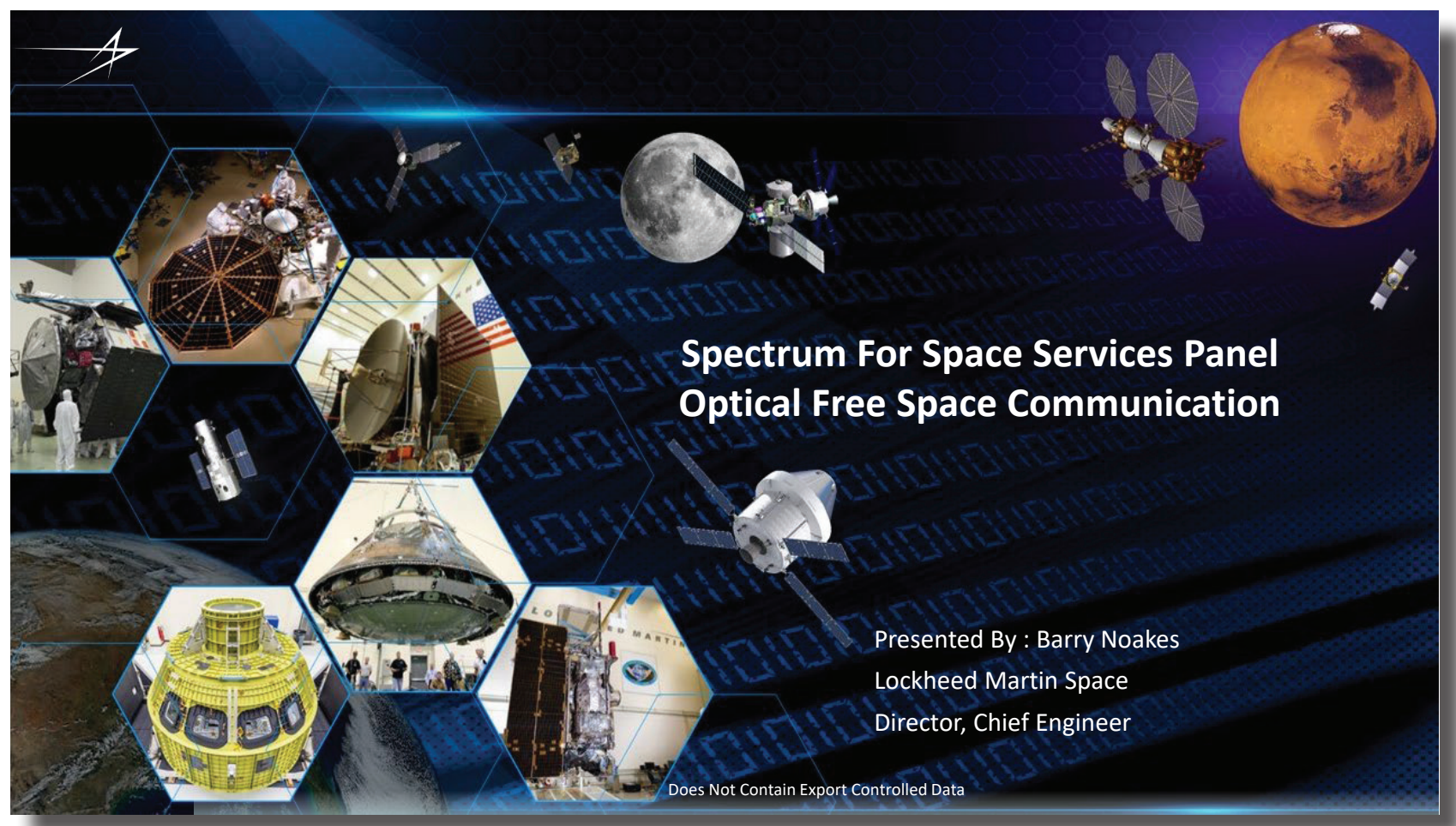




\section{Overview}

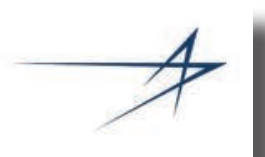

- Optical Free Space Communications use frequencies at $\sim 198 \mathrm{THz}$

- Significant increase in available bandwidth resulting in $>100 \mathrm{X}$ data rates over RF

- Ultra high data rates up to $10 \mathrm{Gbit} / \mathrm{s}$ being achieved today

- Optical systems can have significant mass savings over RF systems for equivalent data rates

- Narrow beam width results in increased gain for fixed aperture sizes

- Laser power outputs are typically around 1-10 W which can result in significant reduction in DC power requirements

- Typical wavelengths in use today are 780-850 nm and 1520- $1600 \mathrm{~nm}$

- Leverages investment in terrestrial fiber networks equipment

- Can be used for sensing payload downlinks, spacecraft cross links, gateway traffic and deep space comms

- Generally are secure links given narrow beam and very high frequencies

- Optical ground stations can be located in crowded RF urban environments

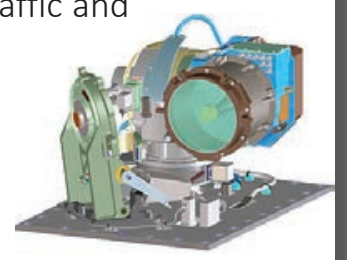

Source: NASA

\section{Other Considerations}

- Pointing Requirements

- Small diameter beam requires tight pointing control to close/maintain link

- Optical benches are typically needed with low distortion and/or tight thermal control

- Jitter sources need to be isolated and controlled

- Telescope receive filters are relatively narrow and therefore Doppler impacts require active management when communicating between vehicles in different orbit/orbit planes

- Atmosphere impacts

- Water molecules and air turbulence are two major contributors to degraded links

- Modeling and ongoing experiments are developing loss models

- Compensating mechanisms such as adaptive optics or more robust modulations can be used

- Downlink/uplink can also use geographic diverse ground sites to find "clear sky"

- Design for Space and Qualification

- Extreme temperature and radiation environments

- Vacuum operation

- Significant expense and risk exists in moving terrestrial technologies to space

- Reliability is critical given the lack of ability to repair

- Cost today can be relatively high as compared to RF systems 


\section{Potential for Interference}

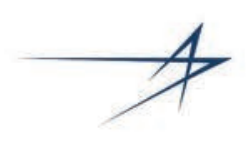

- Bright objects like the sun impact communication within line of sight

- Vehicle glint can contribute noise and needs to be evaluated

- Narrow beam width and operation in the optical band greatly reduces the probability of interference with other vehicles and ground networks

- Ground based astrometry telescopes/sensors represent the one key area where frequency coordination may be needed to avoid impacts

- Space based remote sensing optical payloads may have receive capability in these bands

- Received power levels are generally very low and therefore unlikely to cause noise or damage to focal plane but does need evaluation

- Interference with other vehicles that have optical cross links is possible but given relative velocities and narrow beam width the probability is low

- Impact on nominal operation of other vehicle sensors such has star trackers and earth sensors is low but needs to be evaluated

\section{Evolution/Future}

- Orion Optical Comm Demonstration

- Lockheed Martin is designing Artemis-2 to carry an optical terminal to demonstrate high rate comms from Moon to the Earth

- Will support live steaming, video conference and vehicle data

- Beam width and resulting received power is one of the challenges with deep space missions

- NASA Gateway will be required to support many elements and optical comms represents significant SWAP savings

- Higher power lasers

- Increased sensitively of receivers is easier to implement efficiently

- Use of optical pointing beacon signal to allow auto-pointing of telescopes

- Reduced acquisition time and lower processing requirements to predict where to point

- Requires additional frequency

- Alternative frequencies

- Some potential to move to other frequencies but requires significant investment

- Optical Phased Apertures

- Array of sensors

- Enables electronic beam steering resulting in significant reduction in relative size of telescope and supporting mechanisms 

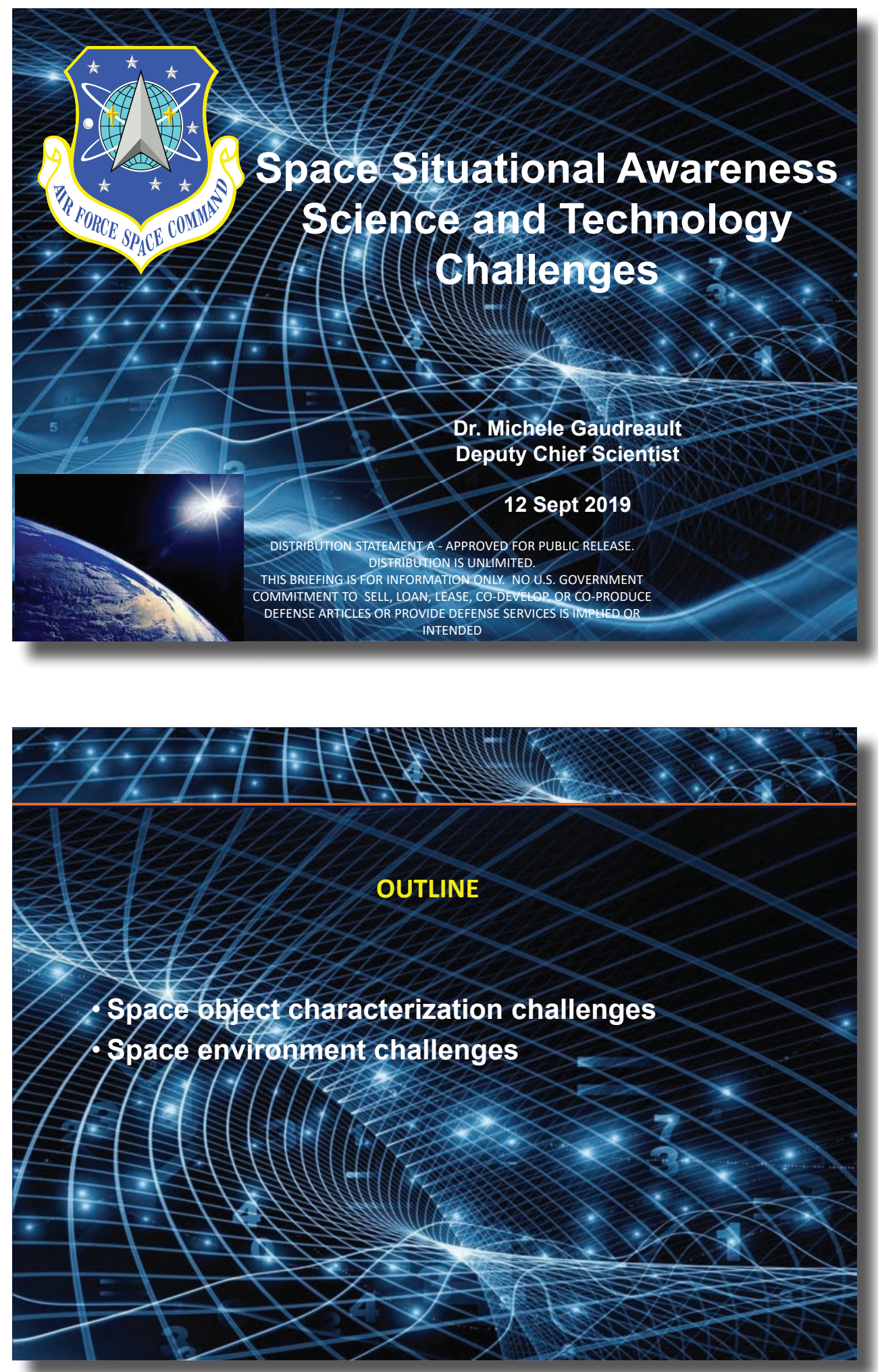

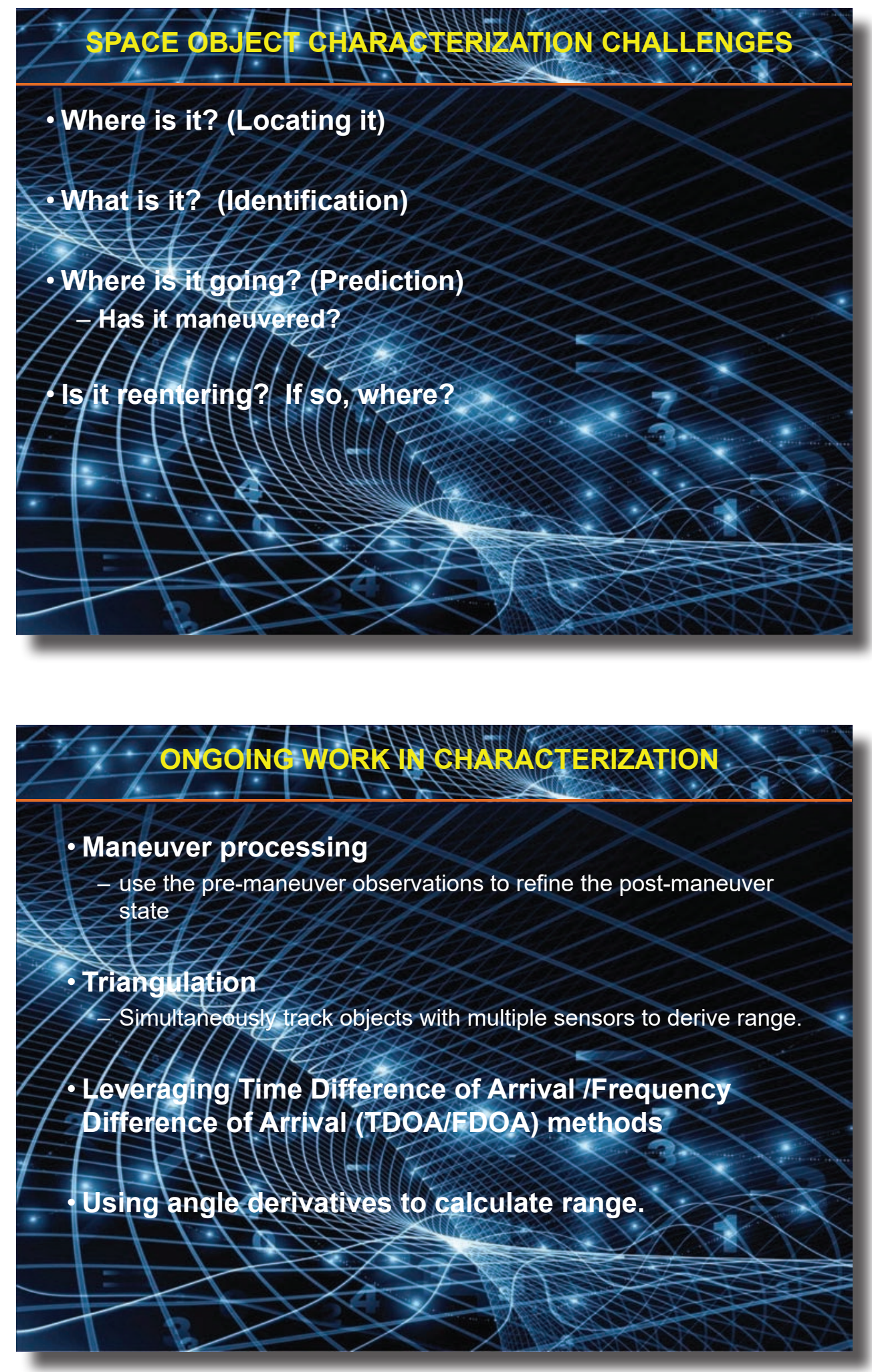

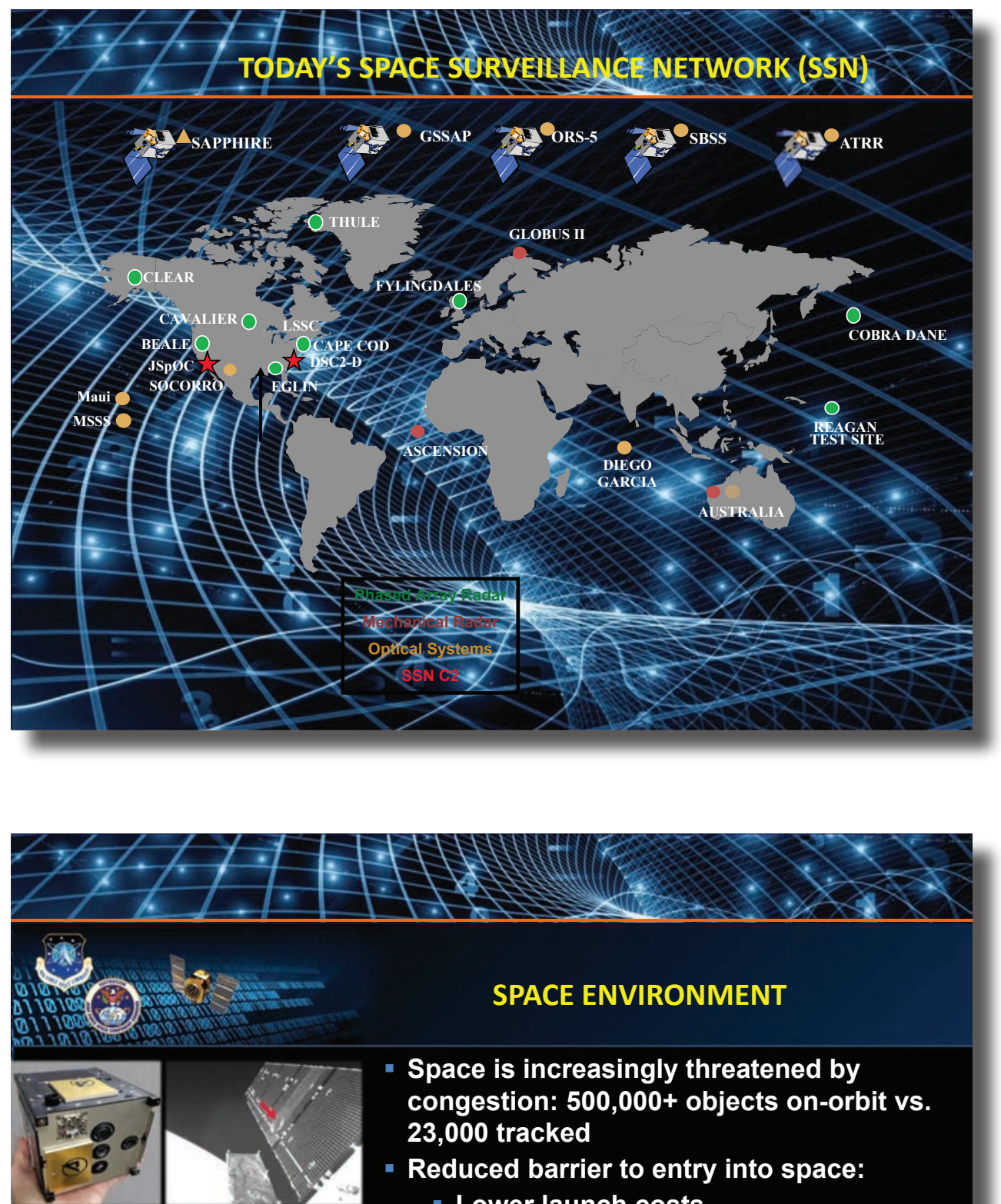

- Space is increasingly threatened by congestion: $\mathbf{5 0 0 , 0 0 0 +}$ objects on-orbit vs. 23,000 tracked

- Reduced barrier to entry into space:

- Lower launch costs

- Smaller, off-the-shelf space hardware

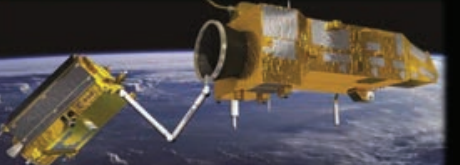

- Growing commercial market increases congestion

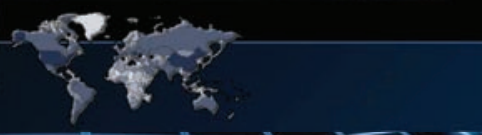

Safe Op eration in space 1 s a V Vial Nationatherest

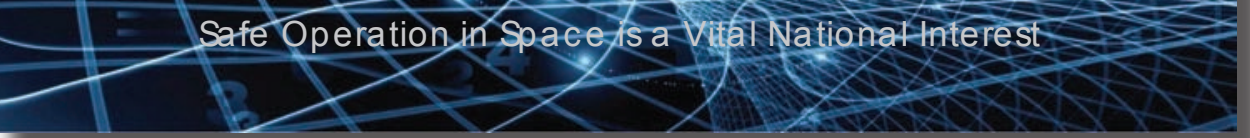



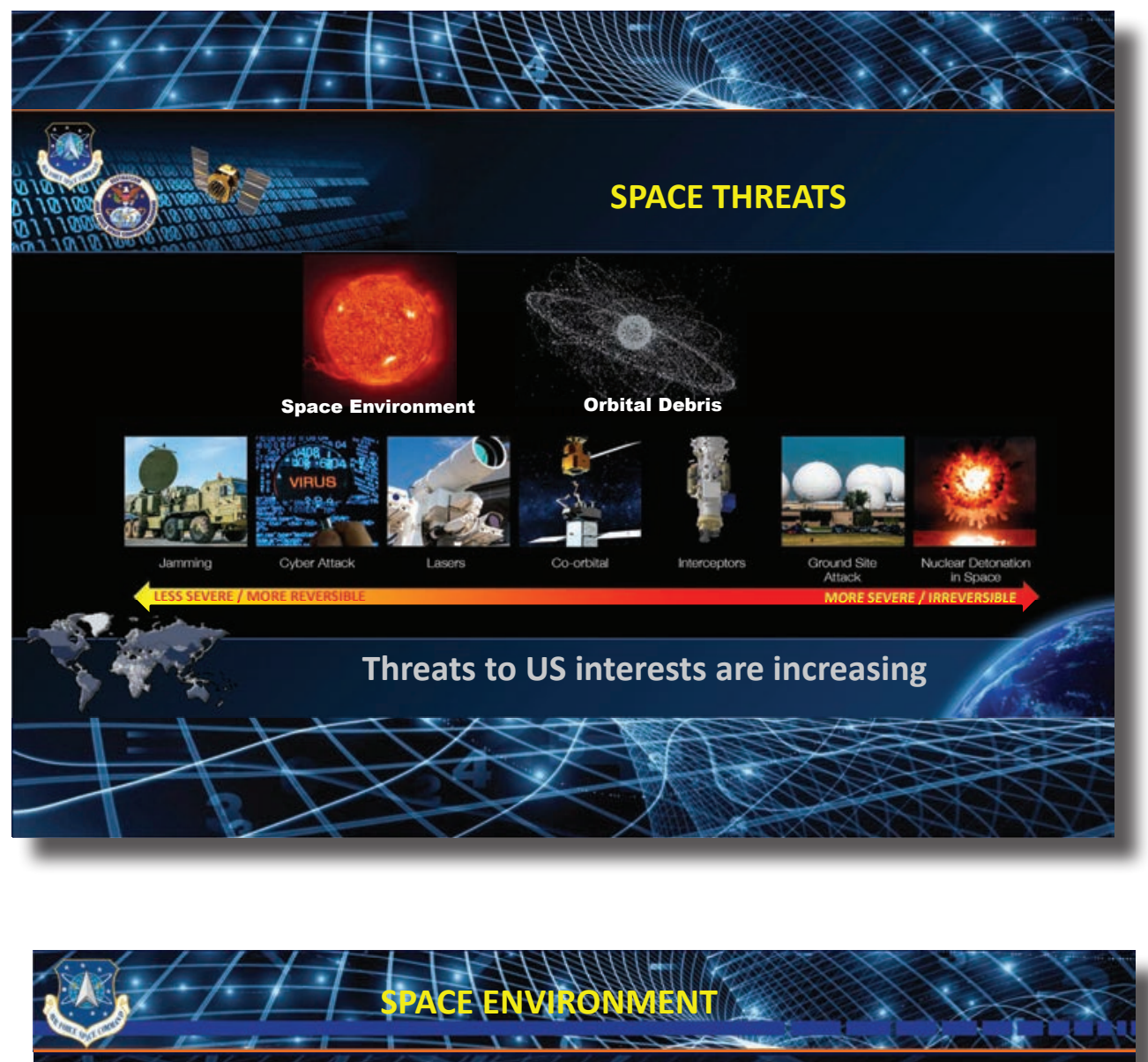

- Space systems and services operate in and through the natural space environment

- For complete space domain awareness, we need to understand the natural space environment:

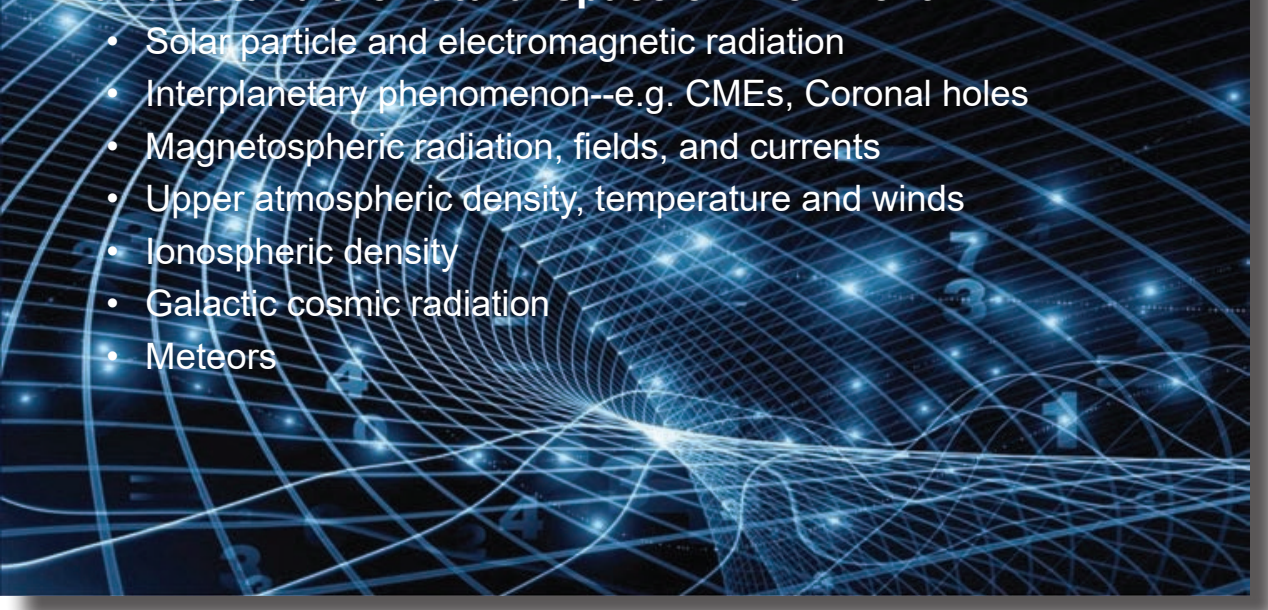




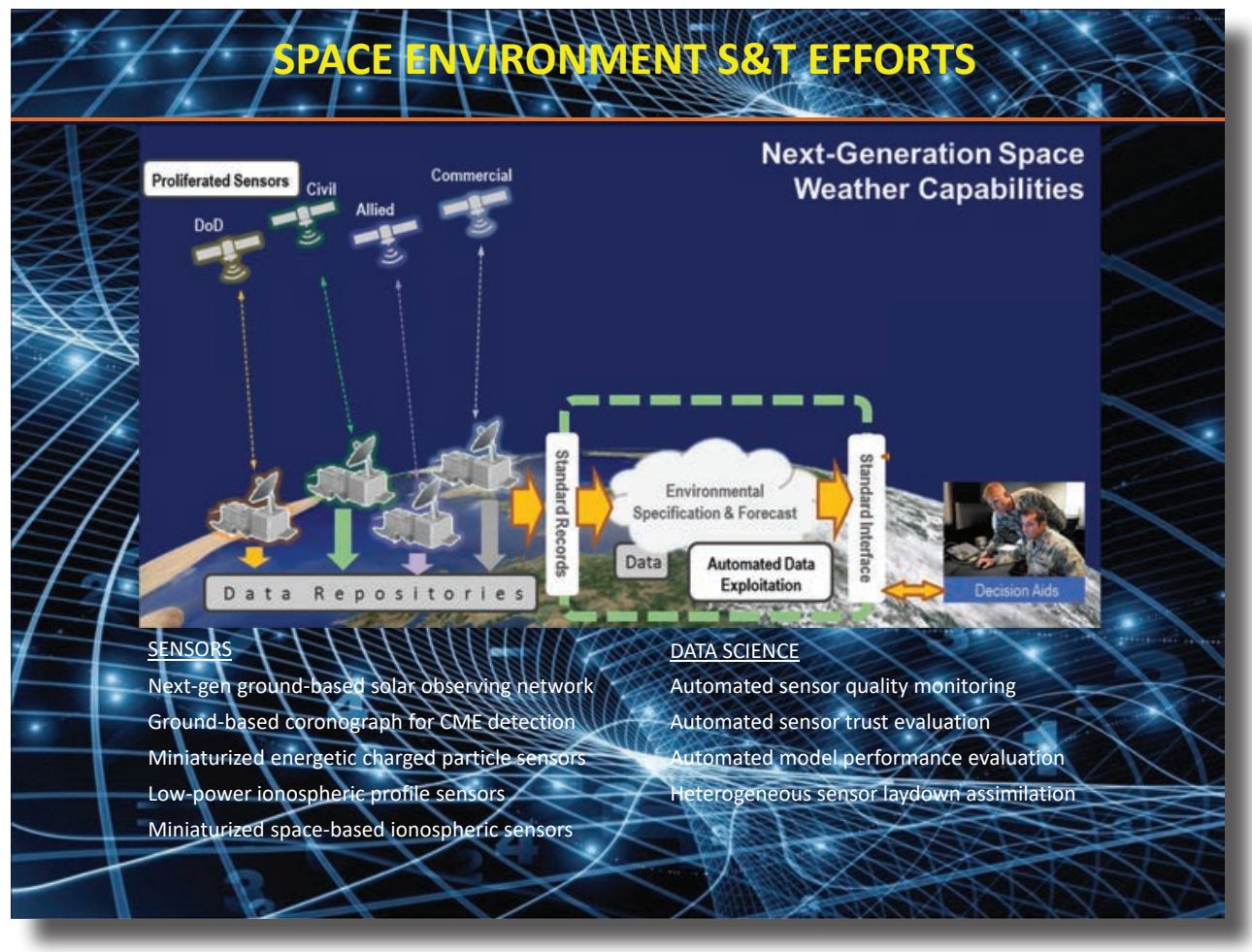

\section{Space Situational Awareness (SSA) \\ - Operational Challenges for STM}

Jim Cooper - Senior Systems Engineer, SSA Solutions

Sep 12, 2019

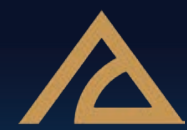

A G I 


\section{Congested space onvirompent}

Challenges

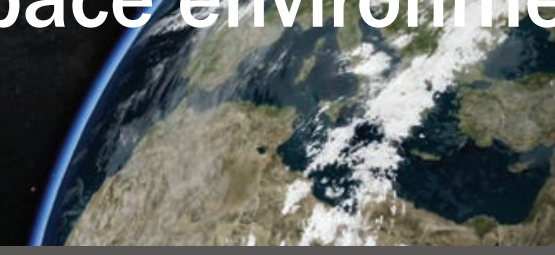

\section{Small LEO space poptilator largely unknown}

Public catalog has 13,29 LEO-crossing $(0$ to. $2000 \mathrm{~km}$ ) objects

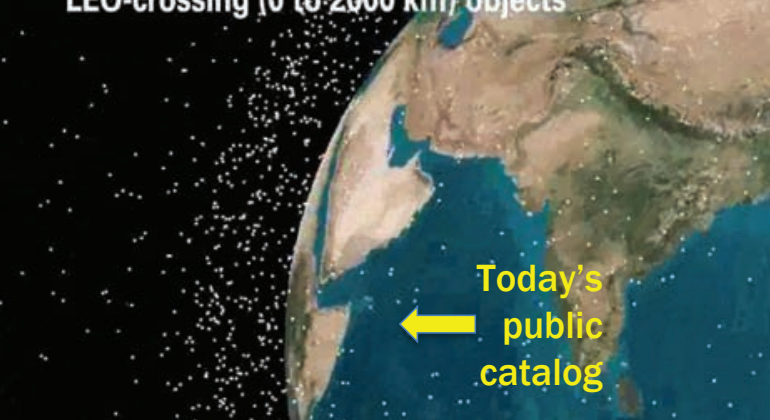

Today's current public

catalog contains $<4 \%$ of

LEO-crossing objects $>1 \mathrm{~cm}$ 


\section{Small GEO space population especially unknown!}

Public catalog has 1,341

GEO-crossing (GEO $\pm 100 \mathrm{~km}$ ) objects

\section{Today's current public}

catalog contains $\approx 4 \%$ of

GEO-crossing objects $>1 \mathrm{~cm}$

Today's

pưblic catalog. 6) sititis $\therefore$ or tal

\section{Russian Rocket Body} Breakup in GEO January, 2016 


\section{Future space opetations}

\section{Challenges}

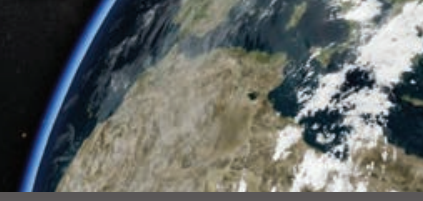

\begin{tabular}{|c|c|c|c|c|c|c|c|c|}
\hline \multirow{2}{*}{$\#$} & \multirow{2}{*}{ Operator } & \multirow{2}{*}{ \# S/C } & \multicolumn{3}{|c|}{$\begin{array}{l}\text { Current RSO catalog } \\
\text { average number }\end{array}$} & \multicolumn{3}{|c|}{$\begin{array}{l}\sim 200,000 \text { RSO catalog } \\
\text { average number }\end{array}$} \\
\hline & & & $\begin{array}{c}\text { Collisions } \\
\text { in } 10 \text { years }\end{array}$ & $\begin{array}{c}3 \mathrm{~km} \text { warnings } \\
\text { in } 10 \text { years }\end{array}$ & $\begin{array}{c}1 \mathrm{~km} \text { maneuvers } \\
\text { in } 10 \text { years }\end{array}$ & $\begin{array}{l}\text { Collisions } \\
\text { in } 10 \text { years }\end{array}$ & $\begin{array}{c}3 \mathrm{~km} \text { warnings } \\
\text { in } 10 \text { years }\end{array}$ & $\begin{array}{c}1 \mathrm{~km} \text { maneuvers } \\
\text { in } 10 \text { years }\end{array}$ \\
\hline $1 \mathrm{a}$ & Boeing V-band & 1,120 & 0.1053 & 394,426 & 43,825 & 2.2404 & $8,392,631$ & 932,515 \\
\hline $1 b$ & Boeing V-band & 828 & 0.0816 & 305,630 & 33,959 & 1.7725 & $6,640,044$ & 737,783 \\
\hline $1 \mathrm{c}$ & Boeing V-band & 1,008 & 0.5155 & $1,931,184$ & 214,576 & 8.514 & $31,893,494$ & $3,543,722$ \\
\hline 1 & Boeing V-band & 2,956 & 0.7024 & $2,631,240$ & 292,360 & 12.527 & $46,926,169$ & $5,214,020$ \\
\hline 2 & CubeSat 380 & 100 & 0.0001497 & 33,687 & 3,743 & 0.00115 & 259,532 & 28,836 \\
\hline 3 & CubeSat $600(\approx$ Planet) & 100 & 0.00075 & 169,376 & 18,819 & 0.0114 & $2,556,868$ & 284,096 \\
\hline 4 & CubeSat 800 & 100 & 0.00174 & 391,512 & 43,501 & 0.0226 & $5,086,080$ & 565,120 \\
\hline 5 & Globalstar & 40 & 0.0637 & 23,871 & 2,652 & 1.3566 & 508,527 & 56,503 \\
\hline $6 a$ & HawkEye 360 & 6 & 0.0000816 & 11,744 & 1,305 & 0.00128 & 184,271 & 20,475 \\
\hline $6 b$ & HawkEye 360 & 6 & 0.0000746 & 10,739 & 1,193 & 0.0008421 & 121,239 & 13,471 \\
\hline $6 c$ & HawkEye 360 & 6 & 0.0000681 & 9,807 & 1,090 & 0.000972 & 139,954 & 15,550 \\
\hline 6 & Hawkeye 360 & 18 & 0.00022422 & 32,289 & 3,588 & 0.003094 & 445,464 & 49,496 \\
\hline 7 & Iridium & 71 & 0.184 & 369,385 & 41,043 & 2.0483 & $3,843,728$ & 427,081 \\
\hline 8 & LeoSat & 140 & 0.0129 & 105,405 & 11,712 & 0.2795 & $2,281,475$ & 253,497 \\
\hline 9 & OneWeb & 648 & 0.0363 & 296,613 & 32,957 & 0.8126 & $6,633,300$ & 737,033 \\
\hline 10 & Orbcomm & 31 & 0.2953 & 94,602 & 10,511 & 3.0618 & 981,006 & 109,001 \\
\hline 11 & SpaceX & 4,000 & 0.4866 & $3,971,912$ & 441,324 & 8.8417 & $72,177,201$ & $8,019,689$ \\
\hline 12 & Spire & 100 & 0.000868 & 195,348 & 21,705 & 0.0136 & $3,070,006$ & 341,112 \\
\hline 13 & Terra Bella & 28 & 0.0022 & 30,878 & 3,431 & 0.0460 & 646,144 & 71,794 \\
\hline
\end{tabular}

$A G I$ 


\section{Aeolus-Starlink Conjunction}

ESA OperationsVerified account @essaperations For the first time ever, ESA has performed a 'collision avoidance manoeuvre' to protect one of its satellites from colliding with a 'mega constellation' \#SpaceTraffic
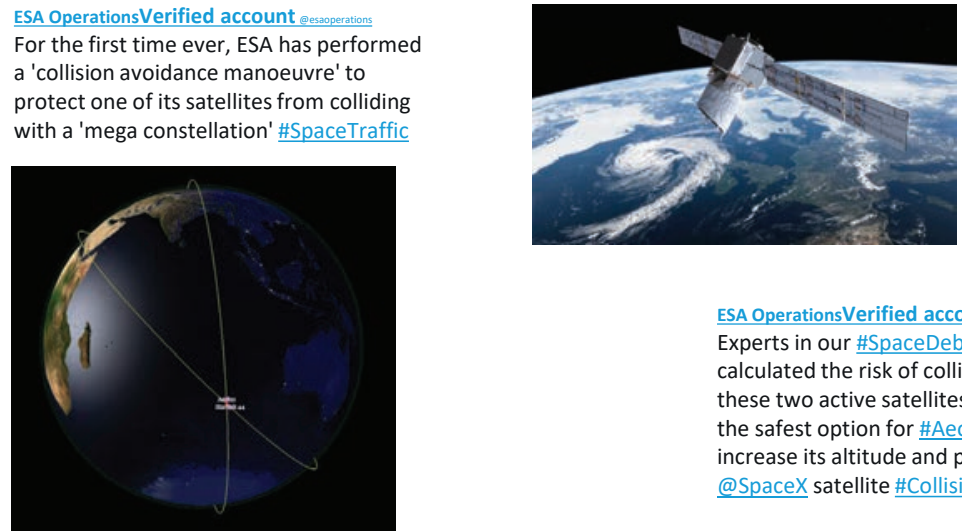

OperationsVerified account This morning, @ESA's \#Aeolus Earth observation satellite fired its thrusters, moving it off a collision course with @SpaceX satellite in their \#Starlink constellation

ESA OperationsVerified account Experts in our \#SpaceDebris team calculated the risk of collision between these two active satellites, determinin the safest option for \#Aeolus would be to increase its altitude and pass over the @ SpaceX satellite \#CollisionAvoidance

ESA Operations Verified account @essoperations time to prepare - from determining the future orbital positions of all functioning spacecraft, to calculating the risk of

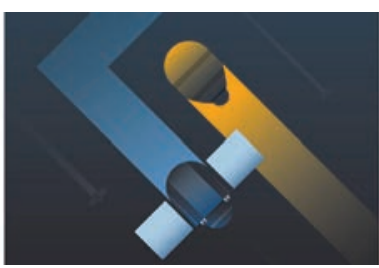

\section{ComSpOC}
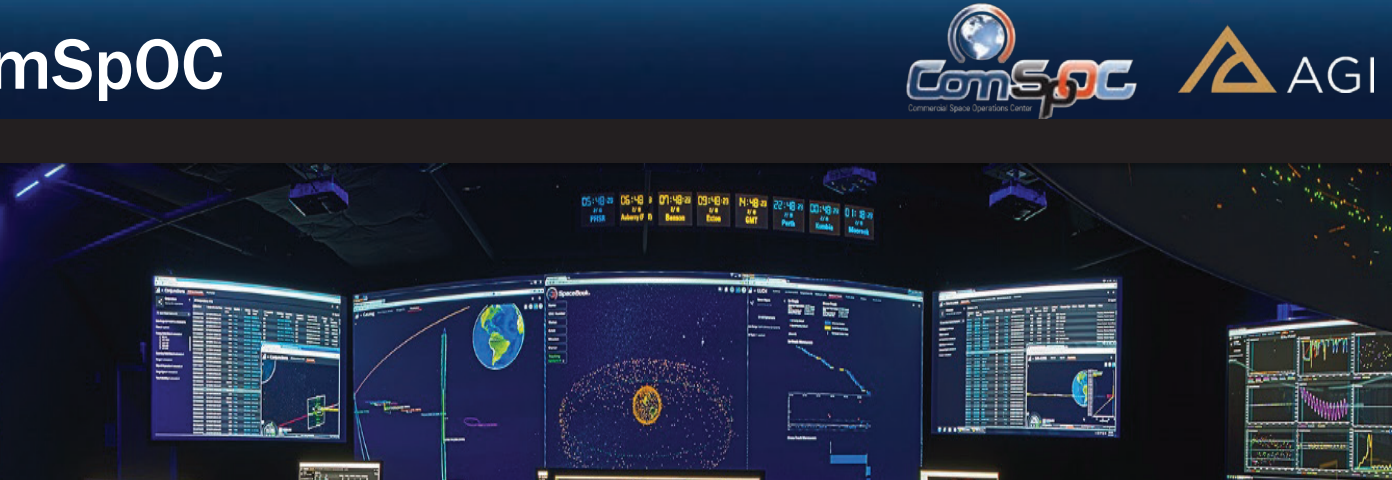

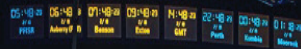
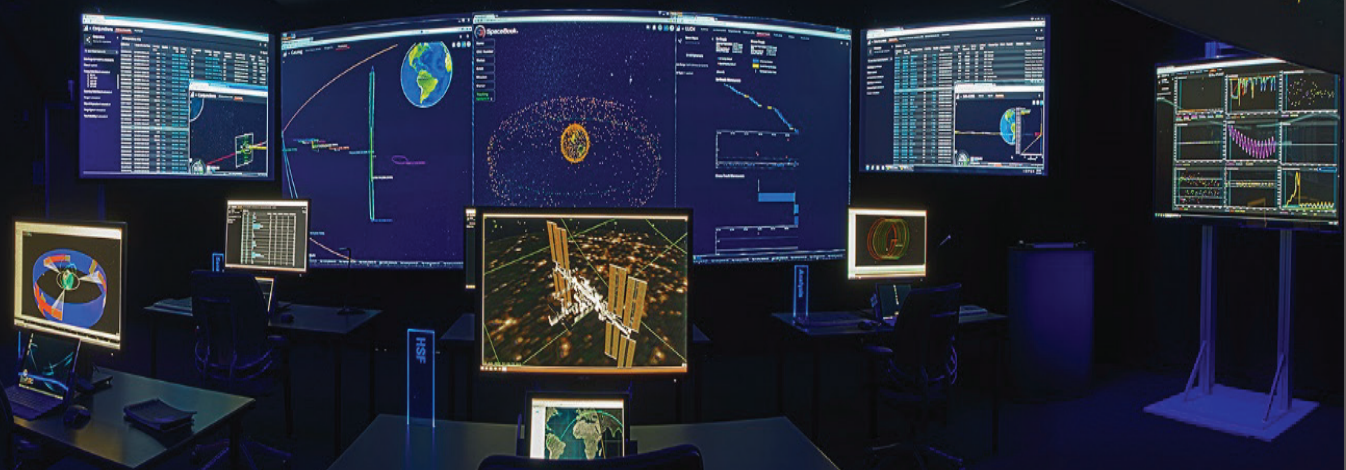

A space domain where everything is detected, tracked, characterized and protected. 


\section{Appendix D: Additional Questions and Answers}

\section{Questions were captured via an electronic polling application and are reported below verbatim.}

\section{Session 1: Partnerships with DOC}

1. Why not charge a launch fee for any launch around the globe to pay into a global fund to develop and pay for debris removal or repurposing?

2. For Professor Salter: many of the challenges you mentioned could be solved by international cooperation and dialogue. Can you speak to this?

3. Appear space junk needs robust international policy, that can be enforced, before any technology solution is deployed. Unless covert operations. Agree?

4. @Prof. Salter: Does the OST's bar on establishing jurisdiction in space further bar establishing personal or governmental property rights in orbits?

5. Standards in the U.S. are voluntary. How do we encourage U.S. space industry to participate in the standards development, which is an international issue.

6. How well is the distribution of materials that comprise debris understood? i.e. what is the proportion of metals, ceramics, foams, etc?

7. Cleanup needs to incentivized to work. How about prioritizing launches or orbits for those companies with a history of good space-junk stewardship?

8. How does a small local business engaged in high tech manufacturing connect with the Hollings MEP?

9. Will there be involvement from gov agencies to fund..such as NSF...innovative research along with allowance for partnership with commercial, gov sectors?

10. What is considered a small/medium manufacturer?

11. How to define standards or strategies for test \& eval of next generation space widgets for commonality; thus, reducing capital infrastructure in the future?
12. Who provides guidance for national and international technical space standards, including SDO boundaries and collaboration?

13. What does successful partnership looks like to DOC and why? Will it follow the DOD's OTA Model?

14. Including everyone is great, so is balance. Ex:selling ISS to marketing opps dilutes it's importance. Thoughts on how to drive STEM talent that's not gimicky/fad?

15. Accountability requires identifiable ownership. Has any thought been given to how to keep track of or reliably identify junk owners? Small parts traveling at 1000's/mph are important too.

16. Talent issue: As a student entrepreneur, I would like to know what resources are provided to support novel emerging technical solutions with space applications.

17. Are there efforts to streamline frequency allocation application for small satellites?

18. What do you believe are the biggest misconceptions about space debris within the general population?

19. Ability to build a manufacturing base is dependent on a market ROI. Rather than encouraging small business to get into space (blindly) we should be promoting the high $\mathrm{ROI}$ applications. MFG will follow.

20. How would we create a market for debris cleanup?

21. Does the USG need to do anything different with respect to standards development to make sure national interests are addressed in highly internationally competitive technology areas like space?

22. How do we level the commerce playing field between rival Countries on earth to project collaboration in the Space economy? 
23. Kevin McWilliams, the CEO of the local MEP is here in the audience. l'll be here all day.

24. How can we mitigate the red tape in dealing with the Federal Gov. for CubeSat communications spectrum launch debris

25. Are there any business accelerators focused upon space entrepreneurship?

26. Commercial space is a global (pun) market with nation state and commercial competitors. How can common standards set a safe, secure and level playing field.

27. Reducing the time and cost of the proposal/ grant process is key for small businesses

28. What are the biggest mistakes made by small space companies as they try to gain traction?

\section{Session 2: Emerging Technologies for Space Commerce}

1. How to define standards or strategies for test \& evaluation of next generation space widgets for commonality? thus, reducing capital infrastructure required to build out space based networks/applications in the future.

2. How will the US government view use of foreign emerging technologies/IP in transnational space supply chain integration?

3. How can we reduce ambiguity between the Commerce solution and National solutions?

4. How can we achieve realistic measures of quantifying and predicting on-orbit safety (e.g. collision risk)?

5. How can we prioritize technology gaps to enable U.S. commercial space activities? E.g., compact cryogen-free systems for cubesats, accelerated reliability testing of components to simulate long-term space deployment.

6. What measurements are needed to determine material suitability in space? Is a repository needed for this information?

7. DoD has increased the use of OTA primarily to encourage commercial industry in warfighter (high tech) widgets; primarily, using more flexible acquisition rules and less Govt. Rights. Does DoC/NASA/other govt. employ this philosophy/process?
8. @Steven Gonzales: how do high tech consulting firms identify other organizations that may need assistance developing tech based on NASA patents?

9. Is there a easy to access central repository for the 1405 NASA patents you are willing to license?

10. Steven: Can you tell us more about how you make the case for research to innovate solutions that may sit on the shelf for a while. Looking for pointers.

11. Is there a need for a library of white papers outlining best testing practices for small businesses and new entrants to commercial space market? Access to lower cost, less rigorous testing facilities that have NIST traceability?

12. What are the current barriers limiting more uptake of optical communications for space?

13. Anyone looked at reviving the Sea Dragon program?

14. @ Steven, is getting tech to support humans in space more important than autonomous $\mathrm{Al}$ systems?

15. How can we leverage the large base of US expertise in COTS tech development for space applications and how to get to the point that COTS parts and engineering approaches gain heritage?

16. Have current RF protocols (QAM 256/512/1024/etc.) come to the end of their evolution, or do you see new protocols that will continue to deliver improved data rates, etc. for space applications?

17. Is there an international (or US) plan for deep-space broadband communications network?

18. What are the metrics a technology must meet to be "space qualified"? Is there a standard that identified such metrics and their values?

19. What is your proposed solution for dialing back qualification requirements? Without qual, the space debris problem will get worse

20. Are there plans to transition the technologies for weather forecasting to low-earth orbit so that satellite positions can be accurately predicted during geomagnetic storms? 
21. Are there technology challenges around making space commerce 'green?'

\section{Keynote Address}

1. How would a CU cooperative institute, in partnership with federal laboratories, complement existing NASA centers?

2. Can you comment further on the role of the social sciences and humanities in growing the space economy, both at CU and (more broadly) with its business, academic, and government partners?

3. Are the existing 485 space technical standards included in the space curriculum at CU Boulder?

4. Has CU partnered with higher educators outside of the US?

5. Has the college of engineering considered partnering with the business school for developing students focused on space businesses?

6. Will tenure requirements ever change to reward tech transfer and commercialization success in addition to research and publication?

7. How does academia deal with an industrial base which mostly wants exclusivity in terms of partnership? Pre-competitive Research am answe?

\section{Session 3: Spectrum for Space Services}

1. Are we ready to open more frequencies? Is the international community, both governments and commercial companies, willing to abide by the regulations in place?

2. How do we define standards or strategies for test \& evaluation of next generation space widgets for commonality; thus, reducing capital infrastructure required to build out space based networks/ applications in the future?

3. What measurements are needed to enable efficient, effective spectrum sharing for space applications?

4. What propagation data is needed to inform models?

5. What terrestrial equipment can improve how data is collected and analyzed for characterizing RF propagation? e.g., could coordination between many ground stations, and future megaconstellations be used to reduce lead time, improve results?
6. How many of the proposed NGSO constellations do you think will actually become a reality?

7. What unique RF communication challenges arise from high-count ride sharing for small-sat launches?

8. @ Jamie - NGSO system in the $40 / 50 G H z$ bands, did you say this will happen or is a proposed use of new spectrum for NGSO? Please elaborate if possible.

9. How does space weather risk inform spectrum allocation, and design, for future small-sat and mega-constellation?

10. Why does it take so long to get spectrum (2 years)?

11. Glenn Feldhake: what are the biggest decisions likely to be made at the World Radiocommunication Conference that will directly affect NASA?

12. How vulnerable are optical comm links to being jammed or flooded intentionally? Can signals be embedded in noise as is done with GPS signals?

13. Should there be a term limit on spectrum licenses for space, that is, when the satellite has reached end of life, spectrum could be release for other applications?

14. @Scott - how many small satellites have propulsion?

15. Who does the independent and unbiased checks and balances on anyone desiring to get licensed?

16. Is it possible to have free optical space down to Earth (without licensing burden from FCC)

\section{Session 4: Models and Algorithms for Space Situational Awareness}

1. What realistic measures can quantify and predict orbital safety concerns (e.g. collision risk)?

2. How will the models and algorithms be classified, documented and communicated?

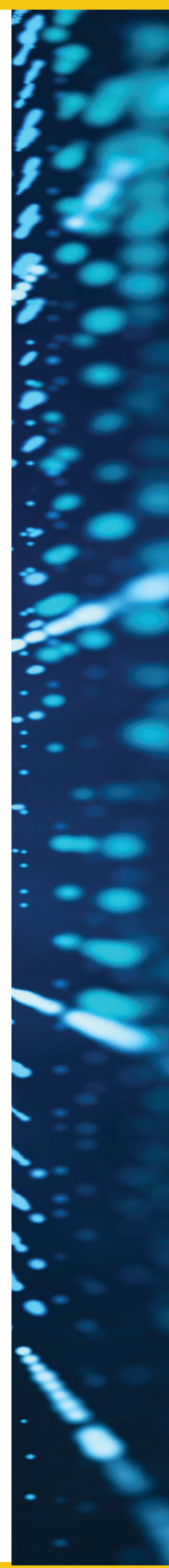


3. How do we define standards for test \& evaluation, and modeling and simulation, of next generation space widgets for commonality; thus, reducing capital infrastructure required to build out space based networks/applications in the future?

4. How can we achieve commonality and reduction of ambiguity between national and commercial solutions?

5. What features do next generation SSN ground stations offer? What future features are needed?

6. Should we require commercial satellites to share with the commercial space community a minimum set of data for tracking and observation purposes?

7. Based on the modeling \& possibility of another "1859 Carrington Event", a major solar flare aimed at earth, what are some recommendations from various models to protect commercial power grids, comm / govt satellites, and ground stations?

8. Can machine learning and neural net techniques be used to rapidly parse and qc the exceptionally large data sets for tracking objects in orbit?

9. What altitude requirements should be required to limit the persistence of space debris in LEO?

10. What can/should SWPC be doing to model the upper atmosphere and satellite drag?

11. What is your preferred source for estimating the probability of a catastrophic collision in LEO and/or GEO?

12. What are some potential concrete solutions to reducing the amount of space debris already on orbit?

13. Do models and algorithms need standards to insure big tech companies are bounded... what are the risk measures for large scale space commerce privatization?
14. Are there plans to $\mathrm{V} \& \mathrm{~V}$ some of the commercial sensor data for incorporation into the SSN especially with Fence technology like LEO Labs uses.

15. Does the U.S. government or another body have the appetite to pay for space debris clean up (intergalactic space men?)

16. The last "extreme" geomagnetic storm was in 2003. What happened to the LEO catalog during that event? This information could inform a "benchmark" study for STM.

17. Can SWPC and Space Command harness the small sat constellations (those that have precise orbit determination capabilities) to improve drag modeling?

18. When it comes to managing our orbital assets, we can make the machines learn, but will we as humans ever learn?

19. Any thoughts on tether-based electric propulsion?

\section{Session 5: Managing Data for Space Traffic Management}

1. Does the US government really want to commercialize the JSPOC data? Will there be an international treaty associated with conjunction mitigation?

2. How to define standards or strategies for test \& evaluation of next generation space widgets for commonality; thus, reducing capital infrastructure required to build out space based networks/ applications in the future?

3. What are standard requirements for close approach, reentry sharing, reporting and international clearinghouses?

4. Which organization should be the curator/caretaker of space traffic data?

5. Are we storing the right data in the UDL?

6. How is the data in the SSA Marketplace validated? What if it's bad data or harbors malicious code?

7. What testing should be required of commercial space operators before a satellite can be launched to demonstrate that they have implemented appropriate tracking and collision avoidance systems? 
8. Who is charged with being the independent and unbiased checks and balances of ssa/stm data and analyses providers?

9. To what extent is the challenge of space management associated with the lack of capacity within the gov't to handle it.

10. With whom is Commerce/NOAA partnering/ contracting for the new open architecture data repository? What is the approach?

11. Are there efforts underway to gain international agreements standardizing the reference frames for launch and maneuver information?

12. W.r.t. policies aimed at disciplining commercial operators: some requirements target outputs (controlling number of space objects) while others target prices (raising the costs of launch). When are these complements vs. substitutes?

13. Big data fusion expertise exists in fundamental research and academia, how could SPD3 tap into this?

14. CSpOC currently uses legacy SSN data to update TLEs. Thoughts on using corroboration through block chain technology, to harness best quality data from all sources.

15. What happens if an operator gets a conjunction Alert but takes no action and a collision happens. Any avenues for legal action?

16. There has been several incidents where industry \& govt contractors have been sued for unethical practices... thoughts on how to protect America's best interest?

17. With whom is Commerce/NOAA partnering/ contracting for the new open architecture data repository? What is the approach?

18. Do we anticipate SP-quality data to flow from DoD to DOC or only GP-quality (i.e. TLEs)?

19. How do venders make money (or shape business models) on data sales when the government shares said data with other departments and allies through their GPR data rights, thus the shrinking the market size? 

$-\infty e^{\circ} \cos ^{\infty}+x_{-}$

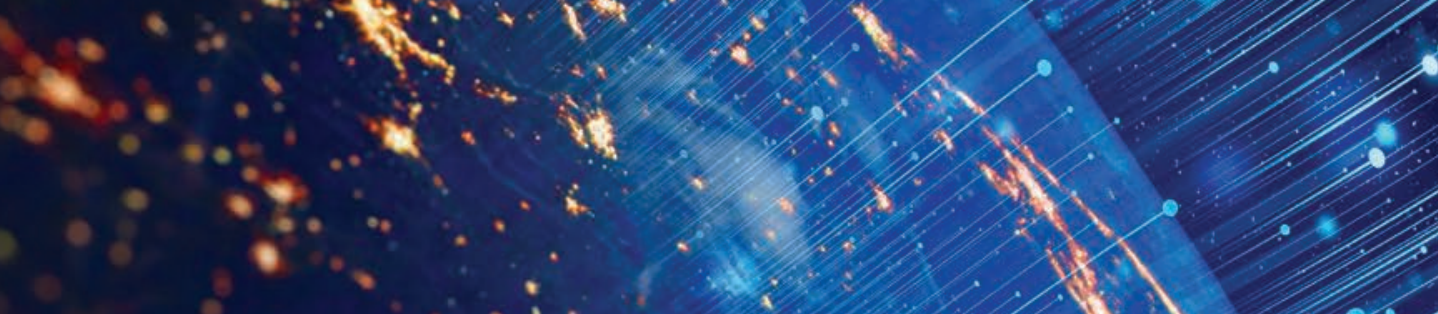

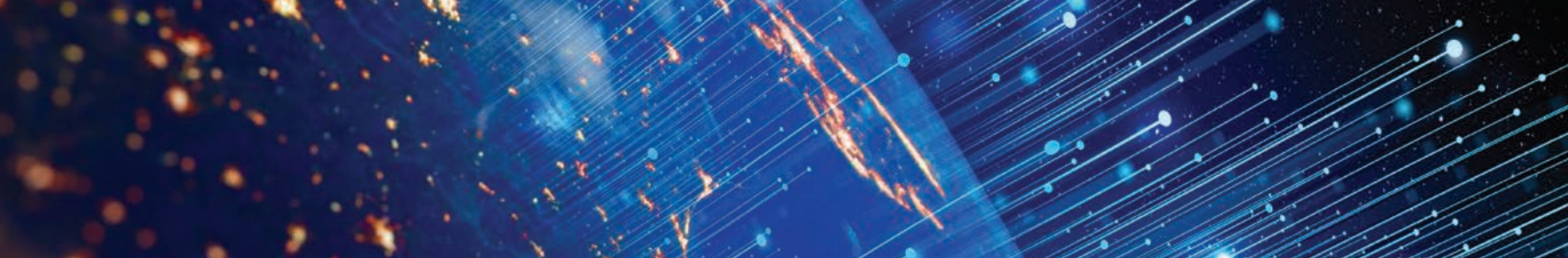

$4 \quad \therefore \quad \cdots \cdots$

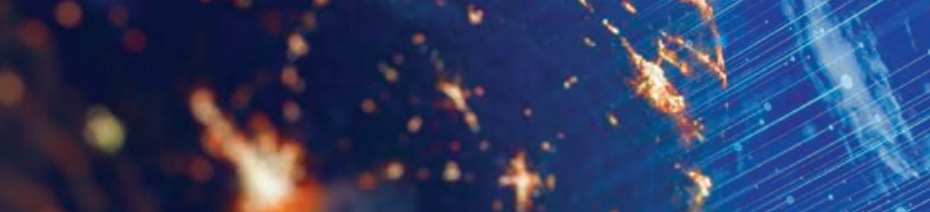

- 12

(n)

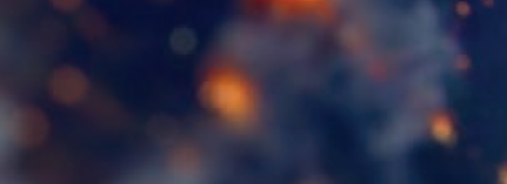

$\because$ \&

i.

$\therefore-\frac{1}{x}$
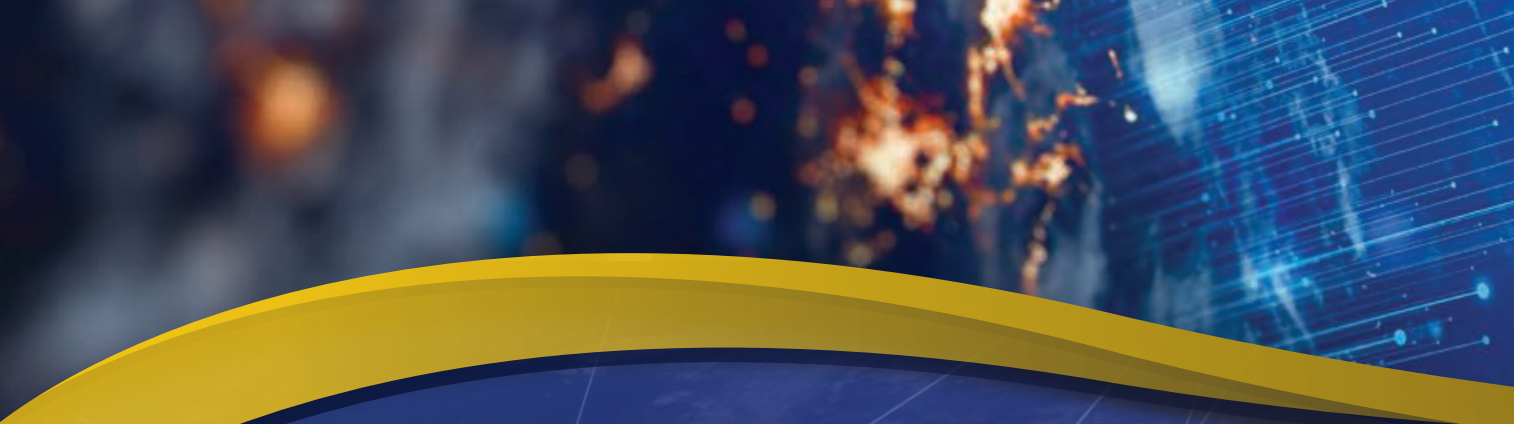